\title{
Changes in Barents Sea Ice Edge Positions in the Last 442 Years. Part 2: Sun, Moon and Planets
}

\author{
Jan-Erik Solheim $^{1 *}$, Stig Falk-Petersen ${ }^{2}$, Ole Humlum ${ }^{3,4}$, Nils-Axel Mörner $^{5}$ \\ ${ }^{1}$ Retired, Department of Physics and Technology, UiT The Arctic University of Norway, Tromsø, Norway \\ ${ }^{2}$ Akvaplan-niva, The Fram Centre, Tromsø, Norway \\ ${ }^{3}$ The University Centre on Svalbard (UNIS), Longyearbyen, Svalbard, Norway \\ ${ }^{4}$ Department of Geosciences, University of Oslo, Oslo, Norway \\ ${ }^{5}$ Deceased, Paleogeophysics \& Geodynamics, Stockholm, Sweden \\ Email: ^janesol@online.no
}

How to cite this paper: Solheim, J.-E., Falk-Petersen, S., Humlum, O. and Mörner, N.-A. (2021) Changes in Barents Sea Ice Edge Positions in the Last 442 Years. Part 2: Sun, Moon and Planets. International Journal of Astronomy and Astrophysics, 11, 279-341.

https://doi.org/10.4236/ijaa.2021.112015

Received: April 26, 2021

Accepted: June 26, 2021

Published: June 29, 2021

Copyright (c) 2021 by author(s) and Scientific Research Publishing Inc. This work is licensed under the Creative Commons Attribution International License (CC BY 4.0).

http://creativecommons.org/licenses/by/4.0/ (c) (i) Open Access

\begin{abstract}
This is the second paper in a series of two, which analyze the position of the Barents Sea ice-edge (BIE) based on a 442-year long dataset to understand its time variations. The data have been collected from ship-logs, polar expeditions, and hunters in addition to airplanes and satellites in recent times. Our main result is that the BIE position alternates between a southern and a northern position followed by Gulf Stream Beats (GSBs) at the occurrence of deep solar minima. We decompose the low frequency BIE position variations in cycles composed of dominant periods which are related to the Jose period of 179 years, indicating planetary forcings. We propose that the mechanism transferring planetary signals into changes in BIE position is the solar wind (SW), which provides magnetic shielding of the Earth in addition to geomagnetic disturbances. Increase in the solar wind produces pressure which decelerates the Earth's rotation. It also transfers electrical energy to the ring current in the earth's magnetosphere. This current magnetizes the earth's solid core and makes it rotate faster. To conserve angular momentum the earth's outer fluid mantle rotates slower with a delay of about 100 years. In addition will geomagnetic storms, initiated by solar coronal mass ejections (CMEs) penetrate deep in the Earth's atmosphere and change pressure pattern in the Arctic. This effect is larger during solar minima since the magnetic shielding then is reduced. The Arctic may then experience local warming. The transition of solar activities to a possibly deep and long minimum in the present century may indicate Arctic cooling and the BIE moving south this century. For the North Atlantic region, effects of the BIE expanding southward will have noticeable consequences for the ocean bio-production from about 2040.
\end{abstract}




\section{Keywords}

Barents Sea Ice Edge Position, Cyclic and Non-Linear Changes, Lunar and Solar Forcing, Planetary Orbit Synchronization

\section{Introduction}

The Arctic ice cover is a particularly important factor for the Earth's climate. Expanding ice cover leads to severe living-conditions for aquatic and land related life in the region. Diminishing and thinning ice cover has increased the total phytoplankton and ice-algae production with increased secondary production (herbivorous zooplankters) followed by an increase in fish and mammal stocks. The seasonal and decadal climate changes have a larger amplitude in the Arctic than elsewhere, wherefore climate trends and shifts may potentially be easier discovered. However, the amplitude of chaotic noise is also larger and may mask the underlying pattern.

\subsection{Background}

The ice cover is modulated by several forces as described in our first paper [1]. The temperature difference between the warm equator regions and the cold polar regions is the prime driving force for the global weather patterns. Heat from the equator regions is transported towards the poles by advection in the atmosphere and by ocean currents. The source of the heat is the Sun. If radiation from the Sun is diminished by less solar energy production or absorbed and reflected én route to the surface or atmosphere of the Earth, by aerosols or increasing clouds, ice and snow, the result will be less heat transport to the Arctic and a larger ice cover.

The Barents Sea (BS) is an Arctic shelf sea with partly ice-free ocean during winter in the present climate (Figure 1). The northward flowing Atlantic Water (AW) that keeps the BS partly ice-free, also keeps the Greenland Sea mostly ice-free during winter. These regions provided the first observations of decadal-scale oscillations in the air-ice-ocean system [2]. Warm AW is entering the shallow BS through the Barents Sea Opening (BSO) or the Fram Strait (FS) via the West Spitzbergen Current (WSC) [3] [4]. The AW heat flow into FS is twice as big in the winter as in the summer, with an estimated heat flow into FS varying from $28 \mathrm{TW}$ in summer to $46 \mathrm{TW}$ in the winter. The heat transport to BS via BSO is steadier, about 70 TW [5]. A rapid warming in the Eastern FS has resulted in a temperature increase of $\approx 2^{\circ} \mathrm{C}$ ocean temperature since about 1850 and a temperature $>1.5^{\circ} \mathrm{C}$ higher than in the Medieval Climate Anomaly (MCA) [6].

In glacial times when the BS was covered by a grounded ice sheet, reducing the inflow of AW through the BS, most of the northward flowing AW would have entered the Arctic Ocean through the FS [7]. However, the warm and salty 


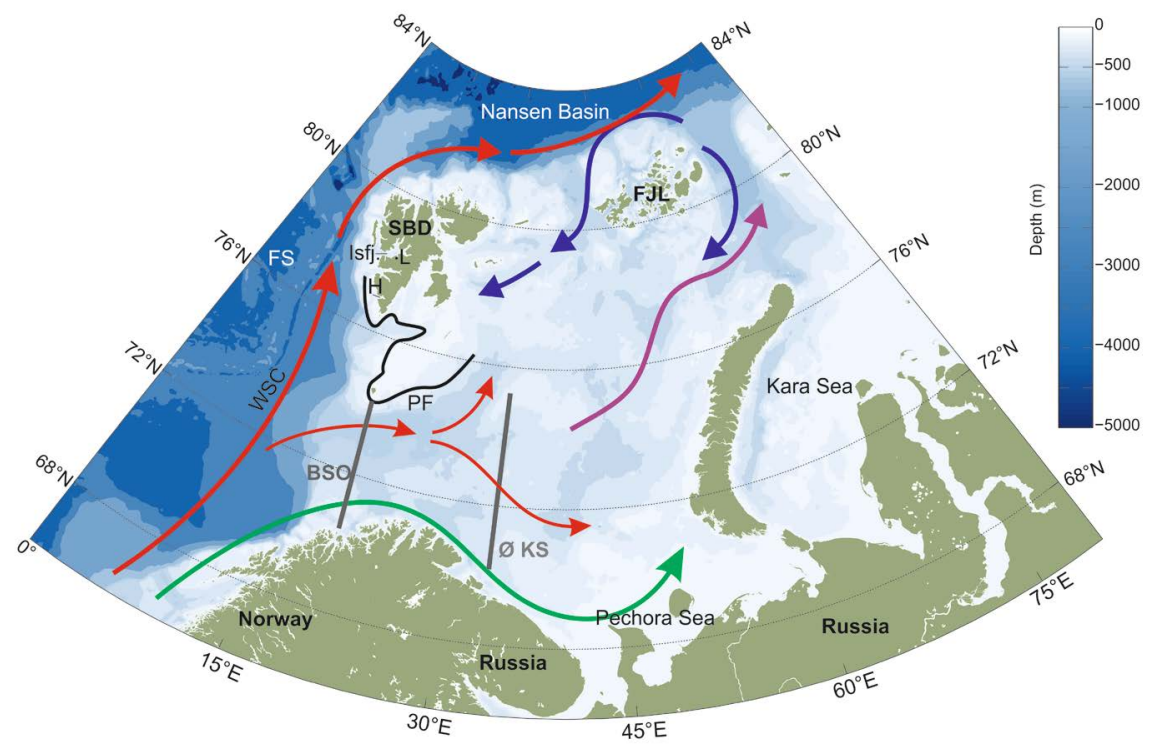

Figure 1. Barents Sea map with depth contours. Circulation of the main water masses is depicted by the arrows (Atlantic water: red; Arctic water: blue; Norwegian Coastal Current: green; Barents Sea Waters: purple). Polar Front: PF, (solid line); BSO: Barents Sea Opening; Ø KS: Kola section; SBD: Svalbard; FJL: Frans Josef Land; FS: Fram Strait; Isfj: Isfjorden; H; Hornsund; L: Longyearbyen (modified from Oziel et al. [11]).

AW is heavier than the fresh water on the surface, which keeps freezing water temperature in the upper 80 to $100 \mathrm{~m}$ [8]. Only in areas with upwelling of AW along the ice edges with wind from northeast and along the shelf break [9] can the AW heat result in melting ice. Fridtjof Nansen [10] observed during his crossings of the Artic Basin that the Sun melted ice from the top while it was still freezing at the bottom in June. We should therefore expect that solar variations should be detectable in the BIE position variations.

Ikeda [2] suggested a positive feedback to oscillations driven by a weak external forcing as the solar activity. The feedback mechanism worked like this: "the increased cyclonic wind-stress curl associated with the atmospheric circulation enhances the exchange of cold Arctic water, including sea ice, and warm Atlantic water, and reduces the amount of Barents Sea ice. The reduced ice cover encourages heat flux from the Barents Sea to the atmosphere, tending to reinforce the low pressure in the Arctic." This we may call the wind-mechanism.

\subsection{Hypothesis}

A review of potential long-period forcings on the sea ice cover is presented in [1]. Our hypothesis is that cyclic changes in movement of the Sun in its barycentric orbit due to the planets, will be transmitted to the Earth as fluctuations in insolation and in the solar wind, and be identified in climatic patterns as shown in [1] Figure $9^{1}$. In addition to solar energy effects, we have also investigated the effects of short-term perturbations of the Sun's orbit by the planets. A high frequency signal from the planets will most likely disappear in the rapid changing ${ }^{1}$ This is a reference to Figure 1 in [1]. 
and at times chaotic weather-pattern, but low frequency fluctuations may survive as climate modulations. This underscores the importance of long, homogeneous, time series.

In this paper we present an analysis of a time-series of BIE yearly positions, obtained from ship logbooks, scientific reports, aerial surveys, and satellite observations updated from [9]. The observations cover a period of 442 years, with completeness increasing from 34 to 66 per cent per century from the beginning in 1579 . The position estimates refer to the summer ice position during the last two weeks of August between the Svalbard archipelago and Frans Josef land, which is named the Western Barents Sea. The data set is unique in the sense that it covers the two last grand solar minima, the Maunder Minimum (1640-1720) and the Dalton Minimum (1790-1820) [12], in addition to the coldest decade (1690-1700) in the last millennium in the Northern Hemisphere [13]. During grand solar minima the BIE position frequently has been southernly at $76^{\circ} \mathrm{N}$ latitude. This corresponds to periods with stronger cold Arctic water currents. This weakens the warm AW transport to the Arctic and may result in the Gulf Stream beat (GSB) between two branches-the northern or southern branch [14] as illustrated in [1] Figure 1.

We investigate the hypothesis that there is a stable or stationary signal from the planets which synchronize the natural oscillations of the position of BIE. If a prolonged low position is reached, the GSB switches to the southern mode (type $\mathrm{b}$ and $\mathrm{c}$ in [1] Figure 5) leading to a cold climate in the North Atlantic region. Our main hypothesis is that this is related to the solar wind (SW) acting on the rotation speed of the Earth making measurable changes in the length of day (LOD). Our starting hypothesis is that the beat itself originates in the switch between Earth rotation acceleration during solar minima and deceleration during solar maxima [1] Figure 4.

We compare the BIE positions with other climatic and solar time series and investigate phase relations. An identical phase indicates identical forcing, different phases may give a clue to what may be cause and effect. We find that the BIE position changes in concert with $\mathrm{NH}$-climate in phase with long solar cycles and the Jose planetary cycles. The BIE movement north was rapid after the deep Maunder Minimum, but slow after the Dalton minimum, using more than a century to gather momentum. This may be explained by a "tired Sun" in the 1800 s, after high activity in the 1700s, related to a bicentennial cycle [15].

\subsection{Organization of the Paper}

The structure of this paper is as follows: We describe the BIE data set in Section 2. In Section 3 we analyze the data and search for fingerprints. Then in Section 4 we compare with other climate data sets. In Section 5 we compare with orbital, solar and lunar forcings; in Section 6 we investigate signs of planetary influence. In Section 7 we have a discussion, and finally the conclusion in Section 8. In Table 1 we present a list of acronyms and explain some of them. 
Table 1. Acronyms and explanations.

\begin{tabular}{|c|c|c|}
\hline $\begin{array}{l}\text { aa Geomagnetic activity index: difference } \\
\text { between two antipodal geomagnetic observatories }\end{array}$ & $\begin{array}{l}\text { GCR Galactic cosmic rays: particles } \\
\text { from exploding stars }\end{array}$ & $\begin{array}{l}\text { NH-SST Northern Hemisphere sea surface } \\
\text { temperature }\end{array}$ \\
\hline $\begin{array}{l}\text { ACRIM Active Cavity Radiometer Irradiance } \\
\text { Monitor: series of satellites measuring TSI }\end{array}$ & $\begin{array}{l}\text { Hale Solar magnetic period: } \\
\text { about } 22 \text { years }\left(\mathrm{S}_{\mathrm{H}}\right)\end{array}$ & $\begin{array}{l}\text { Nyquist-Shannon sampling theorem: } \\
\text { limit for frequencies }\end{array}$ \\
\hline ACSYS Arctic climate system studies & INAO Integrated NAO & $\begin{array}{l}\text { P04 Period 04: program for harmonic } \\
\text { periods analysis }\end{array}$ \\
\hline $\begin{array}{l}\text { AMO Atlantic multidecadal oscillation: A } \\
\text { sea surface temperature index for the North Atlantic }\end{array}$ & $\begin{array}{l}\text { Insolation: radiation energy received } \\
\text { from the Sun }\end{array}$ & $\begin{array}{l}\text { QBO Quasi-biennial oscillation: a tropical, } \\
\text { downward propagating zonal wind }\end{array}$ \\
\hline $\begin{array}{l}\text { ArcT Arctic land temperature: from stations } \\
\text { north of } 60^{\circ} \mathrm{N}\end{array}$ & INAO Integrated NAO & SC Solar cycle \\
\hline AW Atlantic water & IZI Integrated ZI & SCL Solar cycle length \\
\hline $\begin{array}{l}\text { BIE Barents Sea ice edge: positions in last part } \\
\text { of August }\end{array}$ & $\begin{array}{l}\text { Jose Period of } 179 \text { years: a common period } \\
\text { for many of the solar system planets }\left(\mathrm{P}_{\mathrm{Jo}}\right)\end{array}$ & SIM Sun inertial motion \\
\hline BS Barents Sea & $\begin{array}{l}\text { KolaT Kola section sea temperatures } \\
0-200 \mathrm{~m} \text { depth }\end{array}$ & SMM/I Special Sensor Microwave/Imager \\
\hline BSO Barents Sea opening & $\begin{array}{l}\text { LIA Little ice age: cold period } \\
\text { CE } 1350 \text { - } 1850 \text { (1900 in Arctic) }\end{array}$ & $\begin{array}{l}\text { SSMIS Special Sensor Microwave } \\
\text { Imager/Sounder }\end{array}$ \\
\hline $\begin{array}{l}\text { CE Common Era, secular equivalent of } \mathrm{AD} \text { anno } \\
\text { Domini }\end{array}$ & LIG latitudinal insolation gradient & $\begin{array}{l}\text { SMMR Scanning Multichannel } \\
\text { Microwave Radiometer }\end{array}$ \\
\hline CET Central England temperature series & LOD change of the length of day (ms/year) & SN Sunspot number $(R)$ \\
\hline $\begin{array}{l}\text { CME Coronal mass ejection: burst of plasma } \\
\text { from the solar corona }\end{array}$ & $\begin{array}{l}\text { MCA Medieval climate anomaly: } \\
\text { a warm climate period about } 1000 \mathrm{CE}\end{array}$ & SST Sea surface temperature \\
\hline Coif3 Wavelet function for time series analysis & Morlet wavelet function for time series analysis & SW Solar wind \\
\hline DMSP Defence meteorological satellite program & $\begin{array}{l}\text { NAO The North Atlantic Oscillation: Index of } \\
\text { atmospheric pressure difference at sea level } \\
\text { between the Icelandic Low and the Azores High }\end{array}$ & SWS Solar Wind Speed \\
\hline $\begin{array}{l}\text { Ekman transport: water transported to the right } \\
\text { angle of the wind direction in the } \mathrm{NH} \text { hemisphere }\end{array}$ & $\begin{array}{l}\text { NB Northern Branch: northern branch of the } \\
\text { Gulf Stream also called the Norwegian Current }\end{array}$ & TSI Total solar insolation \\
\hline FS Fram Strait & $\begin{array}{l}\text { NDSIDC National Snow and } \\
\text { Ice Data Center, Boulder, USA }\end{array}$ & $\begin{array}{l}\text { VLBI Very long baseline } \\
\text { inter-ferometry(radio astronomy) }\end{array}$ \\
\hline $\begin{array}{l}\text { FT Fourier transform: converting time series } \\
\text { to frequencies }\end{array}$ & NH Northern Hemisphere & WSC West Spitsbergen Current \\
\hline $\begin{array}{l}\text { GSB Gulf stream beat: a change between } \\
\text { northern and southern branch of Gulf stream }\end{array}$ & & $\begin{array}{l}\text { ZI Zonal wind index: pressure difference } \\
\text { between } 35^{\circ} \mathrm{N} \text { and } 55^{\circ} \mathrm{N}\end{array}$ \\
\hline
\end{tabular}

\section{The BIE-Data}

The Arctic seas were for a long time a terra incognito for European sea travelers, but the wish to find an eastern sea route north of the Eurasian continent led to expeditions which found rich animal life at the edge of the sea ice, and hunters went north. The English Muscovy Company was founded as early as 1555, 
opening trade with Russia via Archangel. Around 1580 the Dutch joined the White Sea trade and became frequent travelers in the area. The whale-hunting north of Svalbard became a profitable industry which occupied many ships from the middle of the $17^{\text {th }}$ century [1] (Figure 14 and Section 7.1.) This resulted in information about sea-ice conditions. Most whaling took place in late summer.

A time series of the estimated position of the August ice edge in the sector between $20^{\circ} \mathrm{E}$ and $45^{\circ} \mathrm{E}$, covering the western Barents Sea between Svalbard and Frans Josef Land (Figure 2) was collected and presented by Torgny Vinje [16]. The ice edge position was based on ship-logs before 1900, from whalers and seal hunters who systematically observed and logged sea-ice conditions and ice edge locations. Small islands that appeared or disappeared due to variations in sea ice extent helped in locating the position of the ice edge. Whaling was first a Dutch industry, but also English and French hunters participated. These observations are the base for the ice edge location estimates before 1800 .

After 1800 data came from Norwegian trappers who then started wintering on the islands of the Svalbard archipelago, with annual seal-hunting along the ice edge between Denmark Strait and Novaya Zemlya from 1853. Information on the ice conditions around Svalbard 1850-1922 were collected by Prof. Otto Sverdrup and Capt. A. Hermansen from altogether 285 ship-logs in connection with planning of coal shipping from Spitsbergen [17]. Since then, Norwegian Polar
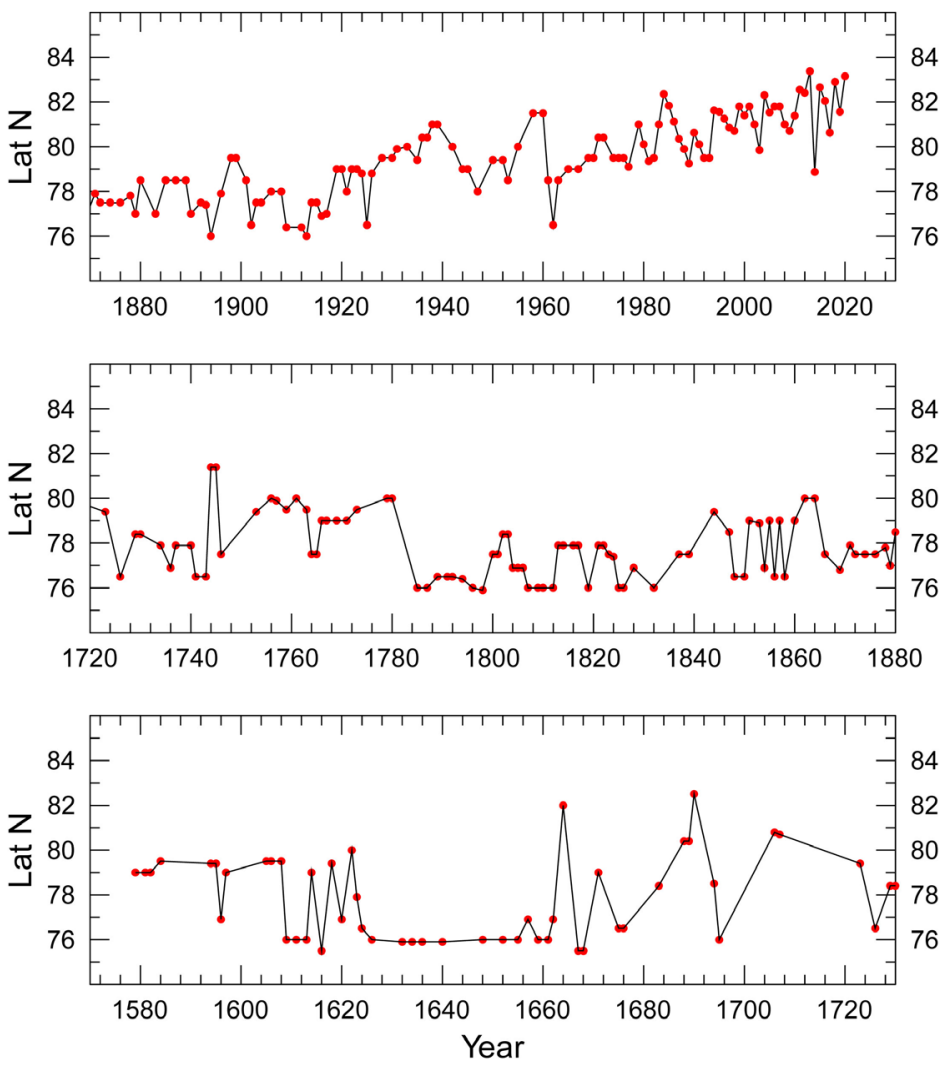

Figure 2. The BIE position 1579-2020. From 1979 the ice edge is defined as $15 \%$ median value of ice. 
Institute has collected information from all kinds of shipping activities in the area. After about 1950 ice-maps were made from observations by US, Russian and Norwegian airplanes. Images from US satellites were included from 1966.

The data have been supplemented from other sources, quality controlled, and made available in ACSYS historical Ice Chart Archive [18] as monthly or yearly ice charts. In this series the ice edge is defined as the outer boundary reported by sealers or whalers, which is estimated to be about $30 \%$ ice covered. In the optical image satellite period, the edge was defined as $>10 \%$ ice coverage. From 1979 data from satellite microwave sensors were available [18]. The minimum sea-ice extent (August-September), is calculated using monthly mean sea-ice concentration from the National Snow and Ice Data Center (NSIDC) [19]. This data set is generated from satellite-based, brightness temperature data derived from the following sensors: Nimbus-7 Scanning Multichannel Microwave Radiometer (SMMR), the Defense Meteorological Satellite Program (DMSP)-F8, -F11 and -F13 Special Sensor Microwave/Imagers (SSM/I) and the DMSP-F17 Special Sensor Microwave Imager/Sounder (SSMIS). These data are provided in the polar stereographic projection at a grid cell size of $25 \times 25 \mathrm{~km}$ for the period 1979-present.

The recent version of the passive microwave data set [20] determines the relative ice area pixelwise and defines the ice edge as the median value of pixels with more than $15 \%$ of ice. We have used the average position of the ice edge in the two last weeks of August to compare with historical data.

The ice cover is determined with automated algorithms which classify types of ice and open water [21]. However, in the summer melting season temporary melt-water-pools may appear on the surface of sea ice, and this may lead to systematic underestimates of the ice area. In an attempt to recalibrate pre-satellite Arctic ice cover data sets, to fit with the satellite observations, the average annual ice-covered area had to be reduced with $\sim 1.5$ mill. $\cdot \mathrm{km}^{2}$ (or $\sim 11 \%$ ) before 1979 [22]. For the BIE positions (Figure 2) the lower latitude of $76^{\circ} \mathrm{N}$ seems to be a common minimum for 300 years and is probably a natural limit. The northern limits have been more variable.

\subsection{A Revised BIE Data Set}

An updated and revised version of the data set was published by Falk-Petersen et al. [9]. In this set, updated positions from satellite maps were used from 1996. In the revision presented in this paper, old data have been corrected and the series has been updated including 2020. It was discovered that in some cases data were extrapolated from adjacent areas (seas) or from other months. These data have been deleted. Our revised data set (Figure 2) has passive satellite radiometer measurements from 1979.

Comparing the old and new data from the overlapping period 1977-90 (Figure 3), we find that there is a systematic position difference of $+1.2^{\circ} \mathrm{N}$ for the revised part of the BIE data set. We have not corrected for this difference in 


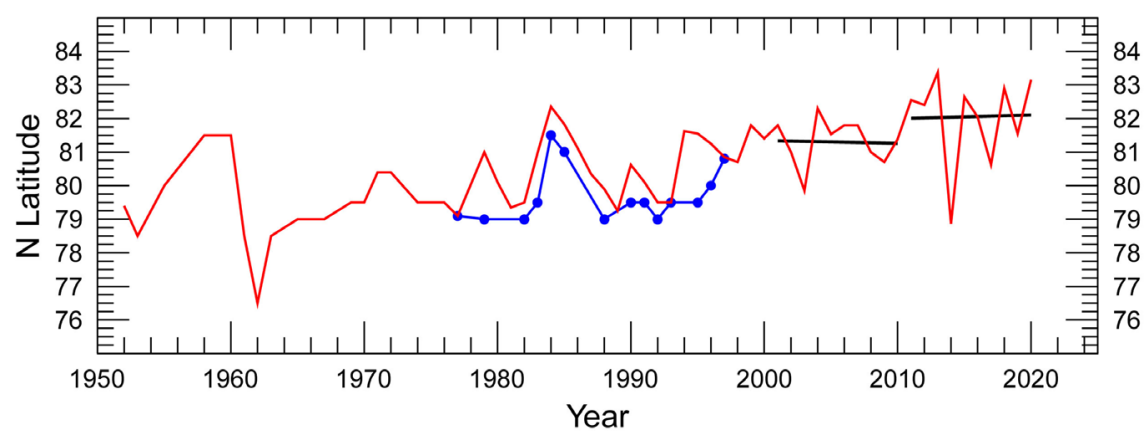

Figure 3. BIE position data 1952-2020. This revised version (red) and overlapping part of earlier version (blue) before satellite microwave sensor data was used for the period 1979-1996. The black bars are trend lines for the two last decades.

the data before 1977 since the difference is of the same order as the uncertainty of the data.

The estimated ice edge positions (Figure 2) vary between $75.5^{\circ} \mathrm{N}(1616$, 1667-68) and $83.35^{\circ} \mathrm{N}$ (2013). The data show two long latitudinal minima 1625-1662 and 1785-1812. The first corresponds to the early part of the solar Maunder Minimum 1640-1720 and the second to the beginning of the Dalton Minimum 1790-1820. However, several times between 1660 and 1710 we find ice edge estimates north of $80^{\circ} \mathrm{N}$. From 1850 the ice edge is almost always north of $78^{\circ} \mathrm{N}$, except in the period 1902-17. After 1990 the August ice edge has always been north of $80^{\circ} \mathrm{N}$, except in 2003 . The data show no trend in the last 10 years with an average value of $82.5 \mathrm{~N}$.

\subsection{BIE Position Data Coverage}

The first 402 years of the series have many missing data points. From 1579 to 1678 the coverage is 39 per cent. For the next hundred years 1679-1778 the coverage is only 34 per cent, and there is a large gap 1708-22. The last part of the 1600s was the coldest in Europe in the Little ice age (LIA) [1] (see Figure 12), and several strong storms destroyed many ships in the Netherlands, where most whalers came from [23], and, presumably, fewer ships were then able to obtain observations for some years.

For the whaling in the Arctic most Dutch ships gathered in the deeper part of the Waddenzee near the coast of the island of Vlieland. Here the ships were readied for the whaling expeditions and waited for a favorable wind to be able to cross the North Sea. The Dutch whaling ships were not able to cruise against the wind. When the wind came from the north and northwest they had to wait-often many weeks, sometimes months [24].

From 1779-1878 the coverage improved to $58 \%$ and in the following hundred years to $66 \%$. From 1979 we have 100 per cent coverage due to the use of satellite passive radiometer microwave measurements. In total we have 238 data points spanning 442 years, or an average coverage of $54 \%$.

In Figure 4 we show the distribution of ice edge position estimates for four centuries. 


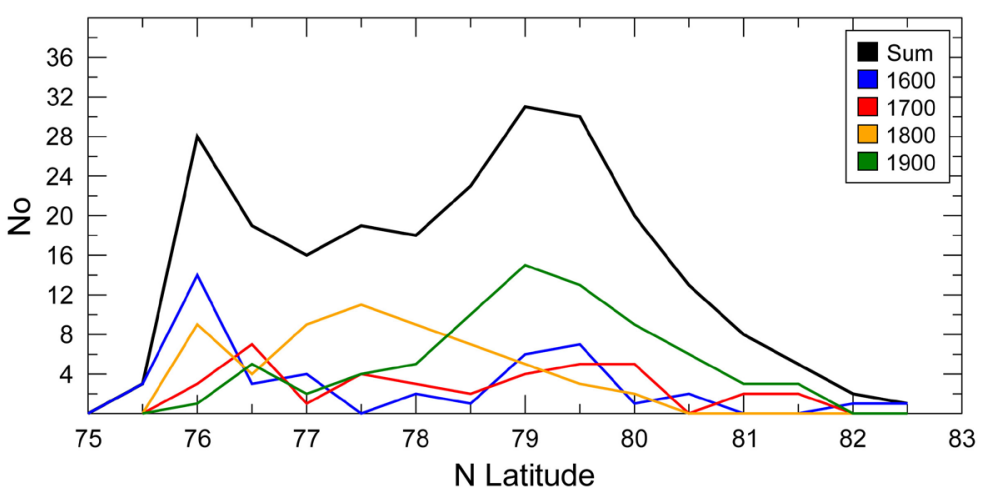

Figure 4. Distribution of BIE position estimates in half degree bins for four centuries.

The distribution is binominal with one peak around $76^{\circ} \mathrm{N}$ and one between $79^{\circ} \mathrm{N}$ and $80^{\circ} \mathrm{N}$. This is true for all centuries-except for the 1800 s with a single peak in the distribution at $77.5^{\circ} \mathrm{N}$. Comparing the extreme values with the map in Figure 1, we find that when the BIE position is $76^{\circ} \mathrm{N}-77.5^{\circ} \mathrm{N}$, then the east coast of Spitzbergen is ice covered. When it is $80^{\circ} \mathrm{N}-82^{\circ} \mathrm{N}$ the entire northern and eastern coasts are ice free.

The binominal distribution suggests two semi-stable positions of the ice edge, that may be related both to the inflow of warm AW on decadal and centennial scale as well as the prevailing winds influencing the ice drift on a much shorter scale. The vessel Fram's drift (1893-1896), showed the existence of a wind-driven polar ice drift from the Siberian shelf over the deepest part of the Arctic Ocean through the FS [25].

In addition to the ice transport through the FS there is a substantial, but variable, inflow of sea ice to the BS between Nordaustlandet (Svalbard) and Frans Josef Land. The interannual variation of the sea ice extent in the BS can exceed the annual variation [26]. This wind driven ice drift can further be transported up the west coast of Spitsbergen with the cold East Spitsbergen Current [27] as far north as Hornsund and Isfjorden.

The long-term variation in ice cover is related to GSBs [1] [28] and the volume and the temperature of the AW into the Arctic Ocean [29], while prevailing winds affect the ice distribution on scales of days, months, years, and decades [25]. Prevailing easterly wind north of Spitsbergen and Frans Josef Land will lead to an off-shelf Ekman transport of ice and surface water and upwelling of warm AW along the shelf break and onto the shelf itself [9] [30]. A prevailing northerly wind transports sea ice far south into the BS and up along the west coast of Spitsbergen [25]. In his analysis T.Vinje [16] tried to separate wind- and ocean effects and concluded "that the variation of ocean temperature and its positive or negative correlation with wind direction seems to be of crucial importance for the variation in the ice extent".

When we compare the BIE-positions with a simple harmonic model based on four significant periods (Figure 5), we find that the scatter in the observational difference from the model is less than \pm 1.5 degrees after 1750 , but considerably 


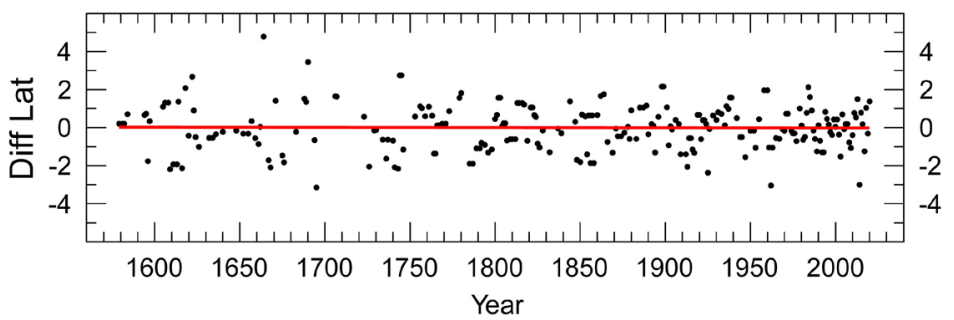

Figure 5. Residuals between BIE positions and a harmonic model.

more before this date. This may be due to higher intrinsic variability and/or less precise estimates. It is also worth noting that the scatter is not reduced in the satellite era beginning in 1979. The two most positive deviating positions are in $1660(+4.8 \mathrm{deg})$ and $1690(+3.4 \mathrm{deg})$-in the coldest period in the Maunder Minimum. The most negative deviations are in $1695(-3.1 \mathrm{deg})$ and $1962(-3.05$ deg).

\subsection{BIE Extreme Positions}

The binominal nature of the data (Figure 3) derives from intervals with almost stable positions, but with rapid changes in between (Figure 2). Our series starts with positions around $79^{\circ} \mathrm{N}$ in the years $1579-1608$. The next year the position moves to $76^{\circ} \mathrm{N}$ and stays there until 1676 , only with a few deviations: 1622 $\left(80^{\circ} \mathrm{N}\right), 1664\left(82^{\circ} \mathrm{N}\right)$ and $1671\left(79^{\circ} \mathrm{N}\right)$. In the period $1683-1707$ the position is far north $\left(78.5^{\circ} \mathrm{N}-82.5^{\circ} \mathrm{N}\right)$, with one exception: $1695\left(76^{\circ} \mathrm{N}\right)$.

We have a gap in the data $1708-1722$, but from 1723 to 1780 the position is generally far north, except for a dip in 1734-1743. It is again below $78^{\circ} \mathrm{N}$ $1785-1839$, except for the years $1802-1803\left(78.4^{\circ} \mathrm{N}\right)$. Then it moved north of $78^{\circ} \mathrm{N}$ for most of the period 1844-1864, before a slow decline to a minimum at $76^{\circ} \mathrm{N} 1909-1913$ and moving north to a maximum of $81^{\circ} \mathrm{N}$ in $1938-1939$. Then, we observe a short dip in $1962\left(76.5^{\circ} \mathrm{N}\right)$, before moving to a northern maximum in $2013\left(83.35^{\circ} \mathrm{N}\right)$. The last decade $(2011-2020)$ the trend is near zero with average position $82^{\circ} \mathrm{N}$. The previous decade the trend was slightly negative (Figure 3). However, there was a position jump from 2009 to 2013, creating a difference of 0.7 degrees between the mean of the two decades. Since 1981 BIE has moved north with an average of $\approx 0.5$ degrees per decade.

The most extreme change of 7 degrees expansion south happened 1690-1695 in the coldest decade of the last millennium. The last large southern advance was 2013-2014 with 4.5 degrees.

\section{Analysis - A Search for Fingerprints}

The BIE position during the period 1579-2020 (Figure 2) can be described as fairly stable around $79^{\circ} \mathrm{N}$ before 1610 , then a long minimum about $76^{\circ} \mathrm{N}$ between 1620 and 1660 . Then we have large variations $1660-1750$, and a long minimum around $77^{\circ} \mathrm{N} 1780-1830$. Then it went north for a few decades followed by a period with much ice 1870-1915. Then the ice cover decreased until 
1940, followed by a period with a slight increase in ice cover until 1980. Then the ice sheet again decreased. In this section we will analyze the spectra of the oscillations and compare with expected periods as described in [1]. We search for stable periods forced by external forces.

\subsection{Harmonic Analysis}

The program Period 04 (P04) [31] is developed to handle series of data with gaps. With this program it is possible to delete false periods which appear due to aliasing because of gaps. Frequencies determined by Discrete Fourier Transform are fitted into the data in the time domain, by determination of phase and amplitude. Sinusoids are then subtracted from the observed time series, one at a time manually. Amplitudes are evaluated against a false-alarm detection limit. Significant periods are subtracted until one ends up with a white noise spectrum.

The first analysis with $\mathrm{P} 04$ gives four significant periods $P$ (years) with amplitudes $A$ (latitude): $(P, A):[(252 \pm 7,1.2) ;(490 \pm 30,1.0) ;(83 \pm 1.0,0.7)$ and (151 $\pm 5,0.6$ ) ], with a residual (least square error) of 1.19 degrees. These 4 periods are harmonically related: $P_{i}=250 / i$ years, with $i=1 / 2,1,5 / 3$ and 3 . We define the periods 500, 250 and 150 years as the centennial periods. In addition, we include two weaker periods $[(19.7,0.40) ;(14.0,0.38)$.$] . The result is shown in Figure 6$. The residual is now reduced to 1.12 degrees. However, the analysis of the BIE-position series may contain errors because of increased noise before 1750 (Figure 4) and diverging edges because of a strong trend. The normal procedure is therefore to detrend the time series before analyzing for periodic variations. The time series contain three intervals with deep minima: around 1650, 1800 and 1900. We find that the series from 1579 to 1890 show a negligible trend $(-0.0009 \mathrm{deg} /$ year $)$ and from $1890-2020$ a trend $0.035 \mathrm{deg} /$ year. This means we have a breakpoint around 1890 .

Figure 7 shows the BIE-position series with these trends (a) and detrended (b). In (c) a spectrum of the whole series detrended is shown and in (d) for the period 1750-2020 only. Panel (c) shows the following significant periods and amplitudes $(P, A)$ : [(176 $\pm 6,0.73)$; $(84.8 \pm 1.6,0.59) ;(245 \pm 14,0.55]$ in addition to the following not-significant periods $[22.3,0.39 ; 13.9,0.39]$. A model position curve based on these 5 periods and amplitudes is shown as a red curve in Figure 7 (b). This model gives a residual 1.16 degrees. The same analysis of the BIE positions from 1750-2020 gave a spectrum shown in panel (d) with the following significant periods: $[(86 \pm 2.5,0.61)$; $(20.2 \pm 0.2,0.44)$; $(43.4 \pm 0.9,0.42),(120 \pm$ $7,0.36)$ ]. A model based on these four periods is shown in blue in Figure $7(\mathrm{~b})$. The residual is now 0.97 degrees, verifying the improvement of the data after 1750. In these series all periods are related to the Jose period of $P_{J_{0}}=178.38$ years with $P_{i}=P_{J o} / i$, with $i=3 / 2,2,4$, and 9 . This corresponds to the formulae found for periods in the solar motion around the solar system barycenter by N. Scafetta [32] (Equation (8)). We consider this as an argument for a solar-planetary connection. 


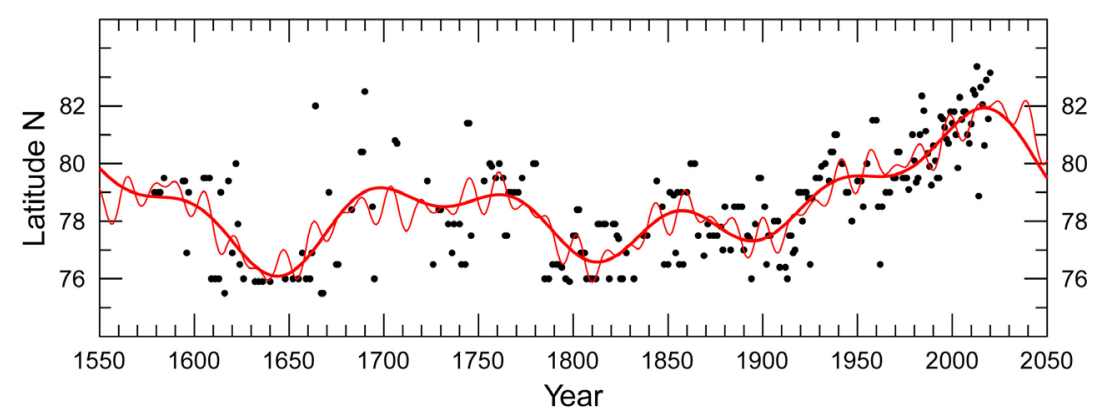

Figure 6. Harmonic analysis of BIE positions with four significant periods (thick red line) and two weaker periods (thin line).
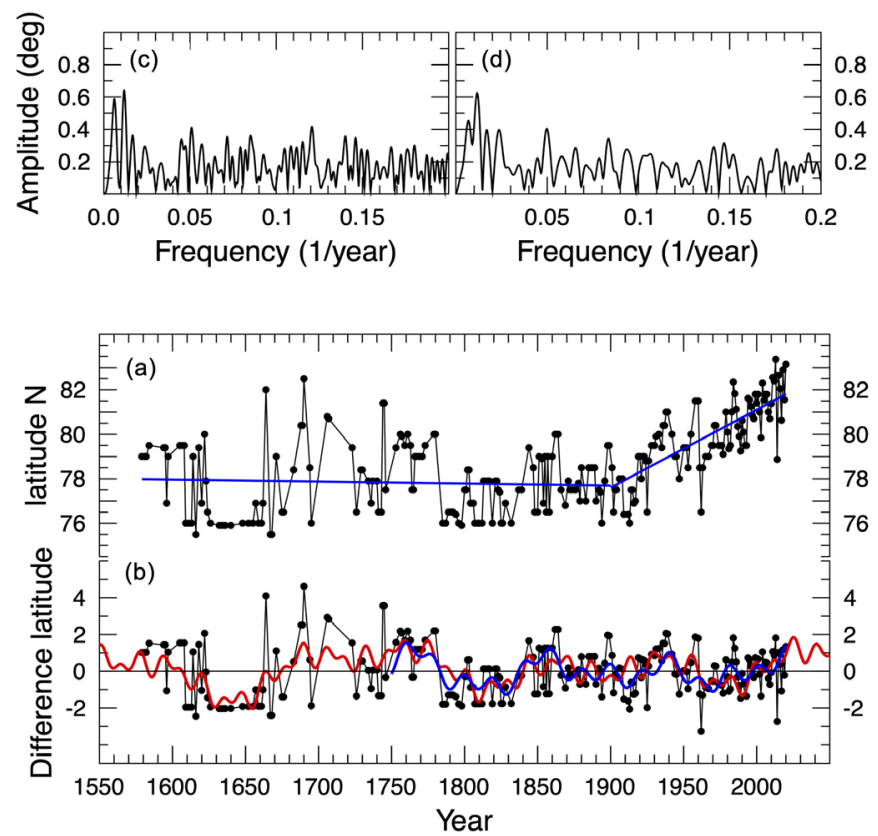

Figure 7. (a) BIE-position series with zero trend 1579-1890, and a linear trend 1990-2020; (b) BIE-position series detrended with the trends in (a); (c) Spectrum of the whole detrended series; (d) Spectrum of the detrended series 1750-2020. In (b) are also harmonic models with 4 periods (blue) and 5 periods shown (red).

\subsection{Morlet Wavelet Analysis and the 60-Year Period}

Visual inspection of climate data series often suggests the existence of one or several recurrent variations. However, describing the character (persistence, period, and amplitude) of such cyclic patterns is difficult, as the variations quite often come and go, lasting only for a limited period at each appearance. For this reason, they may prove difficult to characterize fully from a normal Fourier power spectrum. Especially the dynamics over time of the individual cycles, can be difficult to analyze. However, despite such shortcomings, Fourier analysis remains an extremely valuable tool for the identification of such recurrent natural climate variations.

To overcome the problem encountered when cyclic variations change their period and amplitude, we here also employ wavelet analysis to identify and de- 
scribe oscillating variations in climate series as a supplement to the Fourier analysis. Wavelet analyses can pick up even oscillations that last for a relatively short time and change their phase between one appearance and the next. Thus, wavelets transform represents an analysis tool well suited to the study of non-stationary processes occurring over finite spatial and temporal domains. Among other things, this technique is well suited to visualize the frequency content of a signal as it varies through time. Since its introduction by Jean Morlet [33], wavelet analysis has gradually found application in several fields of sciences, such as, e.g., seismic signal detection, turbulence, fractal research, etc. By this, wavelet analysis is becoming a common tool for analyzing localized variations of power within time series.

Many data series contain cyclic variations that are non-stationary, varying in both amplitude and frequency over long periods of time, which makes identification of such variations difficult. However, by decomposing time series into time/frequency space by wavelet analysis, it becomes possible to extract information on both the amplitude and variation over time of any periodic signal within the series, but only for that part of the signal which can be decomposed into sinusoidal components. An overall trend affecting the whole time series considered will therefore not be identified by this technique. The resulting wavelet diagram provides information on periodic behavior in the data series, making it possible to determine both the dominant modes of variability and how these modes vary with time. This, in turn, provides an important tool for understanding the nature of the main drivers behind observed cyclic variations of different phenomena.

Three types of wavelet types may be considered for analysis of time series: the Paul-, the Gauss Deriv- and the Morlet wavelet. For a given count of evident oscillations in the wavelet, the Morlet offers the best frequency localization, the Gauss Deriv wavelet is slightly less efficient, and the Paul wavelet is the least efficient in this respect [34]. Here we chose to make use of the Morlet wavelet, because superior frequency localization is essential to determine the most likely physical origin of the oscillations identified. At the same time, the Morlet wavelet still provides good localization of the oscillations in the time domain.

To avoid wraparound effects that arise because of non-periodicity in both the data and the response function (daughter wavelet), zero padding is needed equal to the half the length of the non-zero elements in the daughter wavelet's frequency response. Usually, zero padding to twice the data length, ensures that no wraparound effects are possible anywhere in the spectrum. Sufficient zero padding wraparound effects are eliminated but a different issue then arises, as it is likely that a discontinuity is introduced at the end of the data series. This zone of edge effects is known as the cone of influence, outside which spectral information is not likely to be as accurate regardless of whether zero padding is used. Here we used zero padding and computed the cone of influence using e-folding distances as described by [35].

In general, according to the Nyquist-Shannon sampling theorem [36] only 
frequencies lower than $f s / 2$ should be considered in the analysis, where $f s$ is representing the sampling frequency. As an example, for data series representing annual values, only frequencies lower than $0.5 \mathrm{yr}^{-1}$ should be considered, corresponding to periods longer than two years.

The results of a Morlet wavelet analysis of the BIE position series are shown in Figure 8. The first impression is that no stable short periods are present inside the cone of influence. The closest to stable periods are a cluster of periods between 14 and 20 years, which fades away after 1900. This is most likely the 14-year period detected in the P04-analysis. A 33-year period is present from the beginning until about 1850 . A 60 -year period is present through the whole series, just outside the cone of influence. Before 1800 we observe the 60 -year cycle with harmonics $30,14.5$, and 7.5 years. The harmonics pattern is a proof that the 60 -year cycle is real in this period. After 1800 the 60 -year period is still present, but its harmonics disappear, except a 19.8-year period which appears after 1900. When harmonics appear, this indicates that the basic period is strongly forced.

There is also a period $\mathrm{P} \sim 104$ years present through the whole series. This may be the 104-year solar modulation potential $(\varphi)$ period determined from cosmogenic radionuclides ${ }^{10} \mathrm{Be}$ and ${ }^{14} \mathrm{C}[37]$ and is a harmonic of the 208-year de Vries cycle. The 33-year period may be a harmonic of this. The 60-year and 104-year periods are indications of planetary and solar forcings.

\subsection{Analysis with a coif3 Wavelet Function}

The BIE position series have also been analyzed with a coif3 [38] [39] wavelet function. This wavelet provides phase information and handles variable amplitudes in contrast to the Morlet wavelet and the Fourier Transform analysis.

AtlanticSealceVinje1579-2020 Wavelet Analysis Morlet Complex Adj15 Nmin250

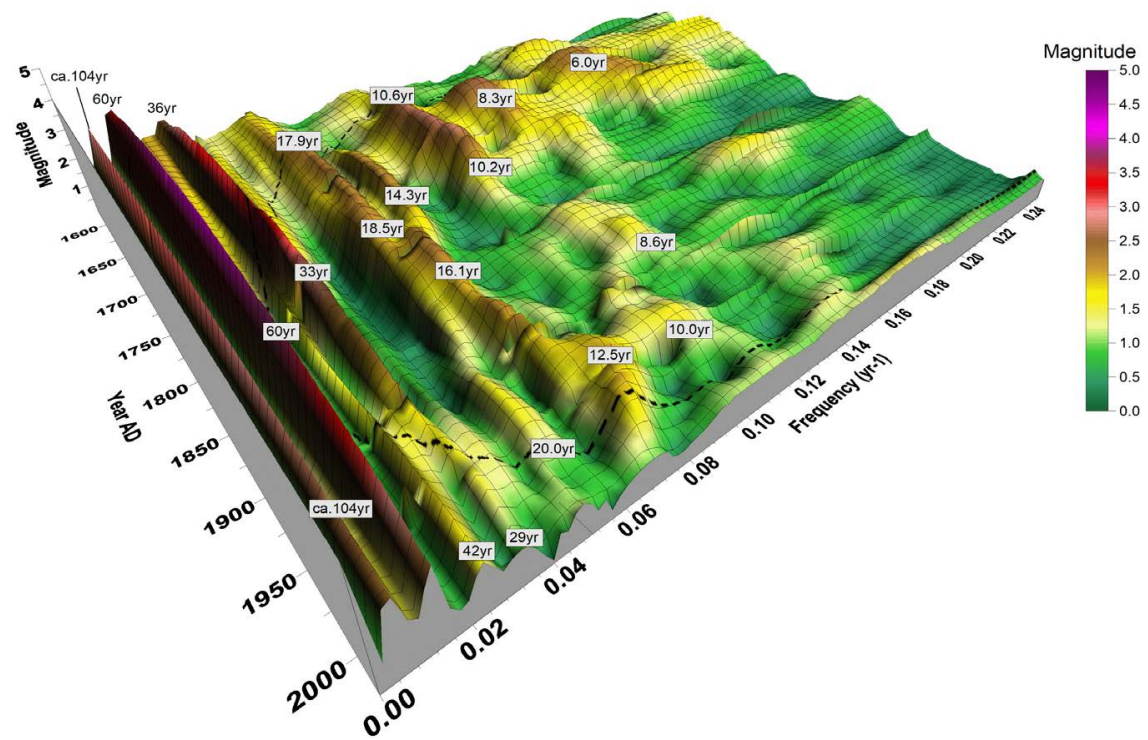

Figure 8. Morlet wavelet analysis based on de-trended data. The black, broken line defines the cone of influence where most accurate periods are found. 
Missing yearly data points were provided by cubic spline interpolation. Figure 9 shows the wavelet power spectrum. The four high peaks and the valleys show the extreme values of a bicentennial period: $(t, e x)$ : $[(1643, m i),(1725, m a)(1851$, $m i),(1986, m a)]$ where $m i$ and ma means minimum and maximum values. The valley bottoms represent the $(+, 0)$ and $(-, 0)$ phase times. The differences between the extreme values are half periods of duration 83, 126 and 135 years, indicating a period of the order 200 years. In Figure 9 we also have peaks of a sub-centennial period.

In Figure 10 we show $\mathrm{O}$-C-diagrams for some of the dominating periods. In this type of diagrams, we compare the phase with expected phase from a clock running with a fixed frequency. If the observed period is the same as the clock-period, we get a straight line parallel with the $\mathrm{x}$-axes. If the period is constant but different, we get a straight line in some other direction.

The top panel shows the bicentennial peaks relative $\mathrm{P}=252$ years clock pulses. The O-C-diagram shows $\mathrm{P}=145$ years before 1740 and $\mathrm{P}=266$ years thereafter. The lower panel shows that a sub-centennial period of 82 years has a stable phase between 1670 and 1910, but then a phase shift takes place between 1910

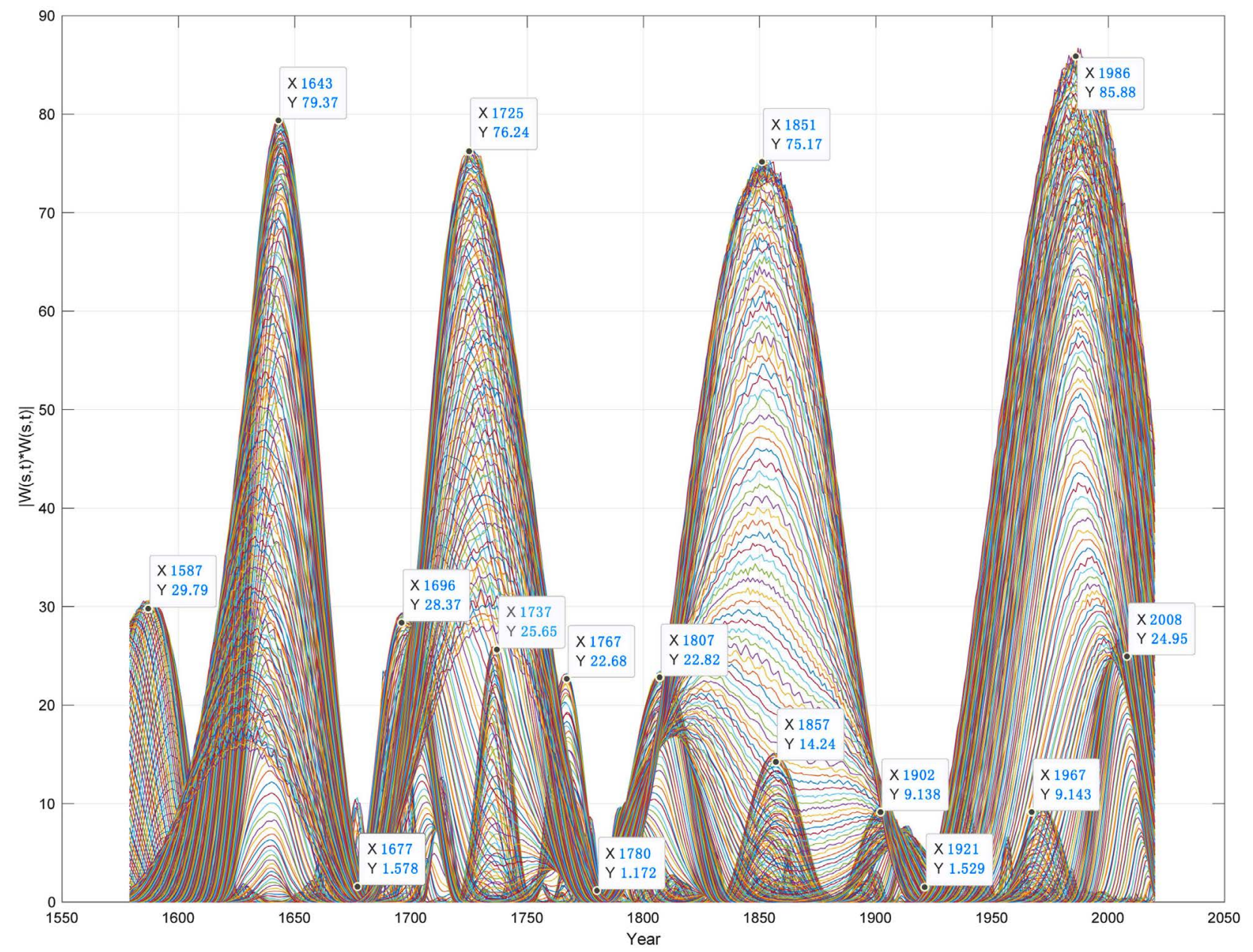

Figure 9. Wavelet power spectrum of the BIE-series with values of peaks and valleys (provided by H. Yndestad [38]). 


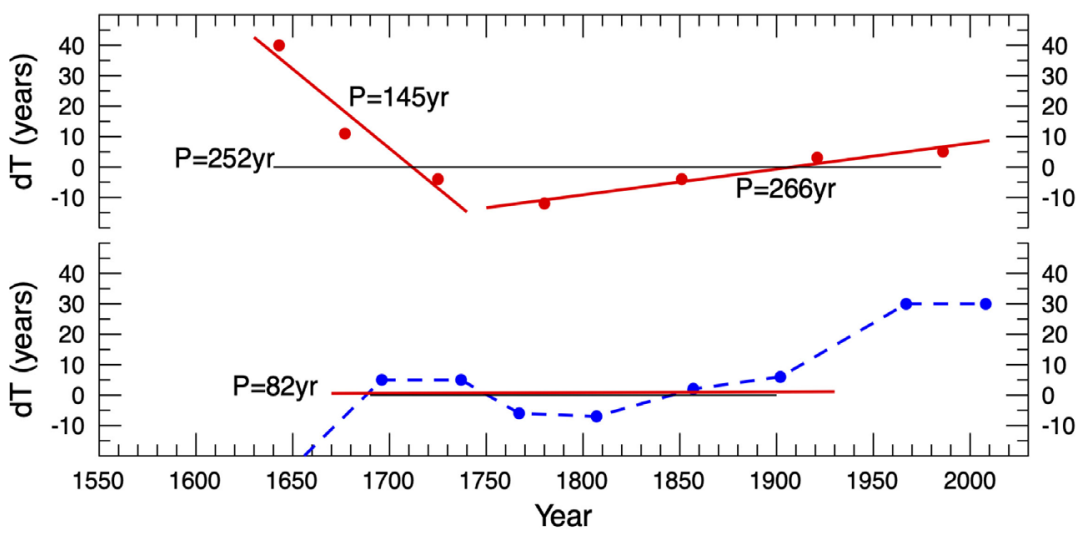

Figure 10. O-C diagram for phase-points marked in the wavelet power spectra in Figure 9, shown relative clock pulses of $\mathrm{P}=252$ years for the bicentennial and $\mathrm{P}=82$ years for the sub-centennial periods.

and 1940. The lack of stability before 1740 may be due to less precise observations (see also Figure 5). The phase shift between 1910 and 1940 may be related to the rapid warming in this period.

\subsection{Conclusions on the Fingerprint Search}

The 268-year period is $\sim 3 \mathrm{P}_{\mathrm{J}_{\mathrm{o}}} / 2$ and the 145 year period $\sim 4 \mathrm{P}_{\mathrm{J}_{\mathrm{o}}} / 5$, which are signs of planets.

Sub-harmonics of the 60-year cycle with periods 120, 240 and 480 years are also detected, as predicted in [1] (see Figure 13 and Section 10.2), but not as dominant periods. The 82 -year period is close to the basic solar period found by [38]. We have detected signatures of the Sun and planets.

\section{Comparison with Other Climate Data Sets}

The BIE position is a result of many driving factors: The freezing of new ice during the winter, the melting in the summer, the sea temperature, the strength of the wind pattern, the solar activity, tidal effects from the Moon and the Sun, and pollution by dust etc. In the following we present some linear correlations based on data from the same year before we present some correlations based on averaged data. Goodness of fit $\left(r^{2}\right)$ explains how much of the variation can be explained by the calculated linear relation.

\subsection{Central England Temperature (CET) Series}

The Central England surface air temperature series is the longest existing meteorological record based on thermometer readings. It is constructed from stations with a minimum urban heating [40] and updated by the Hadley Centre [41].

Climate is defined from 30-year averages. Correlating 30-year averages of CET and BIE positions we get the goodness of fit $r^{2}=0.79$ as shown in Figure 11, left panel, with the relation $B I E=3.62{ }^{\star} \mathrm{CET}+44.6^{\circ} \mathrm{N}$. This shorter data set was 

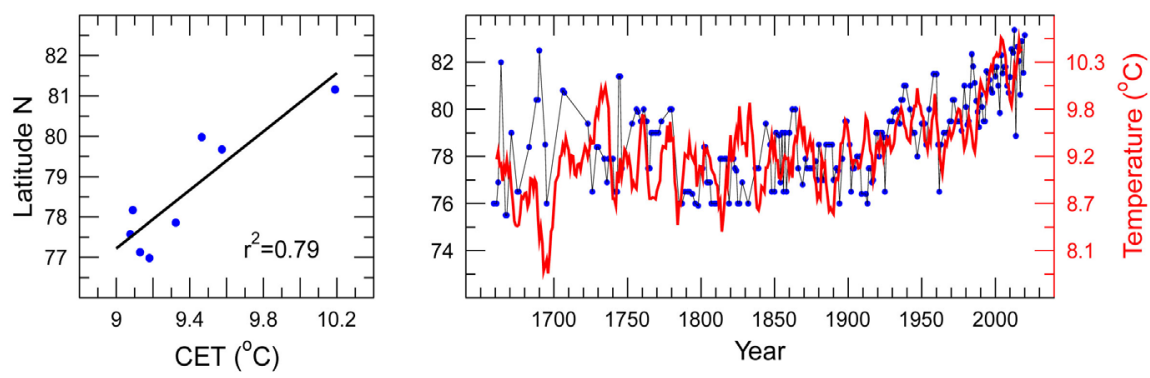

Figure 11. BIE positions compared with CET. The left panel shows the correlation between 30 years averaged values (1778-2018). The right panel shows 5-year running mean of CET converted to latitude by the relation shown in the left panel (red) and the BIE positions (blue dots) 1659-2020.

selected because of being less noisy than earlier data. This relation was used to convert 5 years running mean CET-values to BIE-latitudes in the right panel and compared to BIE position estimates.

CET is decreasing from 1659 to 1695 during the coldest period in the LIA. The CET and BIE positions follow quite well also on shorter time scales. A CET peak in the $1680^{\prime}$ ies corresponds to a BIE position $82.5^{\circ} \mathrm{N}$, and a sharp temperature drop in the $1690^{\prime}$ ies to a rapid BIE expansion to $76^{\circ} \mathrm{N}$. The temperature peak in the $1730^{\prime}$ ies is followed by BIE retreat to almost $82^{\circ} \mathrm{N}$. A CET peak in 1830 is followed by BIE retreat in the 1840 'ies etc.

\subsection{Nordic Arctic Sector Summer Sea-Ice Coverage}

From 1979 both the Arctic summer ice cover in the Nordic sector [22] and the BIE position, have been estimated from satellite observations. In this period the BIE position varied between $79^{\circ} \mathrm{N}$ and $83^{\circ} \mathrm{N}$ and the ice sheet area in the Nordic Arctic sector between 1.5 and $1.0 \mathrm{Mkm}^{2}$. We find a goodness $r^{2}=0.61$. The correlation is shown in Figure 12. Based on a linear least square relation between the summer ice cover shown in the left panel, we show the best fit in the right panel. The residual is flat curve, showing that the summer ice cover and August ice-edge position are well correlated these 40 years. Also including summer ice estimates with other methods back to 1900 , gave $r^{2}=0.22$, indicating less precise estimates.

However, the correlation between the Arctic summer temperature in the Nordic sector and the ice edge position is poor $\left(r^{2}=0.08\right)$ for the period 1979-2015 and is reduced to $r^{2}=0.03$ when we include data back to 1900 . This is because the summer temperatures in the Arctic show small variations from year to year, while the winter temperatures, and thereby annual temperatures, show large variations. For the Nordic sector ice and Arctic summer temperature correlations we have used data from a recalibration of Arctic ice extent by [22].

\subsection{Correlations with Arctic Land and Sea Temperatures}

Since BIE runs from Svalbard to Frans Josefs Land, we expect a correlation 

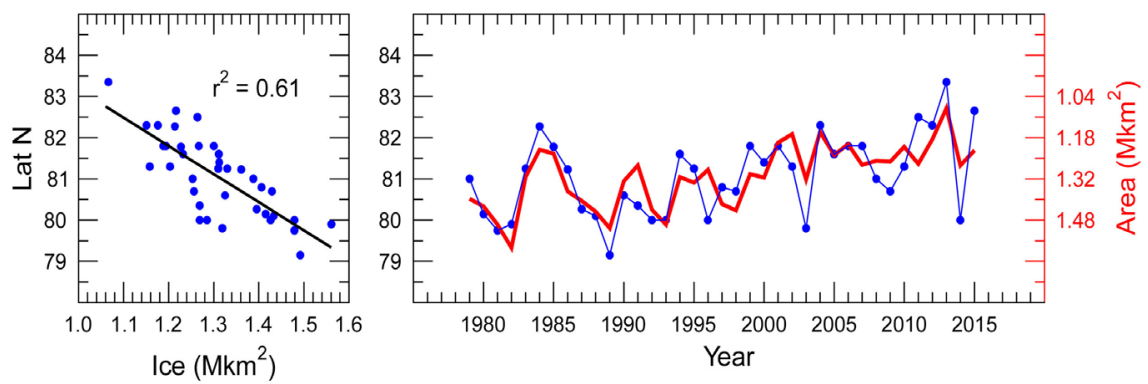

Figure 12. Correlation between the summer sea-ice area in the Nordic Arctic sector and the position of BIE 1979-2015 (left). The right panel shows the summer sea-ice area (red) and the BIE position (blue).

between the BIE position and Longyearbyen air temperatures [42] and Kola section sea temperatures (KolaT) [43]. Longyearbyen is situated in a fjord on the western coast of Svalbard where a branch of the AW keeps the coast ice free in most winters (see Figure 1). The winter temperature is dependent of the winter ice conditions. Longyearbyen temperature measurements are available from 1898. KolaT series were provided by the Polar Research Institute of Marine Fisheries and Oceanography (PINRO), Murmansk, Russia [44]. The data used here are yearly temperature values from the upper $200 \mathrm{~m}$ of the Kola section, along the $33^{\circ} 13.0^{\prime} \mathrm{E}$ meridian from $70^{\circ} 13.0^{\prime} \mathrm{N}$ to $72^{\circ} 13.0^{\prime} \mathrm{N}$ in the Barents Sea.

The relations are shown in Figure 13 panels (a) and (d). Both temperature series peaks around 1920 and 1930 and show a rise from mid 1980-ties, which follows the BIE position quite well. Correlation between BIE position and Longyearbyen temperature gives $r^{2}=0.48$ and with the KolaT $r^{2}=0.29$. The development in KolaT follows the same trend as described for the BSO by [4] where the increase in the temperature started in mid 1980ties. We have also compared with Arctic and $\mathrm{NH}$ land-temperatures based on rural stations (Figure (b) \& (c) in [45]). The Arctic land mean temperature (ArcT) (North of the Arctic Circle) was around $0^{\circ} \mathrm{C}$ from 1830-1920, and then increased 3 degrees in 30 years. This is well correlated with the BIE position $\left(r^{2}=0.55\right)$ (Figure 13 panel (b)). Also, the Longyearbyen temperature, has a steep rise around 1920 and peaks in 1940 or 1950. The NH-land temperature (panel (c)) has the same steep rise around 1920 but peaks 10 years later than the Longyearbyen temperature and ArcT.

As the ocean is a main transporter of heat to the Arctic, we should expect a correlation between the $\mathrm{NH}$ sea temperature and BIE position. The relation is shown in Figure 13 panel (e). The correlation is the same as for the NH rural temperature and somewhat lower than for Arctic land temperature. We interpret this as the land stations and BIE have an equal or larger contribution from airborne heat flow, maybe related to solar variations (TSI or GCR-induced clouds). The sea surface temperature measurement is quite variable before 1900 but tracks the BIE-position quite well after 1900. It seems to give a better fit than the KolaT $\left(r^{2}=0.44\right.$ versus $\left.r^{2}=0.29\right)$. The KolaT peaks in 1935 , about 10 years before the NH-SST. Table 2 shows a summary of the correlations. 


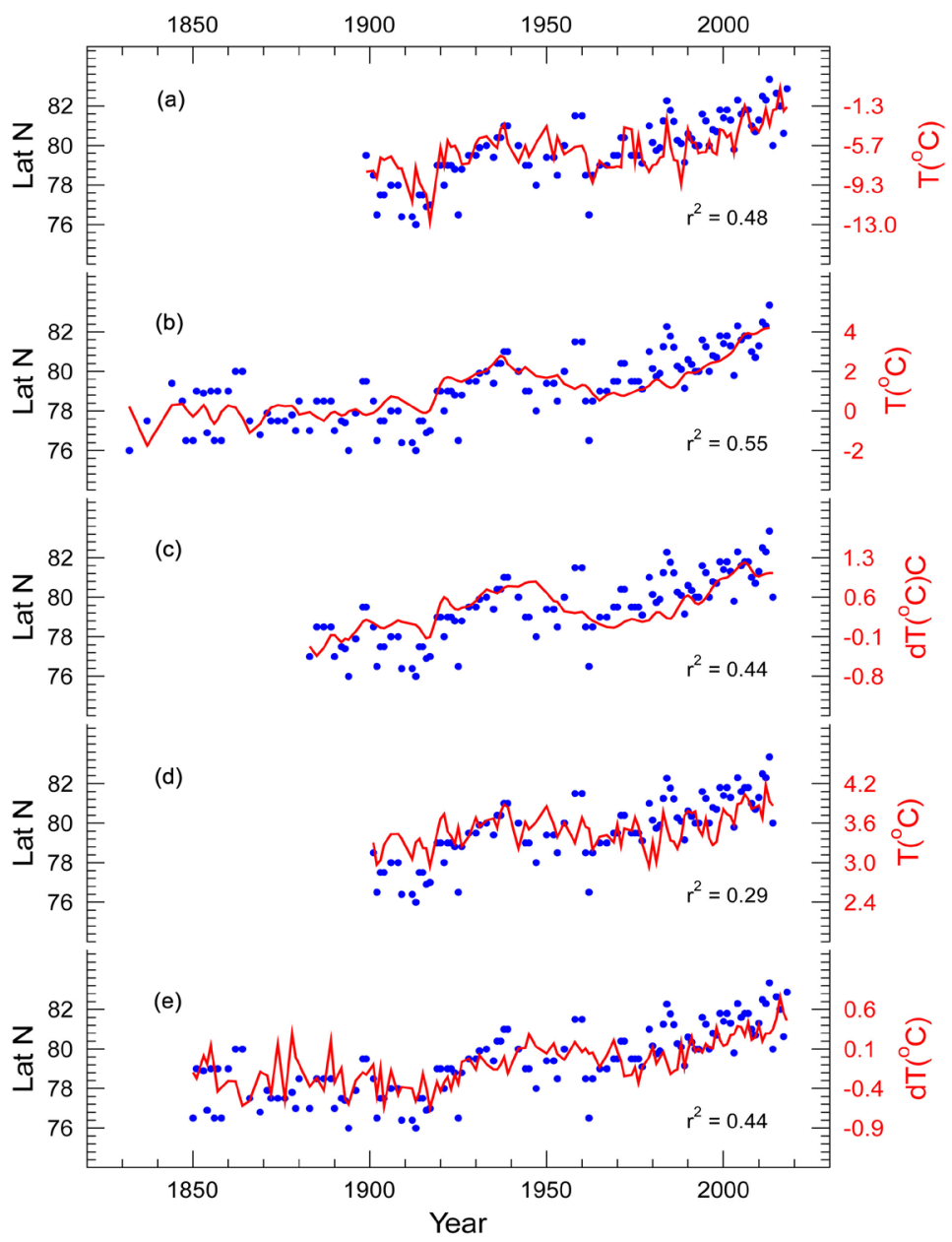

Figure 13. Correlations between temperature series (red lines) and BIE positions (blue dots) based on yearly data. (a) Longyearbyen T; (b) ArcT; (c) NH rural stations; (d) KolaT; (e) NH-SST.

Table 2. Summary of correlations with BIE position.

\begin{tabular}{ccccc}
\hline Series & Years & no. & $r$ & relation \\
\hline CET 30years mean & $1779-2018$ & 8 & 0.89 & $3.62{ }^{*} \mathrm{X}+44.6$ \\
CET yearly & $1659-2018$ & 285 & 0.37 & $0.98{ }^{*} \mathrm{X}+69.6$ \\
Nordic sector summer ice & $1979-2015$ & 37 & -0.78 & $-6.83 * \mathrm{X}+90.0$ \\
Nordic sector summer ice & $1900-2015$ & 90 & -0.46 & $-7.66{ }^{*} \mathrm{X}+89.9$ \\
Nordic sector summer temp & $1979-2015$ & 37 & 0.28 & $0.39{ }^{*} \mathrm{X}+80.8$ \\
Nordic sector summer temp & $1900-2015$ & 90 & 0.18 & $0.50 * \mathrm{X}+79.5$ \\
Longyearbyen air temp & $1899-2018$ & 94 & 0.69 & $0.55 * \mathrm{X}+82.9$ \\
Arctic land temp & $1832-2014$ & 124 & 0.74 & $1.54{ }^{*} \mathrm{X}+79.1$ \\
NH rural land temp & $1883-2014$ & 100 & 0.66 & $2.84{ }^{*} \mathrm{X}+79.0$ \\
KolaT & $1901-2014$ & 89 & 0.54 & $1.67{ }^{*} \mathrm{X}+79.7$ \\
NH-SST (HadCRUT3) & $1850-2018$ & 124 & 0.66 & $3.95 * \mathrm{X}+79.6$ \\
\hline
\end{tabular}




\subsection{Cyclic Variations after 1800}

In [1] we proposed that external forcings work through Earth's rate of rotation (LOD) and by the ocean surface and atmosphere circulation [1] (see Figure 7 and Figure 9). In the following we will investigate the period and phase relations between LOD, BIE and other climate series and investigate how BIE position series fit in the SW concept [46] and [1] (Section 9.5).

To compare the oscillating patterns, we have compared detrended and 11 years running mean values of BIE position (1800-2020), with KolaT (1900-2015) [44], Arctic land temperature (ArcT) [45], AMO (1856-2018) [47], NAO (1800-2018) [48] [49] and LOD [50] series. LOD is determined by observations, mostly solar eclipses and occultation timings from ancient Babylonian, China, and the Arab and European worlds through early telescope observations to modern Very Long Baseline Interferometry (VLBI) observations after 1962 [50]. The BIE-positions have been detrended as shown in Figure 7 with a break in 1890. Since the BIE-series has many gaps of variable length, we have made running mean values based on 11 successive numbers. In the other series with yearly values, we have calculated running mean of 11 yearly numbers. The result is shown in Figure 14. The general impression is that all series, except NAO and LOD, have maxima between 1930 and 1960, and minima 1900-1920, and 1960-1980. $\mathrm{NAO}$ and LOD have maxima and minima some years earlier.

All the series show periodic variations $50<\mathrm{P}<100$ years. LOD, AMO and NAO have periods 65 - 67 years. BIE has $\mathrm{P} \sim 82$ years with a phase shift between 1900 and 1950 (Figure 10). The KolaT P 77 years and ArcT P 82 years, are closer to the BIE-period.

If we compare the dominating periods, we find the following phase shift sequence [-0] starting around 1900: LOD (1891) $\rightarrow$ NAO (1902) $\rightarrow$ ArcT (1914) $\rightarrow$ KolaT $(1920) \rightarrow$ BIE (1921) $\rightarrow$ AMO (1929). This may indicate LOD as driving with NAO forcing-resulting in ArcT, KolaT and BIE changing 15 - 30 years later. In the next [-0] phase shift the sequence is slightly changed: LOD (1957) $\rightarrow$ NAO (1967) $\rightarrow$ BIE (1980-90) $\rightarrow$ ArcT (1996) $\rightarrow$ AMO (1997). The sequence again starts with LOD and NAO with the others 15 - 30 years later. Around 1850 the peak in BIE, ArcT and NAO are almost in phase.

The series have the following max values: LOD $(1974) \rightarrow$ NAO (1983) $\rightarrow$ KolaT $(2010 ?) \rightarrow$ BIE $(2010-2020) \rightarrow$ AMO $(2012) \rightarrow$ ArcT (2015 or later). The Longyearbyen temperature (not shown) lags BIE with $\sim 5$ years. The phase difference LOD-NAO and LOD-negAMO is $0.3 \pi$, where neg means negative. This indicates that LOD can be the driver of NAO and AMO, the most important periodic climate variations in the North Atlantic region. On the other hand, the BIE position last century, is in antiphase with LOD 65-year period which has [0,-] shift in 1926 and 1991, which is 5 or 3 years after BIE [-0] shifts.

The longer period Arctic temperature series (ArcT) has changed from being in phase with LOD and NAO around 1850, to be in antiphase after 2000. The opposite has happened with AMO and ArcT, which now are in phase. BIE position and KolaT have gradually been phased to AMO. 


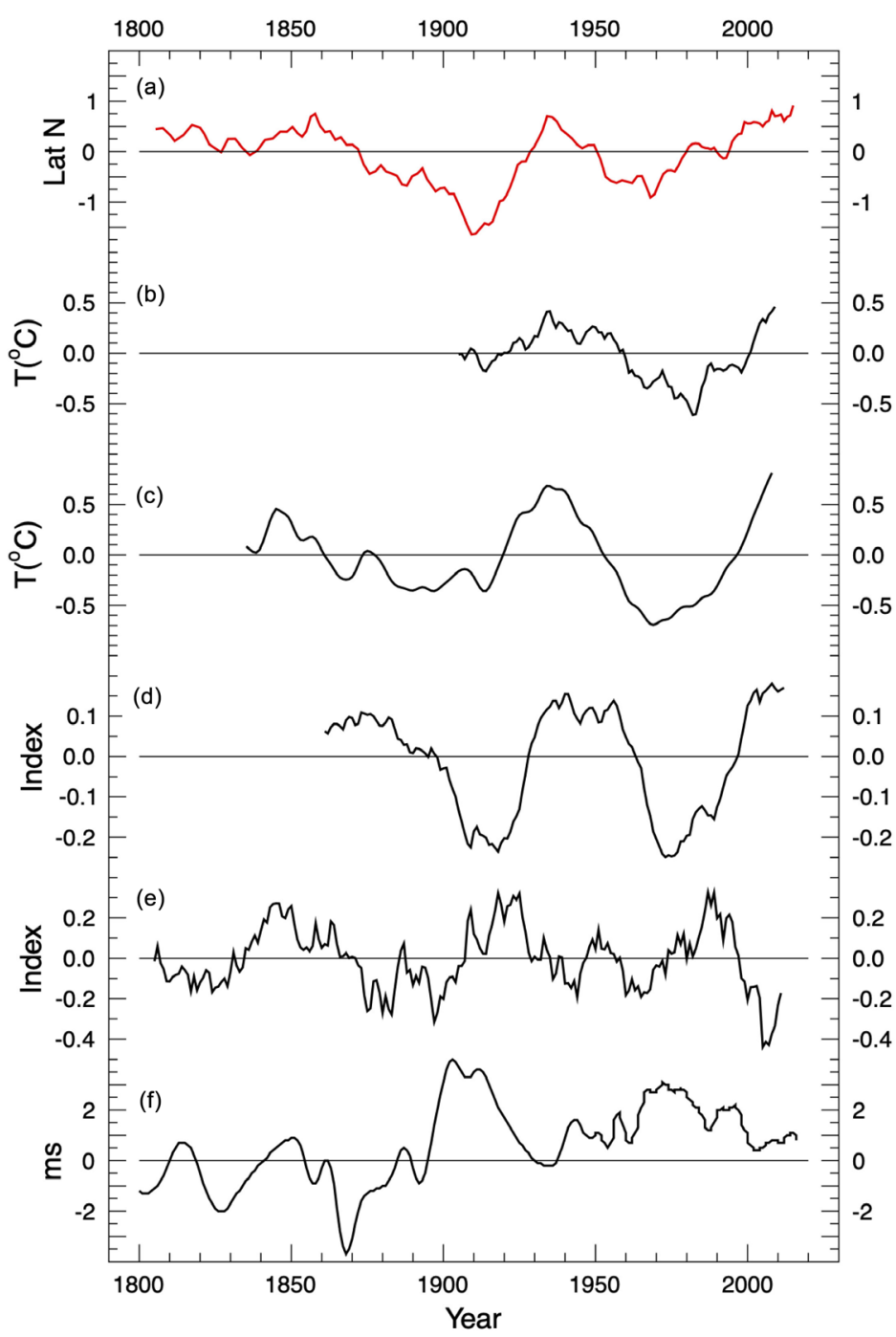

Figure 14. Oscillating pattern after detrending and 11 points running mean of (a) BIE position; (b) KolaT; (c) ArcT; (d) AMO temperature index; and (e) NAO pressure index; (f) LOD (not detrended).

The period pattern indicates decreasing BIE, AMO, ArcT and KolaT relative the trends the next decades, while LOD and NAO are increasing. The next BIE minimum relative the trend is about 2050. It should be remembered that a main component responsible for the trend is the 268-year period found in Section 3.3. This period had maximum in 1986 and is decreasing this century. A decreasing KolaT is also predicted by [43].

\subsection{The Stadium Wave Pattern}

In the Stadium wave concept [1] [46] (see Section 9.5 and Appendix 1), various periodic or quasi-periodic climate phenomena are found to vary in phase and given membership in distinct temporal groups (TG). Anomaly of NHT, AMO, negLOD and ArcT were all assigned to TG IV with maxima around 1938 and 1998. Cool Atlantic sea-surface temperatures (negAMO) correlated strongly 
with positive sea ice extent of the Greenland and Barents Seas. This means that we should expect AMO in phase with BIE far north positions.

Our analyses (Figure 14) places AMO in TG I with maxima around 1945 and 2012 and NAO in TG II with maximum in 1983, while ArcT has a longer period and moves from TG II in 1933 to TG I in 2015. It is now in phase with AMO. Wyatt \& Curry [46] analyzed boreal winter indices of NAO and the Arctic Oscillation $(\mathrm{AO})$ and found that they behave differently from their yearly counterparts, and co-varied within TG II. We have used the yearly version of NAO in our analysis. That may explain the difference.

The BIE position varies from TG III in 1938 to TG -I in 2011. This means that the BIE position and ArcT are not at fixed positions in the Stadium wave but moves relative to the pattern. Periods longer than the Stadium wave period may be due to external forces as the Moon, Sun and planets as indicated in [1]. We will explore this in Section 5.

\subsection{BIE and NAO}

When NAO is in its positive phase, the subtropical high-pressure center is stronger than usual, and the Icelandic low-pressure center is deeper. The positive phase is associated with stronger-than-average westerlies across mid-latitudes, warm and wet winters in Northern Europe, dry winters in Southern Europe, cold and dry winters in Northern Canada and Western Greenland, and mild and wet winter conditions in Eastern USA. The negative phase is associated with the opposite anomalies

A study of the ice edge anomaly and winter NAO-index by [51] demonstrated a nearly anti-phase behavior indicating that positive NAO with increased northern meridional circulation, promote a retreat of the ice cover. They found the strongest NAO-effect on the ice cover in the Greenland Sea and western Barents Sea with a correlation coefficient $r=-0.5$ to -0.6 . The variations suggested presence of a 60 - 80-year variability in the BIE position.

Vinje [16] investigated the relation between the change in NAO winter-index $(d N A O / d t)$ and the April ice extent and found a correlation $r=-0.97$ with in the eastern area of the Nordic Sea. A sequence of southern winds (positive NAO change) reduced the ice, while northern winds (negative NAO change) increased the ice. For the western area he found a negative correlation $r=-0.60$, and for the Newfoundland-Labrador area a positive correlation $r=0.61$. This demonstrated the "seesaw effect" between eastern and western areas [52].

Polyakova et al. [53] reported that the relationships between NAO and key North Atlantic climate parameters like the sea surface temperature, surface air temperature, and sea level pressure are not as stable as the accepted paradigm of relations. For example, the ice-decline the last decades is accompanied with negative NAO-index, as demonstrated in Figure 14, while the ice-declines previous decades have been accompanied with positive NAO-index and with high atmospheric cyclonicity. A possible interpretation of this reverse relation is that 
we are in the starting phase of a deep solar minimum.

\subsection{Integrated Effects (LOD and INAO)}

The detrended values for BIE position correlate with the detrended negLOD (Figure 14). In [1] we have proposed LOD as the mechanism to transfer internal and external forcings to the ocean surface and atmospheric circulation [1] (Figure 7). Since negLOD correlates with SST [54], it is a good candidate to transfer the solar and planetary forcings to the Arctic ice cover by the geostrophic (zonal) wind which is set up by the temperature difference between the tropics and Earth's poles. The temperature difference generates the pressure difference as defined by NAO. The variation of wind speed $(\Delta \mathrm{Ug})$ is related to the integrated zonal index (IZI) or integrated NAO (INAO). Mazzarella and Scafetta [55] proposed the following relation: IZI $\sim$ INAO $\sim \Delta \mathrm{Ug} \sim$ negLOD and showed that SST was well correlated with INAO and negLOD, at least from 1840, and used this to hindcast SST back to 1700 . They assumed that the trend after 1840 also was present before that date. This resulted in a SST temperature minimum $1.0^{\circ} \mathrm{C}$ $-1.5^{\circ} \mathrm{C}$ colder than today [55].

In Figure 15 we show the linear least square fit of BIE position to INAO and LOD for the period 1800-2018. The fit is quite good, except that INAO and BIE are diverging after 2000 and LOD has a less steep trend after 1960. Hindcasting before 1800 does not work since the trend in BIE then is zero as shown in Figure 7.

The failure of hindcasting with respect to BIE position may be related to the two negative GSB events 1687-1703 and 1808-1823, which has a period of positive GSB in between. The positive GSB 1703-1808 brings warm water to the North Atlantic and may push BIE north.

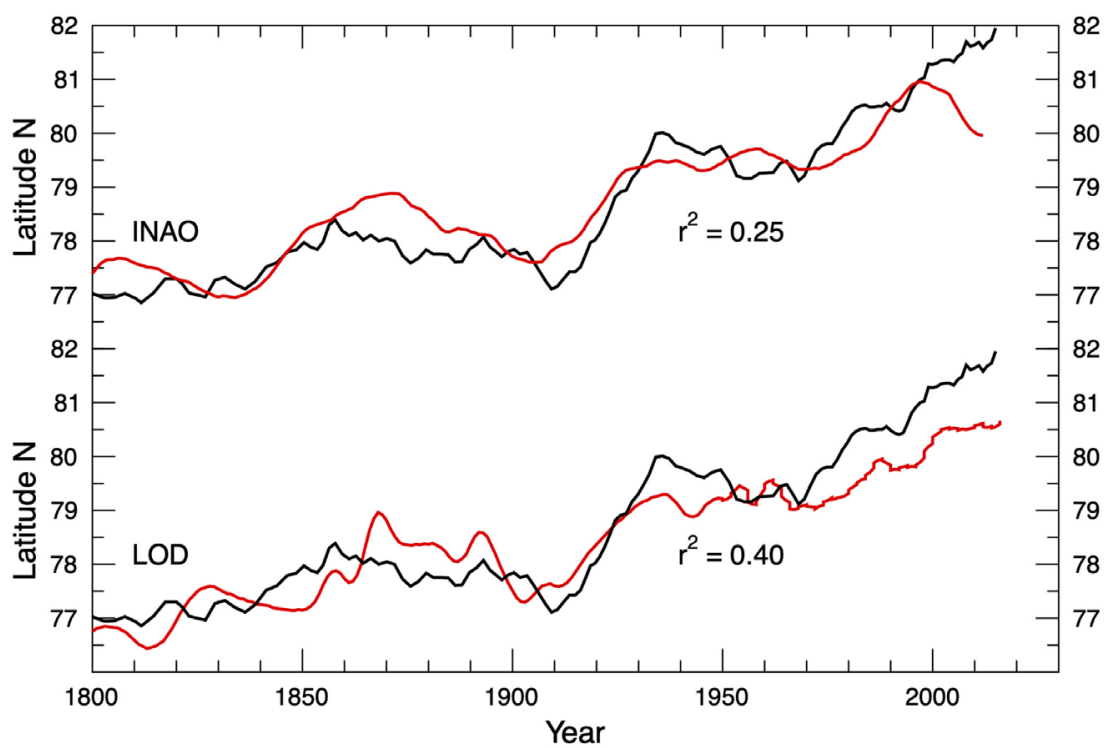

Figure 15. 11-Point running mean BIE position (black), INAO (top, red) and negLOD (bottom, red). 


\subsection{Summary of Oscillating and Integrated Internal Effects}

The strong correlations between the BIE position and other climate parameters as the Nordic Sector summer ice, Longyearbyen air temperature, ArcT, NH-SST and KolaT, show that the BIE position is related to other regional climate factors. The most important observation is the near linear change in BIE position from $1900\left(r^{2}=0.61\right)$. The trend before 1900 is near zero. This may be an effect of the GSB events 1676-1703 and 1808-1821.

Compared to cyclic changes after 1800 in the Stadium wave 60-year period group, AMO, NAO, and LOD show the same periods, with AMO in antiphase of LOD and NAO. BIE position, KolaT and ArcT oscillate with a longer period, but with the same phase. However, the difference in periods means that the phase similarity is only temporal.

INAO is clearly in antiphase with LOD. Both correlate well with BIE position and have linear trends after 1800 .

\section{Forcing by the Sun and the Moon}

The Arctic ice cover shows dramatic changes during the year. The major reason for ice and snow melting in the summer season is the presence of the Sun. When the first rays from the Sun hit the ice edge after the long period of no Sun in the winter, ice melting starts, first slow, then faster-until minimum ice is reached at the end of August or early September, when cold nights again start the freezing cycle. It is important to notice that the melting season starts when temperature rise above $-5^{\circ} \mathrm{C}$. The yearly cycle is clearly a function of how the solar insolation changes during the year.

In addition to direct solar insolation the ice cover is also modified by the influx of warm Atlantic water which heats the Arctic atmosphere. A simulation with the forced global ocean model NorESM20CR, aided by hydrographic observations shows a poleward ocean heat transport last century of $68 \mathrm{TW}$, with typical variations $40 \mathrm{TW}$ over time scales 5 - 10 years, due to thermohaline and wind stress forcings [56]. In the model simulations 45 TW entered through BSO and $15 \mathrm{TW}$ through the FS. The rest of the heat transport came through the Davis and Bering straits. The observed heat transport through BSO is about $70 \mathrm{TW}$, and the seasonal difference is small, with a winter volume transport of $1.7 \mathrm{~Sv}$ and a summer mean of $1.3 \mathrm{~Sv}$.

Since the insolation changes with Earth's orbit and the solar energy output varies with solar cycles, we may expect that the BIE position mirrors solar and orbital variation. This is also true for the ocean currents which transport heat from tropical oceans with a delay of decades. We may therefore expect both direct solar signals and solar signals with short and long delays. In the following we will take a closer look at orbital and solar variations, and, in Section 6, investigate if there are relations to the orbits of the planets.

\subsection{Orbital Forcing (The Milanković Cycles)}

There are three orbital forcings: the change of ellipticity, axial inclination and 
orbital precession. Figure 16 shows the integrated total summer insolation (ITSI) during the summer at $60^{\circ} \mathrm{N}$ during the last 13,000 years [57]. The summer season is defined as the time between spring and autumn equinoxes. The decrease in insolation from the Holocene maximum until recent times is about $6.2 \%$ and is mainly due the change in obliquity. The wiggle in the curve (Figure 16) is due to the perturbation in the distance to the Sun because of the 18.6 years lunar nodal precession period.

The reduction in ITSI from the Holocene Maximum in Figure 16 corresponds to a reduction in ocean surface temperatures of about $4^{\circ} \mathrm{C}-5^{\circ} \mathrm{C}$ to a LIA minimum between 550 and 250 cal years BP, determined from high-resolution sediment cores from the Vøring Plateau in the Norwegian Sea at $67 \mathrm{~N}$ [58] as shown in Figure 17.

Biochemical proxy records from Icelandic lake sediments show the same evolution, a millennium scale cooling after the Holocene warm period, a $\sim 0.5^{\circ} \mathrm{C}$ summer cooling the first millennium, with stronger cooling starting $\sim 1450 \mathrm{CE}$, reaching maximum cooling of $1^{\circ} \mathrm{C}$ shortly after $1850 \mathrm{CE}$. Model simulations with CESM1.1 state-of-the-art global climate model show Arctic-wide cooling from $1 \mathrm{CE}$ to $1900 \mathrm{CE}$ and a following sharp rise in temperature, the Medieval warm episode from $950 \mathrm{CE}$ to $1250 \mathrm{CE}$, the LIA 1300-1850 CE and abrupt cooling in response to major explosive eruptions [59].

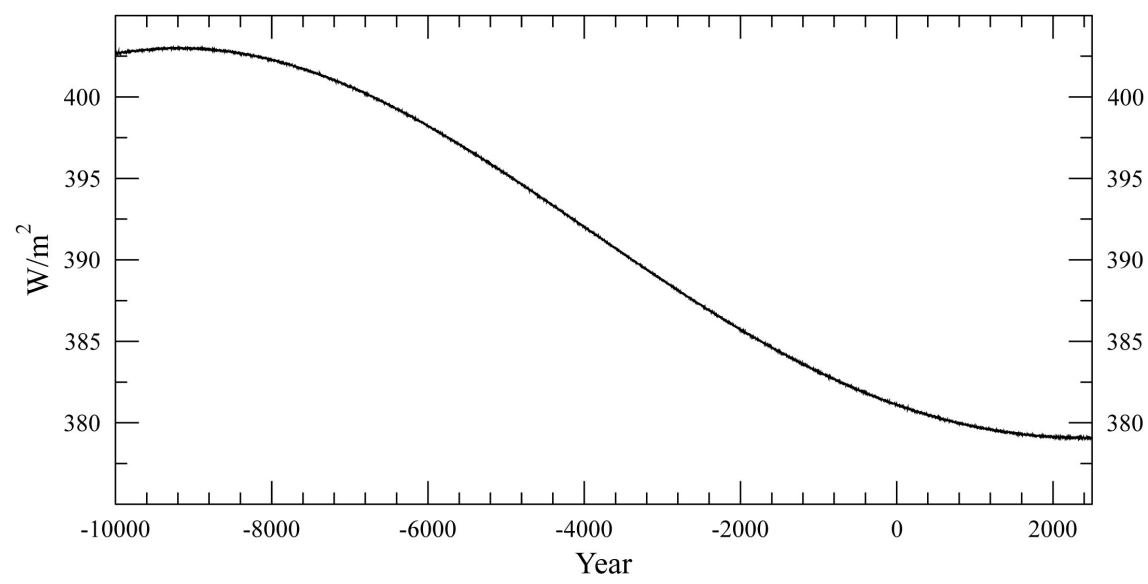

Figure 16. Integrated daily insolation for the astronomical summer at $60^{\circ} \mathrm{N}$ for a constant Sun and no atmospheric absorption (calculated by R.G. Cionco [57]).

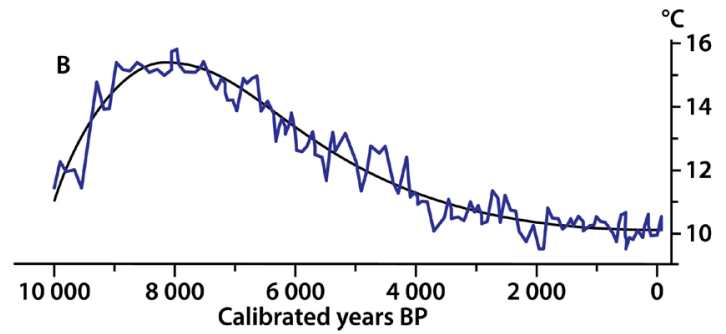

Figure 17. Reconstructed SST for the Vøring Plateau at $67^{\circ} \mathrm{N}$ in the Nordic Sea based on high-resolution sediment cores (modified from [58]). 
At the BIE average position $78^{\circ} \mathrm{N}$ we can study the difference in TSI at the NH vernal and autumn equinoxes and summer solstice in Figure 18. The top panel shows the reduction of TSI at summer solstice. This is an effect of the reduction of the Earth's axial tilt. This is partly compensated for in the spring, due to the precession effect moving the Earth's perihelion closer to the vernal equinox. The lower panel shows the difference in TSI at the equinoxes. During the last 2000 years, TSI has increased at the vernal equinox, while it has declined at the autumn equinox. From $1242 \mathrm{CE}$, when perihelion was aligned with the winter solstice, it has advanced about two weeks to the first week of January. From then on, the spring TSI is larger than the autumn TSI. This results in increased insolation at the start of the melting season. Since the ice is $0.7-0.8$ and open sea albedo is less than 0.1 , this means a huge change in the ability to absorb sunlight and earlier melting of the ice and warming the sea. We may call this an Early spring effect [54]. This may be the main reason for the general movement of BIE to the north.

In situ measurements of solar and ground radiation on an expedition [26] to $81^{\circ} \mathrm{N}$ shows solar insolation as high as $400 \mathrm{~W} / \mathrm{m}^{2}$ at clear sky during the Arctic summer, which means a transmission of almost $78 \%$, while the average insolation was of the order $100-200 \mathrm{~W} / \mathrm{m}^{2}$ due to mostly cloudy conditions. The longwave radiation was approximately $-50 \mathrm{~W} / \mathrm{m}^{2}$ during the expedition period. With more open water during the melting season, more evaporation creates more local clouds as the melting season develops. This means that the melting by direct sunlight is more effective early in the spring.

\subsection{The Equator-to-Pole Temperature Distribution and the Latitudinal Insolation Gradient}

The current annually averaged equator-to-pole temperature difference is about
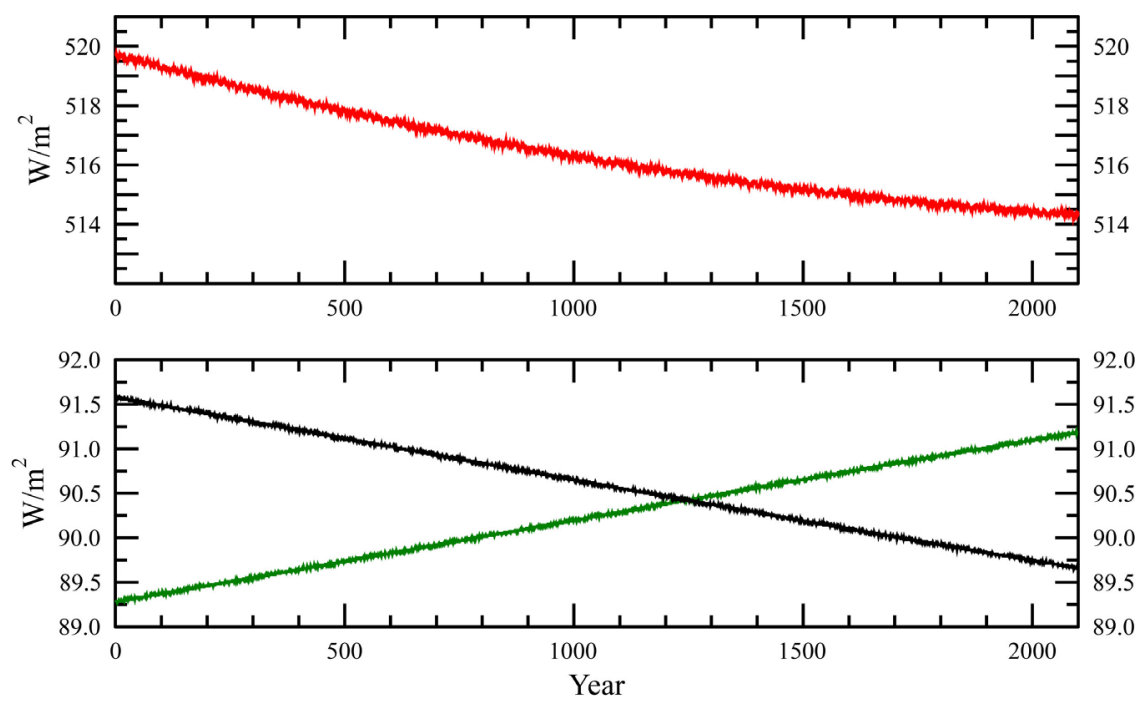

Figure 18. TSI at summer solstice (top panel: red) and TSI at spring (green) and autumn (black) equinoxes (lower panel) at $78^{\circ} \mathrm{N}$ latitude. This is for a constant Sun (calculated by Rodolfo G. Cionco [57]). 
$40^{\circ} \mathrm{C}$. In the absence of dynamic transport this would have been about $100^{\circ} \mathrm{C}$ [60]. The atmospheric heat transport is believed to arise from baroclinic instability, which again depends on the intensity of the Hadley circulation [61] (see Figure 8).

The difference in solar energy at low and high latitudes drives the climate system on planetary scale through both atmospheric and oceanic different heat storage and release mechanisms. This has its origin in the difference in insolation at different latitudes. The insolation received depends on the height of the Sun relative to the horizon and the Sun's magnetic activity level. This changes with the Earth's orbit during the year and with the Milanković cycles and are demonstrated in Figure 16 and Figure 18 for a constant Sun.

The temperature difference between latitudes originates in the latitudinal insolation gradient (LIG). The variation of LIG throughout the Holocene is calculated by [57] for low and high [62] frequency variations. LIG for the latitude difference $30^{\circ} \mathrm{N}$ and $78^{\circ} \mathrm{N}$ with variable solar TSI is shown in Figure 19. There are at least sixteen different estimates for TSI since the $19^{\text {th }}$ century and a few for earlier periods [63]. For this work we have selected an estimate by [64], based on the ACRIM reconstructions [65]. The green and red curves show the insolation difference for spring (solar longitude 0 - $90 \mathrm{deg}$ ) and summer (solar longitude 90 - $180 \mathrm{deg}$ ), where the solar longitude is measured along the ecliptic from the vernal point. Increasing LIG means stronger temperature gradient and stronger wind forcing for moving air eddies and sea currents. The effect of steeper LIG in the spring, means more advection of warm and humid air to the BIE, and earlier start of the melting season. This is an important contribution to the BIE northward displacement.

\subsection{BiE and TSI Correlations}

The Earth's slow orbital variations lead to changes on centennial and millennial time scales in the decreasing integrated TSI (black curve for constant solar output) in Figure 20. A wiggle in the curve is due to perturbations from the lunar

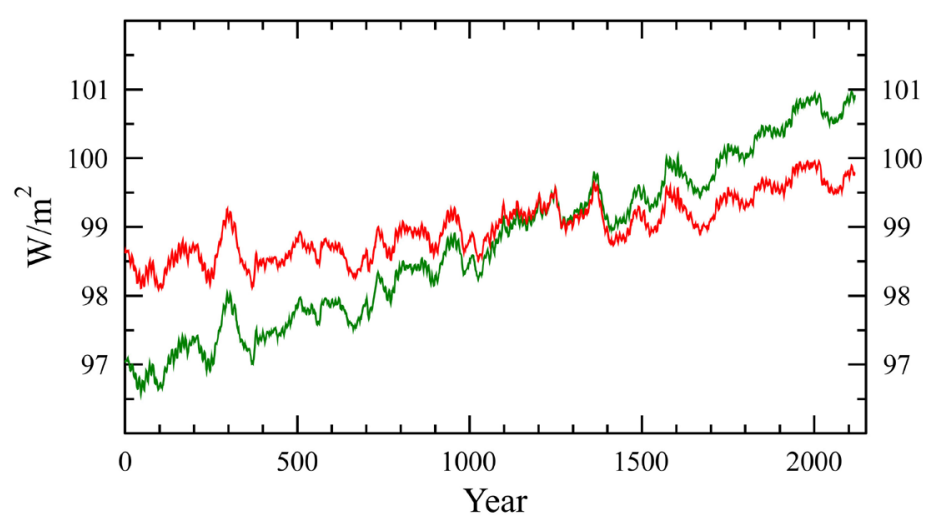

Figure 19. The average daily latitude insolation difference (LIG) between $30^{\circ}$ and $78^{\circ} \mathrm{N}$ for the spring period (green) and the summer (red). A TSI reconstruction by [64] based on ACCRIM observations [65] is used for the calculation by R.G. Cionco [66]. 


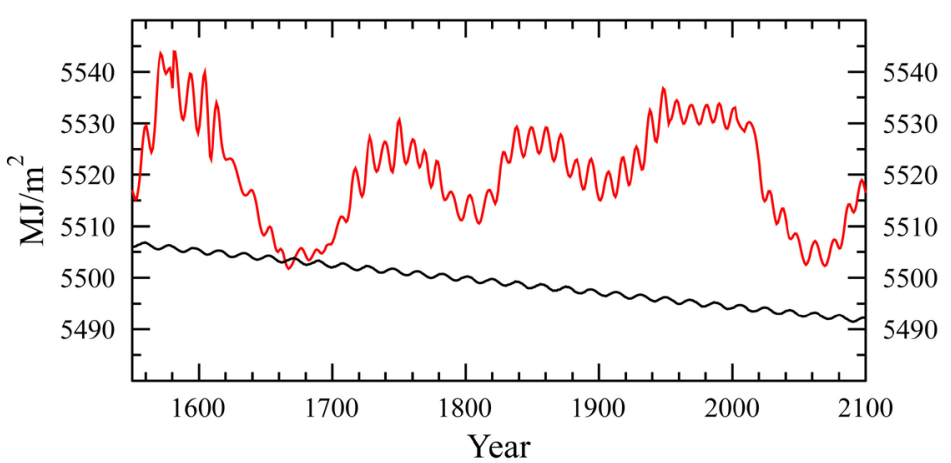

Figure 20. Integrated total summer (solar latitude $0-180 \mathrm{deg}$ ) insolation at $78^{\circ} \mathrm{N}$. The black curve is for a constant Sun. The red curve is estimated TSI ACRIM-calibrated [64] (calculated by R. G. Cionco [57]).

nodal cycle with a period of 18.63 years. In the same figure is drawn a red curve which is the changing TSI due to solar magnetic activity. The wiggle in this curve is due to the 11-year solar activity cycle, which is related to the 22 years solar magnetic cycle, the Hale cycle. The downward trend due to the obliquity change is more than compensated from the deep minimum 1650-1700 CE by the increasing solar activity. It also tells us that the next deep solar minima may produce less summer insolation than the previous due to the downward trend in orbital variation (the grey curve).

Understanding the influence of solar variability on Earth's climate requires knowledge of solar variability, solar-terrestrial interactions and mechanisms determining the response of the Earth's climate system. A summary is given by [67] and possible relations with solar cycles and BIE periods are discussed in [1] (see Section 8.1).

The summer season melting power depends on atmospheric transparency, clouds, and albedo. If we calculate insolation with $40 \%$ transmission and albedo of 0.8 we get $440 \mathrm{MJ} / \mathrm{m}^{2}$ solar insolation available for melting in the summer. The heat necessary to melt $1 \mathrm{~kg}$ ice is $0.334 \mathrm{MJ}$, which means that the available insolation melts $1300 \mathrm{~kg} / \mathrm{m}^{2}$ or $1.3 \mathrm{~m}$ thickness of ice. This should be sufficient to melt the ice at $78 \mathrm{~N}$ each summer. The increase in insolation from 1690 to 2000 is about $0.5 \%$, which translate to $6 \mathrm{~mm}$ more ice melted. An amplification is therefore clearly needed to explain the increased melting from $76 \mathrm{~N}$ to $83 \mathrm{~N}$. A reduction of albedo by 0.1 and the cloud cover with 0.1 , would nearly double the summer melting. Comparing with $70 \mathrm{TW}$ heat entering BSO by ocean currents: insolation in the summer season with albedo 0.8 provides 38 TW for melting ice with albedo 0.8 or 170 TW for heating open ocean with albedo 0.1 -producing warm air or warm surface water which again melts ice. One should also remember that on top of the sea ice cover is a layer of snow, which also needs to be melted before the ice-melting starts [68].

How the drift-ice is melting is described by [10] in the drawing shown as Figure 21. The Sun melts ice floats from the top, where freshwater melting-pools absorb heat from the Sun and accelerate the melting. Solar irradiation also heats 


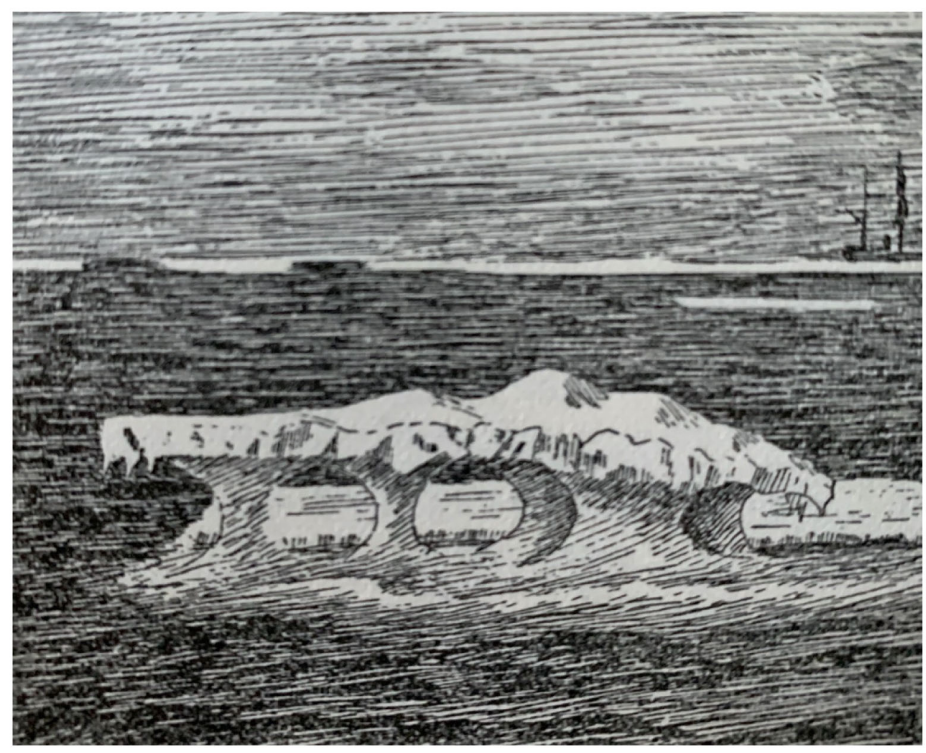

Figure 21. Ice melting off the East Coast of Greenland in 1882 (F. Nansen [10]).

the upper part of the sea which provide melting at sea level. At the same time the temperature in the fresh top level sea water is below freezing and the ice float grows in the deeper layers-even in the month of June when the insolation is maximum.

In Figure 22 we present correlations between two estimated TSI-series and the observed BIE-positions. The top panel shows the correlation between the summer insolation at $78^{\circ} \mathrm{N}$ and BIE position. The peaks at 1750, 1850 and 1950 are well correlated, but the minima are not as deep and flat in the TSI-series as in the BIE-observations. In the Hoyt-Schatten-ACRIM reconstruction [69] (lower panel), the peaks fit better and the minima around 1800, 1900 and 1960 are better reproduced. In both TSI reconstructions the BIE position is too far north after $2000 \mathrm{CE}$. We also notice that the correlation is much better for the TSI-HS-record starting $1700 \mathrm{CE}$. Table 3 shows the correlations between TSI and BIE positions.

The TSI-HS series also shows a high correlation with the Arctic and NH temperatures (see [1] Figure 18) and both series show planet-related periods [32]. It must be mentioned that the TSI reconstructions in Figure 22 are only two of at least 16 various reconstructions presented and evaluated in [63].

\subsection{BIE and Sunspot Cycle Length (SCL)}

Another indication of the solar connection is the high correlation $\left(r^{2}=0.59\right)$ between SCL (low pass filtered with L12221) and the normalized mean of BIE position in the first version of the BIE data set [70]. The low pass filtering means that only periods longer than 30 years are investigated. They concluded that the good fit between solar cycle length and BIE position was lost at the end of the $20^{\text {th }}$ century and interpreted this as a possible sign of the appearance of another forcing as for instance anthropogenic warming. 

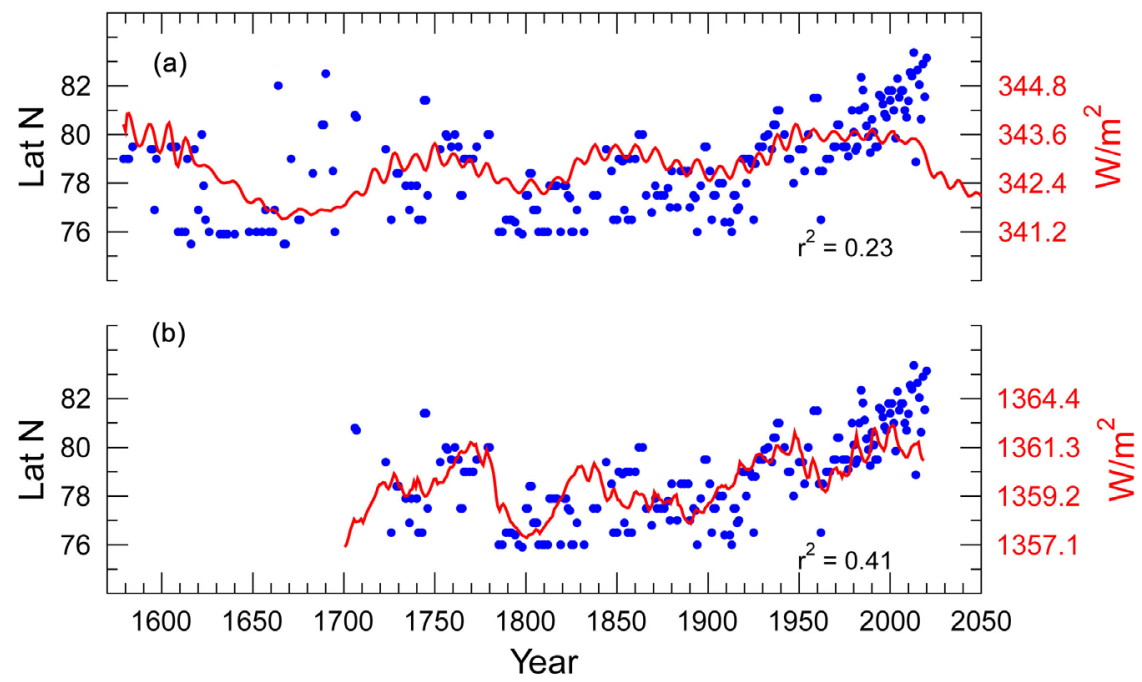

Figure 22. Correlations between solar insolation and BIE position. The top panel shows summer insolation at $78^{\circ} \mathrm{N}$ based on the [64] TSI-estimates and the lower panel Hoyt-Schatten TSI recently revised and updated by satellite observations [65]. (a) TSI-78N; (b) TSI-HS.

Table 3. Correlations with BIE positions.

\begin{tabular}{ccccc}
\hline Series & period & no. data & $r^{2}$ & trend \\
\hline TSI78N & $1579-2018$ & 236 & 0.23 & $1.688{ }^{\star} \mathrm{X}-499.8$ \\
TSI-HS & $1706-2018$ & 191 & 0.41 & $0.967{ }^{\star} \mathrm{X}-1236.3$ \\
\hline
\end{tabular}

We have correlated the L12221 filtered updated SCL-series with the revised BIE data set (11 points mean), shown in Figure 23, left panel. The goodness is $r^{2}$ $=-0.48$. Periods with long solar cycles correspond to BIE positions south and short solar cycles to less ice. From 1950 the SCL-trend has shifted to longer solar cycles and the BIE position followed until 1980, but thereafter the BIE position is north of what is expected from the SCL-relation. The high correlation indicates a possible low frequency relation between solar activity and the BIE position.

Solheim et al. [71] found a correlation between the length of the previous solar cycle and the mean temperature in the next cycle for certain observing stations. This correlation was highest for stations bordering the North Atlantic. Figure 24 shows how much of the temperature variations $\left(r^{2}\right)$ are explained by the length of the previous solar cycle. For stations bordering the North Atlantic $r^{2}>50 \%$. This is a strong indication that there is a delayed solar heating of the North Atlantic and the Barents Sea. This delay is at least the length of a solar cycle. Lansner and Pepke Pedersen [72] showed that inland stations with little ocean influence, warmed up quickly around 1930, while both coastal and inland stations warmed up during the 1990-2010 temperature peak. This indicates that the warming by ocean was delayed 60 years or more.

It is observed that long solar cycles in general correspond to low BIE, and short cycles as 1700-1800 and after 1900 corresponds to high values of BIE (see Figure 2). It is shown [15] that SCL varies with periods 190 and 86 years. This 


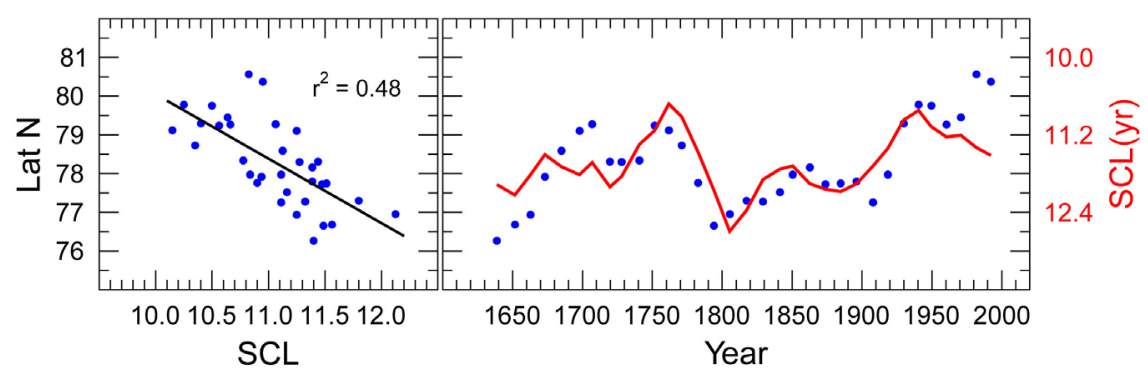

Figure 23. BIE position (blue dots: 11 points mean) compared with low pass (L12221) filtered SCL. The left panel shows the correlation and right panel the fit to the SCL curve (red). Shorter solar cycles correspond to less ice.

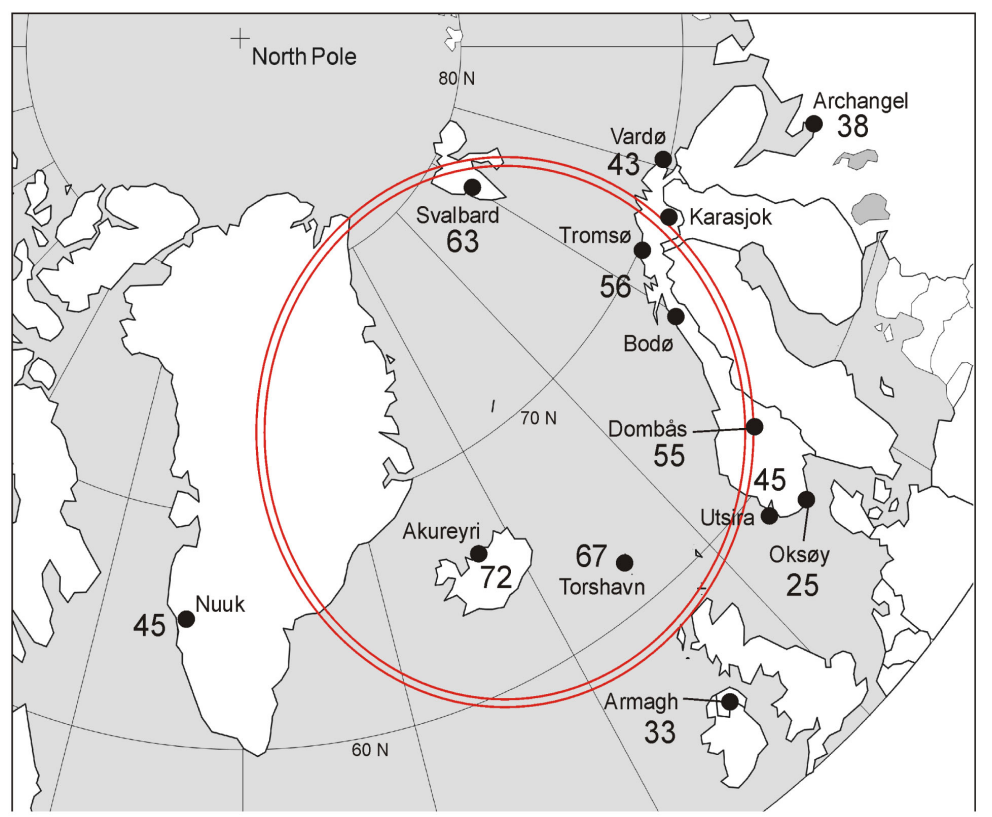

Figure 24. Contribution $\left(r^{2}\right)$ from the length of the previous solar cycle to the temperature in the next solar cycle (in percent) [71].

corresponds to planetary periods (Section 6 ). The longer cycles in the $19^{\text {th }}$ century means there are only 9 solar cycles in that century, while there are 10 in the next. In addition to the cycle length, it should be noted that the solar activity, described by sunspots, was very low in the $17^{\text {th }}$ century (Maunder Minimum) and in the period 1790-1820 (Dalton Minimum), and again around 1900 (see Figure 25).

\subsection{BIE, Sunspots, and Earth's Rotation (LOD)}

In [1] (see Section 7.3 and Figure 17) we proposed that the BIE position may be related to a solar-planetary beat, synchronized by the orbits of the planets. One forcing is direct solar irradiance modulated by the Earth's orbit on Milanković and shorter time scales as discussed in the previous section. The other route for forcing is by solar wind which acts on the Earth's magnetosphere. The wind modifies (see [1] Figure 20) the magnetic shielding which protects the Earth 


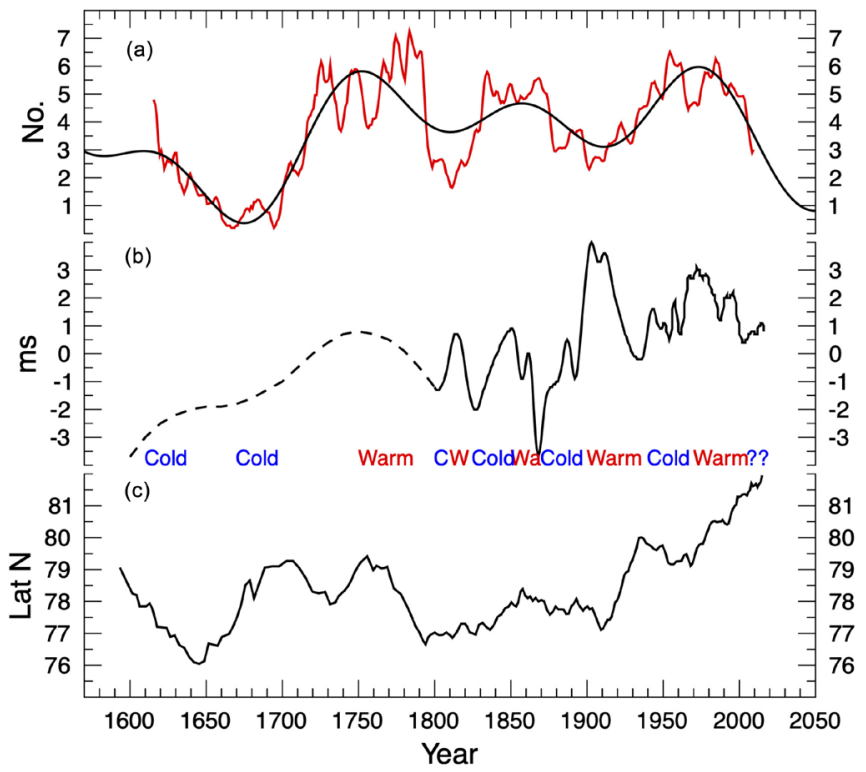

Figure 25. (a) Group sunspot numbers (11-year running mean), grSN; (b) LOD; (c) BIE position (11-points mean). Increasing LOD indicates cold and decreasing LOD indicates warm periods.

from galactic cosmic rays (GCR) [1] Figure 4 and contributes to the magnetospheric ring current which controls the momentum exchange with the Earth's magnetic core. This introduces a change in the Earth's rotation which is observed as Length of Day or LOD-changes.

In Figure 25, we show group sunspot numbers (A) (Gnbb2) [73] [74]. This data set is a pure solar index and does not rely on input from other proxies. It shows that the solar activity has risen from a low level between 1650 and 1700 (Maunder Minimum) and had three long maxima about the same level the last 300 years. The black curve is a P04-periodogram with three significant periods (437, 213, 118 years). A weaker oscillation with $\mathrm{P}=55$ years is not included. The most rapid increase happened between 1690 and 1730. There is also a deep short minimum around 1800 (Dalton Minimum) and a longer, not so deep minimum between 1880 and 1930. All these minima are observed in the BIE position (c). Panel (b) shows LOD. Peaks in sunspot numbers correspond to the BIE peaks around 1750, 1850 and 1975. Except for the peak in 1850, BIE always start moving north before the sunspot numbers increase. According to our hypothesis, we expect warming when LOD decreases. Then the Earth is rotating faster. This is marked with "Warm or W" in red under (b). When the Earth is rotating slower, we expect cooling. This is marked with "Cold or C" in blue. We find that BIE always respond to the LOD-changes if the trend in LOD lasts long enough. The last LOD change around 2005 may have initiated the cooling in the North Atlantic shown in [1] (see Figure 10), but the expected effect on BIE is not yet observed.

The correlation between sunspot numbers and BIE position from 1700 is only $r^{2}=0.01$. We note that the sunspot minimum around 1900 was almost as deep as 
the during the Dalton minimum, and that BIE has not yet moved south after 2000 as it did during other deep sunspot minima. The correlation between sunspot numbers and LOD is also low, only $r^{2}=0.03$, which means that we cannot link sunspots and Earth rotation directly. However, the correlation increases to $r^{2}=0.08$ for 11-year running mean sunspot numbers. In Figure 25, panel (a), the black curve is a best fit harmonic model with periods 99,53 and 65 years.

On the other hand, there is an anti-correlation between LOD and BIE for low frequency variations as shown in Figure 25. In addition, the GSB-beats during periods of low solar activity shown in [1] (see Figure 5), are an indication of a connection with variations in LOD, which regulates the inflow of warm Atlantic water to the Arctic. Increasing LOD means decreasing speed of rotation and increase of warm water flow towards the Arctic. LOD-acceleration during deep solar minima and deceleration (retarding) during maxima is predicted by Mörner [75]. He proposed a simple mechanism: The solar wind intensity affects Earth's rotation. More intense solar wind gives more pressure and slows the Earth's rotation. When the Sun is less active, the solar wind decreases and the Earth speeds up, as it has done since 1975 and BIE moves north.

We have in Section 4.4 shown that BIE positions anti-correlate with detrended LOD $\left(r^{2}=0.40\right)$. This means that decreasing LOD, which means increasing Earth's speed of rotation leads to less ice or warmer Arctic. The geomagnetic index aa is a measure of the solar wind in the ecliptic plane, and a zonal wind in$\operatorname{dex}(\mathrm{ZI})$ is the pressure difference between $35^{\circ} \mathrm{N}$ and $55^{\circ} \mathrm{N}$ latitude circles. Mazzarella [76] finds a correlation $(r=-0.97)$ between 23-year running mean, detrended integrated geomagnetic index (Iaa) and integrated zonal index (IZI) with Iaa 5 years ahead. This indicates that an increase in solar wind speed causes a decrease in zonal atmospheric circulation with a delay of 5 years. IZI and LOD appear inverse correlated $(r=-0.87)$ with LOD 4 years after IZI. Mazzarella [76] explains the relation between solar activity and LOD in the following way: When solar activity increases the Sun ejects plasma (charged particles) both in the continuous solar wind and in hydrodynamic shock waves which interfere with the Earth's magnetosphere and create turbulent pressure waves which decelerate atmospheric circulation and slows the Earth's rotation. This cools the Earth. When solar activity decrease, we observe a faster Earth rotation and BIE moving north, as seen in Figure 25 since 1975. We may call this the direct SW-driven mechanism.

Another explanation proposed by Duhau and Martinez [77] is that geomagnetic storms in the solar wind modulate the magnetospheric ring current's control of momentum exchange with the Earth's interior. It is well known that short periodic variations in LOD are due to exchange of angular momentum between the atmosphere and the solid Earth's core. Some of these periods may be excited by geomagnetic storm variations following solar activity cycles. Longer periods are related to torsional oscillations in the Earth's liquid core. They may be excited by variations in the magnetic field carried with the solar wind as described in [77]. Duhau and de Jager [78] (in their Figure 61.3) show that a bi-decadal 
period in LOD oscillates synchronous and anticorrelated with the sunspot number $R$. A semi-secular period is also anticorrelated with $R$ but with a lag of 94 years. This lag is a sign of a different mechanism. Signals in the decadal band and below are exited in the mantle by atmospheric motions that appear to be driven by solar activity (synchronous). Torsional oscillations have their sources at the outer-inner core boundary and need nearly 100 years to travel to the surface [77]. In addition, the amplitudes of both the bi-decadal and semi-secular cycles are modulated with the Jose period of 179 years, indicating a relation to the orbits of planets. This will be discussed in Section 6 .

The anti-correlation and lag create the apparent lack of correlation between sunspots and LOD in Figure 25. However, the figure shows a good correlation between peaks in LOD and turning points of BIE movements. All the BIE peaks are within periods of maximum sunspots and BIE moves south when the sunspot number decreases rapidly, as seen for the periods 1600-1650, 1790-1810, and 1870-1910. A repeat of this pattern indicates that we should expect a rapid move of BIE south in the period 2010-2030.

The 66-year LOD period in Section 4.4 is also found for the AMO- and $\mathrm{NAO}$-variations and is also close to the Stadium wave period and is equal to the solar magnetic period $3 \mathrm{P}_{\mathrm{H}}$, where $\mathrm{P}_{\mathrm{H}}$ is the solar magnetic Hale period of 22 years. The dominating BIE sub-centennial period of 82 years is $5 / 4$ of the period $3 \mathrm{P}_{\mathrm{H}}$.

Figure 26 shows the relation between inverted, and 94-year lagged 11 years running mean sunspot numbers (SN11) and LOD as proposed by [77] and [78]. The blue curve shows observed LOD-values which follow closely $S N 11$ in the period $1820-1970$. If we shift the blue curve \pm 179 years, to indicate the planetary period repetition (the Jose period), we get the blue (broken) curve. This also fits well with the SN11 curve around 1700 and 2020-2070. A peak at 2090 should probably be moved to 2120 to follow $S N 11$ better. With this relation between SN11 and LOD, we get an answer to the problematic relation between BIE and sunspot number $(R)$ around 1700, when we observe that BIE moves north before

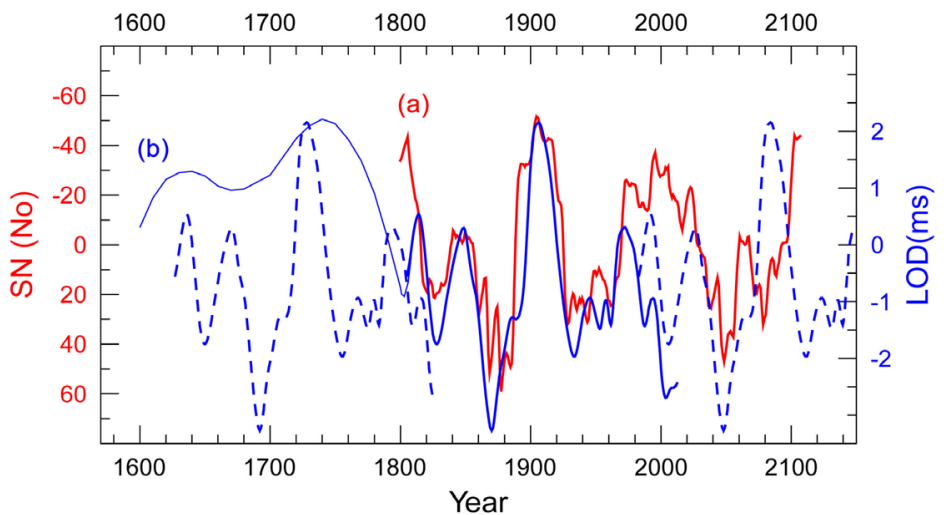

Figure 26. LOD11: (11 years running mean, observed: blue, repeated and shifted \pm 179 years: blue-broken) compared with group sunspot no, SN11: (11-year running mean, inverted and forwarded 94 years: red). (a) SN 11; (b) LOD 11. 
$R$ increases. Figure 26 shows that BIE gets a kick north by the LOD peaks forced by the strong $S N 11$ pulse from 1720 and 1900. Figure 25 and Figure 26 indicate that the BIE position around 1850 is so far south that an increasing LOD has little effect. A longer cycle of $\approx 240$ years was also found in LOD by [77]. This follows a similar cycle correlating with $-R$ with a lag of 74 years. This may be related to the BIE bi-centennial period of 266 years (see Figure 10). The hindcasting of the LOD-pattern to the period 1600-1800 gives an indication of a LOD acceleration 1670-90, which may the reason for the extreme BIE-estimates in this period, before the cold period 1690-1730, which corresponded to a GSB type c 1687-1703.

With declining averaged sunspot numbers from 1975 and Earth deceleration from about 2000, we expect an effect on climate. A cooling in the north Atlantic is already recorded in [1] (see Figure 10(a) and Figure 10(b)) and documented in [79]. They show a trend-reversal from warming to cooling from 2004-2005 in the north Atlantic which is a verification of this relation. This is also documented by [80]. However, if the 94 years forward effect of SN11 and the repetition of LOD-pattern, is correct, then the LOD will again accelerate from 2025 to 2040, with BIE increasing, before the large increase in LOD 2050-80 makes BIE position decrease.

An analysis of the LOD changes since 1970 by [81] shows how a LOD-period of 21.93 years correlate with the 11.06 years solar cycle: If the magnetic S-pole is at the Sun's north pole, the Earth's rotation with a 21.93-year period will start to accelerate. At the next sunspot maximum, the Earth's rotation will start to decelerate. The magnetic cycles are slightly biased to higher deceleration than acceleration, which means that the overall result of a complete magnetic cycle is deceleration. This supports the relation proposed by [75]. If the same relation holds back to 1700 , this means that a part of the linear trend in LOD may be explained by the systematic increase in LOD with the Hale cycle.

\subsection{Magnetic Shielding and Cosmic Rays}

In [1] (see Section 4), we wrote that the type-a circulation for the GSB is typical for Grand Solar Maxima, while types b and c happen during Grand Solar Minima. The alteration between solar maxima and minima changes the Earth's magnetic shielding capacity, both at the 22-year magnetic (Hale) cycle, described in the previous section, and at longer cycles as the centennial sunspot cycles shown in Figure 25, which lead to grand minima or maxima.

By using the method of singular spectrum analysis (SSA), Le Mouel et al. [82] identified a rising trend and Gleissberg cycles of period $\sim 90$ years in the international sunspot series 1700-2015. Four extended minima were identified, also shown in Figure 24 with group sunspots numbers back to 1612. The rising trend was quasi-monotonic with an acceleration around 1900. This compares well with the trend in BIE (Figure 24). Their Gleissberg periods varied from 85 to 94 years, with an average of 90.5 years. 
To study modulations on longer time scales, one must use proxy data. Variations in solar activity leads to modulation of the flux of galactic cosmic rays entering the terrestrial atmosphere, generating radionuclides such as ${ }^{10} \mathrm{Be}$ and ${ }^{14} \mathrm{C}$ in ice cores and tree rings. In [1] (see Figure 4), the changing ${ }^{14} \mathrm{C}$ production rate is shown. This is anticorrelated with cosmic ray's corpuscular radiation, which may generate clouds which strongly affect the climate. The cooling periods, with BIE moving south, as in the periods 1600-1700, 1780-1820, 1870-1900 and 1940-1950 are clearly present.

Figure 27 shows ${ }^{10} \mathrm{Be}$-flux measured in a Northern Greenland ice core [83] compared with BIE estimated positions. We find that southern positions of BIE correspond to high level of ${ }^{10} \mathrm{Be}$. We also notice that the ${ }^{10} \mathrm{Be}$ level during the Spörer minimum (1400-1520 CE) is about the same level as the maximum around 1900.

The ${ }^{10} \mathrm{Be}$-flux as shown in Figure 27 is not available after 1994. To investigate what happens in recent times we compare the BIE estimates with neutron counts from the Oulu Observatory in Finland. The result is shown in Figure 28. Inverted sunspot numbers $(-R)$ follow the neutron counts. The BIE position follows the inverted neutron counts until about 1995. This is according to the hypothesis that less galactic cosmic rays create less clouds, the Earth heats up and the Arctic ice cover shrinks. However, this relation is broken after 1985. Then we observe more neutron counts while BIE is still moving north. We interpret this as a sign of a less shielded magnetosphere. This means that magnetic storms originating from solar flares and CMEs penetrate easier the Earth's magnetic shield. This heats the polar region and increases the cyclonicity and moves BIE to the north and explains the almost instant response of BIE to change in solar activity.

Two 9400 -year-long ${ }^{10} \mathrm{Be}$ data records and a ${ }^{14} \mathrm{C}$ record of equal length was analyzed by [84]. They found 15 significant periodicities between 40 and 2320 years and concluded that cosmic radiation is the primary cause for periods $<250$ years, but for longer periods some terrestrial origins were possible. They found a very stable ( $0.5 \%$ variations) Gleissberg period of 87 years. They determined 26

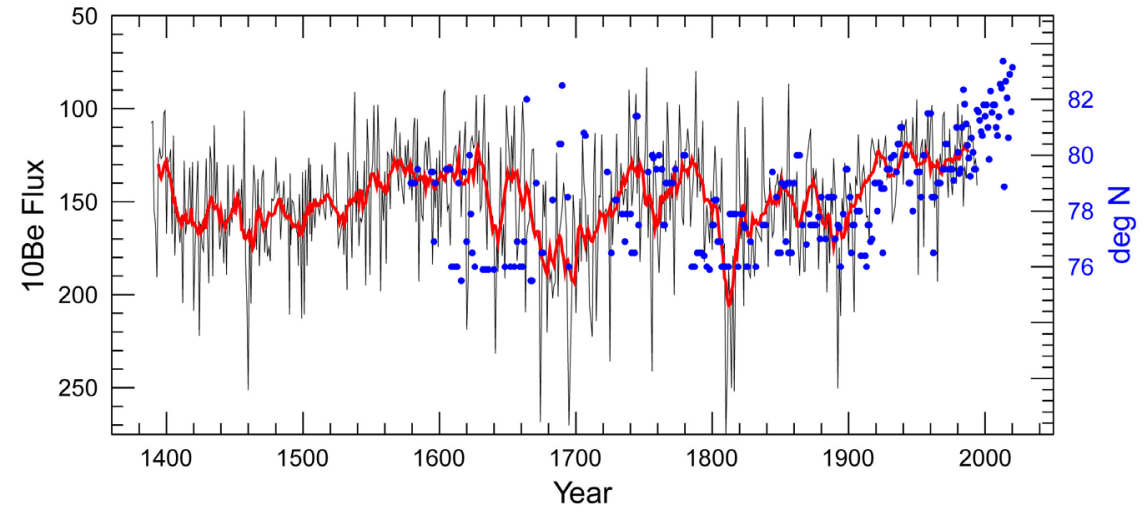

Figure 27. Yearly average ${ }^{10} \mathrm{Be}$ flux from the NGRIP (Northern Greenland) [83] ice core with 11-year running mean (red) from 1389-1994 compared with BIE position estimates (blue dots). The ${ }^{10} \mathrm{Be}$ flux is increasing downwards. 


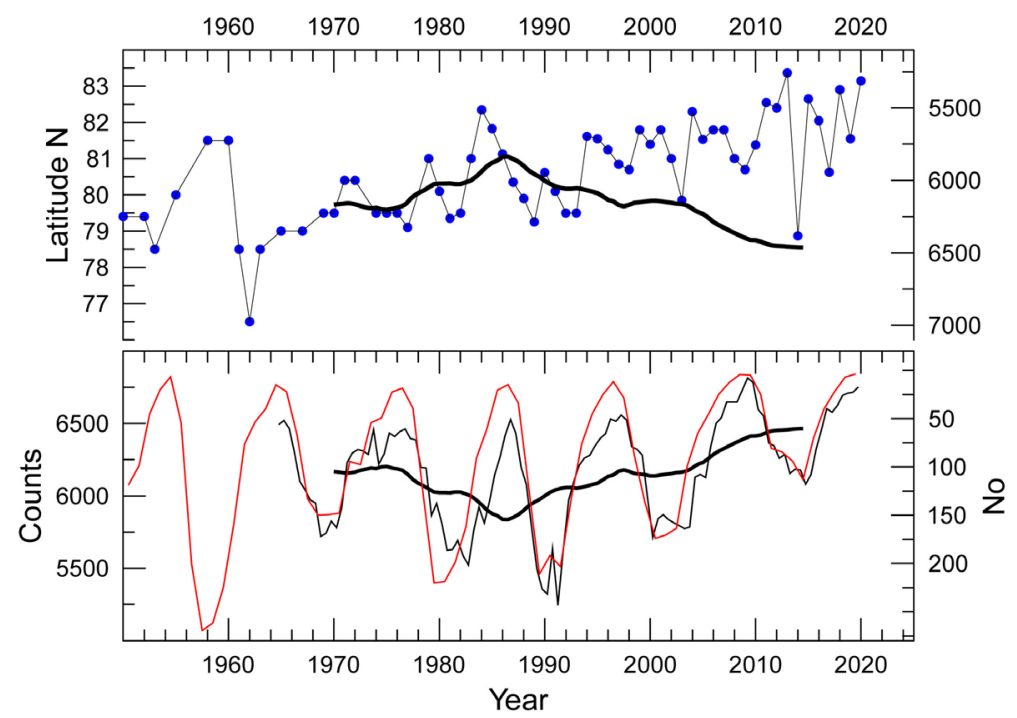

Figure 28. Oulu neutron counts 1964-2019 (lower panel with 11year running mean). The upper panel shows BIE positions (blue) with inverted Oulu neutron counts (downloaded from http://cosmicrays.oulu.fi).

Grand Minima like the Maunder Minimum, which appeared in groups of 2 - 7 Grand Minima with intervals of 800 - 1200 years between. Some periodicities were harmonically related pairs (65 and 130 years), (75 and 150 years), and (104 and 208 years). The 208-year (de Vries) period was present during Grand Minima, and not detected outside those.

The transition between periods with Grand Minima and no-Grand Minima is related to a super-modulation period of about 2300 years, called the Hallstatt cycle, which may be the upper limit to periods associated with the solar dynamo [85]. However, [86] has shown that the amplitude of the $\sim 210$-year oscillation [1] (Figure 4-the thin grey line) depends on the phase of the 2300-year variations in the dipole moment of the Earth's geomagnetic field. They used empirical mode decomposition and calculated a cross-spectrum which had as its most significant feature a spectral line with period $\sim 2300$ years, confirming that this period originates in the Earth's magnetic field. This geomagnetic field component had its minimum around 1450, which indicates maximum amplitude of the 210-year oscillation, leading to the deep Spörer and Maunder minima. On the other hand, direct observations of Earth's magnetic field strength have shown a $10 \%$ decrease in dipole strength the last 180 years due to even longer period components [87].

\subsection{BIE and Solar Wind}

Tails of bright comets visualize the wind from the Sun blowing evaporated material away from the comets' nuclei. We often observe two tails, one curved composed of neutral particles, governed by gravitational laws, and one straight, containing ionized particles forced by the streams of ionized particles from the Sun. Since the Sun is a rotating body, the solar wind streams become curved like 
an expanding spiral, eventually hitting the Earth, passing through the stream pattern, also called a Parker spiral after E.N. Parker [88] who first calculated its structure.

The relation between the solar wind (SW) and the Earth is described by [89] as follows: Magnetic fields produced by the dynamo mechanism in the interior of the Sun, find their way to the surface and are leaked into the heliosphere with the solar wind, which sustain the magnetosphere of the Earth. The solar wind is classified as three basic flow types: the high-speed streams associated with coronal holes and co-rotation interaction regions, the slow wind originating from streamer belts and the transient flows related to interplanetary CMEs. Near Earth the wind causes geomagnetic activity like magnetic disturbances and auroras. CMEs and burst of high-speed streams are more frequent near solar maxima.

Mörner et al. [1] Figure 21 show estimated yearly mean solar wind speed (SWS). It is between 250 and $400 \mathrm{~km} / \mathrm{s}$ just before the Maunder Minimum. The largest yearly variation is 300 to $600 \mathrm{~km} / \mathrm{s}$ in the 1720 ies, otherwise it has been between 400 and $500 \mathrm{~km} / \mathrm{s}$ most of the time after 1740. The 11-year running average velocity curve of the solar wind is repeated in Figure 29. The velocity curve after 1720 shows two small dips, one about 1820 and one about 1920. A P04-periodogram gives a dominating 100-year period with a weak 52-year harmonics. They are approximately the same periods as found for the sunspots-series (Figure 25 panel (a)).

We have also analyzed the solar wind series with the Morlet-wavelet as shown in Figure 30. The similarity with the BIE Morlet-wavelet (Figure 8), is striking. A 60-year period is present for both series, and a period 95 - 98 years is just outside the cone of influence for the SWS series matching the 104-year period for BIE. The main difference between BIE and SWS is that BIE has many shorter periods that may be internally or lunar driven.

Analysis of long ${ }^{14} \mathrm{C}$ records has shown that a 900 -year cycle has intensity 5 - 7 times the centennial cycle [90] and a 420-year cycle, much stronger than the centennial and sub-centennial cycles [91]. The peaks found are 414, 216, 142, and 85 years. Three of those are also in BIE spectrum: 82, 208/2, and 145 years. The strongest cycle found is 11,500 years with intensity several times the centennial and sub-centennial cycles [92]. In addition to the 11,500 years cycle they

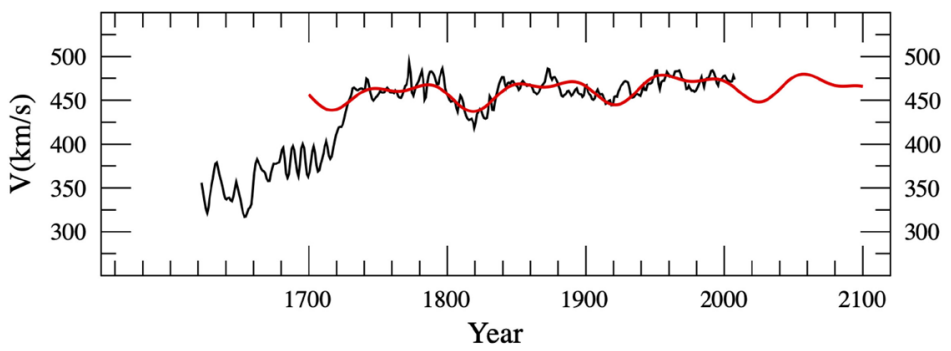

Figure 29. Solar equator wind (11-year running mean), with harmonic model based on data from 1720 (red). 


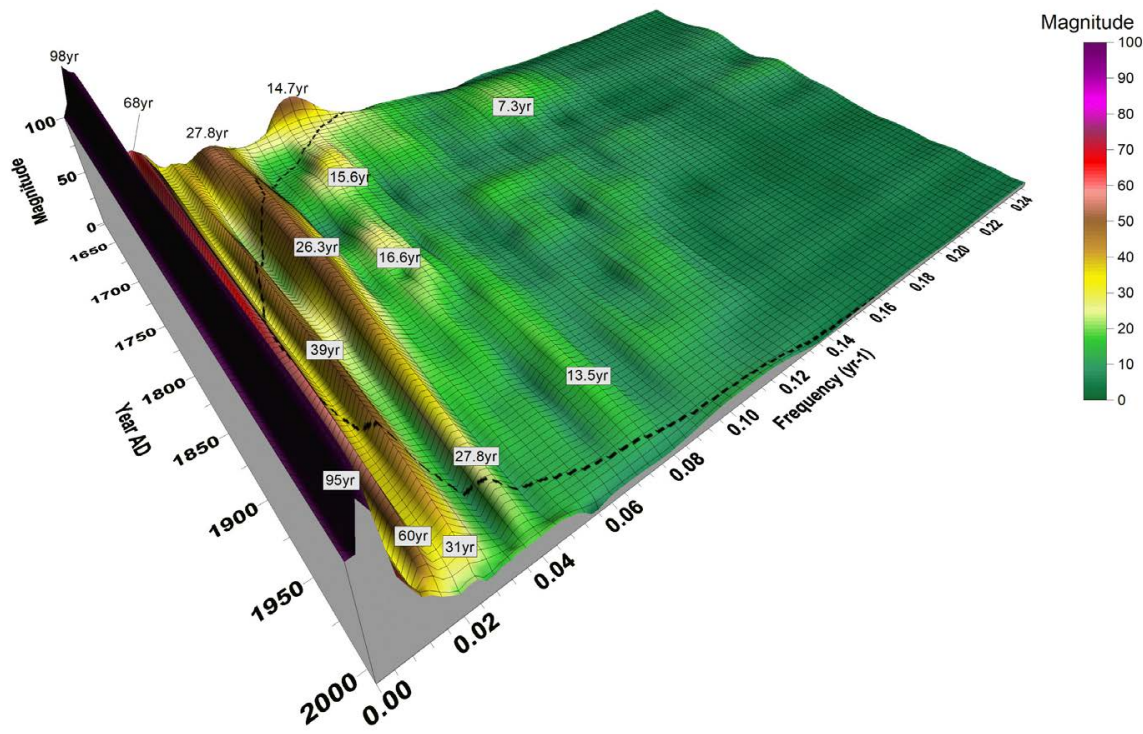

Figure 30. The solar wind analyzed with the Morlet wavelet.

found cycles of $1670,1420,1280,924,835,787,750,663$ and 545 years in various long solar wind proxies. We suggest that the big dip in the SW-curve at the Maunder Minimum is the result of this 545-year cycle and will return to this in our discussion (Section 7).

Several studies have shown relations between winter climate at high northern latitudes and the solar cycle [67]. Proposed drivers include TSI, solar UV, galactic cosmic rays and energetic magnetic particles from the Sun. To identify the drivers [93] analyzed the relation between different drivers and the phase of the solar cycle. The geomagnetic activity and magnetospheric particle flux have a maximum in the declining phase of the sunspot cycle while TSI and UV radiation follow more closely the solar cycle. They analyzed 13 solar cycles (1859-2009) and compared with winter temperatures and NAO-phases. This is interesting in connection with BIE, since a low winter temperature means more ice to melt next summer and a more southern BIE. The most significant relation was found during the sunspot declining phase with temperature pattern resembling a positive NAO, suggesting that the solar wind and magnetic particle flux is the main driver of winter temperature variations. Negative NAO and cooling in the Barents region were found in the increasing phase of the sunspot cycle. The same pattern was found during low and high sunspot activity cycles, suggesting that the pattern is independent of the level of solar activity. On the other hand, maximum frequency of CMEs is found near peaks in the solar cycle.

Comparing winter (DJF) season ice cover with sunspot numbers during solar cycle 21 - 24 [94] showed that during winters with low sunspot numbers, the BS area is warmer than average, and the ice cover is decreasing. Cooling, on the other hand is dominant over Scandinavia and Siberia. The largest warming happens at the surface because of enhanced exchange of sensible and latent heat flux 
from the open ocean to the atmosphere during low sea ice years. In the same period the $\mathrm{NH}$ snow cover has been constant, proving that this relation is a sun-ice-ocean relation.

Possible models suggested by Roy [94] (see her Figure 7), are either 1) a 6\% increase in UV-radiation in solar maximum years, creating more Ozone heating in the upper stratosphere and a stronger jet stream in $\mathrm{NH}$, which strengthen the polar vortex. Perturbations are transported all the way down to the surface by planetary waves and create a cold Arctic for solar maximum years. Or 2) the stronger jet causes a poleward shift of the Ferrel cell and supports a cold polar vortex leading to cold Arctic and more ice. Since 15 of the last 16 years have had less than average sunspot numbers, this may explain less ice and BIE far north in this period. The same may have happened during the Maunder and Dalton Minima, making West Svalbard unusually warm during the LIA. D'Andrea et al. [95] have determined a gradual warming in eastern FS CE 1600-1900 followed by accelerated warming the last 120 years. Analysis of lake sediments from Western Svalbard showed mild summers from CE 1600, even when the rest of the Arctic was cooling. They interpreted this as increased heat transport into the Arctic via the WSC from ca. CE 1600.

Zhou et al. [96] have found a significant correlation between the solar wind speed (SWS) and sea surface temperature in the region of the North Atlantic Ocean for the NH winters from 1963 to 2010, based on 3-month seasonal averages. The correlation is dependent on $B_{z}$ (the interplanetary magnetic field component parallel to the Earth's magnetic dipole) as well as the SWS. It is stronger in the stratospheric quasi-biennial oscillation (QBO) west phase than in the east phase. The correlations with the SWS are stronger than with solar UV inputs to the stratosphere. Sea surface temperature responds to changes in tropospheric dynamics via wind stress, and changes in cloud cover affecting the radiative balance. Suggested mechanisms for the solar influence on sea surface temperature include changes in atmospheric ionization and cloud microphysics affecting cloud cover, storm invigoration, and tropospheric dynamics. Such changes modify upward wave propagation to the stratosphere, affecting the dynamics of the polar vortex. Also, direct solar inputs, including energetic particles and solar UV, produce stratospheric dynamical changes. Downward propagation of stratospheric dynamical changes eventually further perturbs tropospheric dynamics and the sea surface temperature.

From Russian rocket soundings in the Arctic, it has been found that the SW contributes to the thermal regime of the polar middle atmosphere via delivering electric current to the global electric circuit [97]. The passive element of this circuit is the ionospheric E-layer and the conducting layer of the Earth's surface. It is observed that the temperature in the stratosphere increases with the disturbances if the conductivity of the ground is high and decreases if it is low (ice and tundra). It is calculated that the Earth's magnetopause can move from a distance of $12 \mathrm{R}_{\mathrm{E}}$ to $6 \mathrm{R}_{\mathrm{E}}$ (Earth radius) during a magnetic storm, and this can dissipate an amount of Joule heating comparable with the heating of the ozone layer by solar 
UV radiation. Such energy burst changes the atmospheric circulation and is enforcing cyclonic activity which is observed related to CMEs. Joule heating included in a dynamical photo-chemical model of atmospheric circulations shows that $\mathrm{NH}$ lower stratospheric temperature increase $1^{\circ} \mathrm{C}-3^{\circ} \mathrm{C}$ during minimum of the solar cycle [98].

Returning to the question of the trend in BIE from 1800 or 1900, this may be a result of an integrated forcing. The melting in the summer depends primarily on the heat available for melting, but also on the freezing previous winter, and the left over from last summer etc. We have identified several processes which may lead to increased melting and reduced freezing: The Early Spring Effect, the LIG variations, increasing TSI, increasing solar activity, decreasing LOD, and INAO (see Figure 15). There may also be an integrated effect of CMEs acting on the Earth's rotation and forces the Atlantic current to the north. Geomagnetic storminess determines the average BIE position either with pressure bursts which decelerate the Earth's rotation or modulating the magnetospheric ring current's control of momentum exchange with the Earth's interior

Since we the last 300 years observe a nearly flat SWS-curve, what happens in the future depends on the evolution of the ongoing solar activity reduction, whether this evolves into a deep minimum or not. In addition to deep minima, shallow minima appear 100-year apart. In addition to the processes described above we also must consider lunar modulations described in the next section.

\subsection{The Lunar-Solar Tides, the Lunar-Nodal Cycle, Polar Tides, and the Sun}

We observe tidal effects on all levels of the planet: from the atmosphere to the inner structure which has a fluid outer core surrounding the solid inner core of the Earth. Luni-solar tides are the result of the Earth and Moon orbiting their common barycenter, with perturbing effect of the Sun, and the Earth, Moon and Sun orbiting the solar system barycenter.

The luni-solar tides have 9 main periodicities [99]: Twice daily, fortnightly, 27 days, 9.3, 18.6, 62, 93, 222 and 1500 years. The lunar nodal oscillation with pe$\operatorname{riod} \mathrm{L}_{\mathrm{N}}=18.61$ years with several harmonics is observed in sea level changes and analyzed by many researchers. Hansen et al. [100] analyzed 26 long-time (1840-2015) tide-gauge series from the eastern North Sea and central Baltic region. They found a strong correlation $\left(r^{2}=0.94\right)$ between sea-level changes and the sum of identified harmonic oscillations, corresponding to the lunar nodal period and four multiples of it, i.e. high amplitudes for $P=18.6,60.5$, and 76.1 years, and statistically less significant for $P=28.1$ and 111.1 years. A purely mathematical extension of the oscillations suggests the production of 223-year pulses of quasi-oscillations which can be divided into 158-year periods (e.g. 1747-1905 and after 1970) with large oscillations, followed by 65 -year periods (e.g., 1905-70) with much smaller oscillations.

The main Atlantic current continues through the Faroe-Shetland Channel and the Norwegian Sea before reaching the BSO or FS and arriving in the BS. Analy- 
sis of two 100 years long hydrographic series from the Faroe-Shetland Channel and the Kola section by [101], shows dominant cycles in sea level, salinity and temperature correlated to a sub-harmonic 74-year cycle of the nodal tide, with an advective delay of two years between the Faroe-Shetland Channel and the Kola section. In addition, correlations were found between dominant Atlantic water temperature cycles and the $\mathrm{L}_{\mathrm{N}}$ period, and for the $\mathrm{L}_{\mathrm{N}} / 2=9.3$-year lunar nodal phase tide [101]. Phase reversals of temperature and salinity curves took place in 1925 and 1960 when the 74-year lunar nodal cycle changed phase $[-0]$.

Analysis of time-series for the polar position, the extent of Arctic ice, sea level at Hammerfest, Røst winter air temperature, and the NAO winter index with a coiflet3-wavelet impulse function by [101] shows for all series a harmonic spectrum based on the $\mathrm{L}_{\mathrm{N}}$-cycle with a stationary period, but with non-stationary amplitudes and phases. The phase relation between the identified cycles indicates a possible chain of events from lunar nodal gravity cycles to long-term tides, polar motions, Arctic ice extent, NAO winter index, weather, and climate. Yndestad et al. [101] explain this by the gravity force from the $\mathrm{L}_{\mathrm{N}}$ cycle which affects the polar position (nutation) and the circulating water in the Arctic Ocean. A stationary polar-position cycle forces the Arctic oceans and introduces the Arctic oscillations which interacts with the Arctic ice extent, water temperature and atmospheric conditions. The $\mathrm{L}_{\mathrm{N}}$ cycle has harmonic and sub-harmonic cycles.

The Earth's nutation is a predictable cycle of the Earth's spin around its axis with periods 18.6134 years, 9.3 years, half year and half month. Analysis of the observed positions show dominant periods of 1.2, 6, 18 and 74 years [102]. The $\mathrm{L}_{\mathrm{N}}$-cycle is in phase with the nutation cycle in the y-direction from 1870 to 1950 but phase reversals take place when the 74-year cycle have minima at about 1865 and 1940. This shows that the phase is controlled by the 74-year cycle in the $\mathrm{y}$-direction. This is not the case in the $\mathrm{x}$-direction.

\subsection{Summary of Forcings by the Sun and the Moon}

The 442-year BIE-position data set covers the coldest part of the LIA and the recovery from it after 1900. The LIA may be due to a combination of less solar irradiance because of decreasing obliquity of the Earth and a series of deep solar minima. The recovery from LIA in the Arctic after 1900, is partly due to increased solar activity and the precession of the Earth's orbit providing an Early Spring Effect and increased spring LIG at BIE-latitudes.

The correlation between solar cycle length and BIE position $\left(r^{2}=0.59\right)$ indicates a strong solar forcing. A relation is established between the rotation of the Earth, measured as LOD and the sunspot number $-R$ with a lag of 94 years. This is explained by an electric current brought with the solar wind, inducing magnetic torque on the solid core of the Earth, creating LOD-pulses, slowing the Earth's rotation. The LOD-pulses appear with a period of 66 years or three magnetic solar cycles $3 \mathrm{~S}_{\mathrm{H}}$. In addition, we have pressure bursts from geomagnetic storms slowing Earth's rotation and cooling with a delay of about 15 years. 
Periodic variations of the BIE position are controlled by bi-centennial and semi-centennial cycles. The bi-centennial cycle has a period of 145 years before 1750 and 268 years thereafter. The amplitude is constant, and the period is controlled as $4 / 5$ and $3 / 2 \mathrm{P}_{\mathrm{J}}$, indicating planetary control. The semi-centennial period has a quasi-stationary period of 82 years which is close to $4 / 3$ of the 60 -year period. The amplitude of the semi-centennial period is variable with peaks around 1587, 1696 and 2008. If the first two peaks indicate a maximum between 1590-1690 which declined to a minimum around 1935, this indicates a modulation period of about 600 years. The disappearance for some time around 1650, may be due to a GSB during the Maunder Minimum. The next GSB during the Dalton Minimum did not affect the amplitude.

\section{Planetary Influence}

The focus of this paper is to investigate a possible relation between planetary beats and climate variations as observed in the 442-year BIE series, as shown in [1] Figure 9. A forcing can be transferred directly to the Earth or the Earth-Moon system or it can be relayed via the Sun which then acts via irradiance or solar wind as outlined in [1] Figure 20. A mechanism is presented in [1] (see Figure 7), where an external force, like the solar wind, acts on the Earth's rate of rotation, which again results in sea level changes and ocean current variations, and in extreme cases a GSB. The BIE variations can be split into a linear trend and various oscillations. The linear trend is the dominating feature-at least since 1900 (see Figure 7). It may be due to an integrated effect, as investigated in Sections 4.9 (LOD and INAO) and 5.7 (ISW) or be a temporary linear part of a sum of long period oscillations. In Table 4 we have listed some periods related to Moon, Sun and planets which we may find in Earth's climate.

Table 4. Some relevant periods with origin in the Moon, Sun, and planeta.

\begin{tabular}{ccc}
\hline Name & P (years) & Type \\
\hline $\mathrm{SC}$ & 11.07 & Schwabe Sunspot Cycle (variable) \\
$\mathrm{P}_{\mathrm{J}}$ & 11.86 & Jupiter orbit \\
$\mathrm{L}_{\mathrm{N}}$ & 18.61 & Lunar nodal \\
$\mathrm{P}_{\mathrm{JS}}$ & 19.86 & Jupiter-Saturn synodic \\
$\mathrm{S}_{\mathrm{H}}$ & 22.3 & Hale solar magnetic (variable) \\
$\mathrm{P}_{\mathrm{S}}$ & 29.46 & Saturn orbit \\
$\mathrm{P}_{\mathrm{SU}}$ & 45.36 & Saturn-Uranus synodic \\
$\mathrm{P}_{\mathrm{U}}$ & 84.01 & Uranus orbit \\
$\mathrm{P}_{\mathrm{G}}$ & $88 \pm 1$ & Solar Gleissberg (variable) \\
$\mathrm{P}_{\mathrm{Jo}}$ & 178.7 & Jose Solar system (variable) \\
$\mathrm{P}_{\mathrm{dV}}$ & 208 & Solar deVries \\
\hline
\end{tabular}




\subsection{The Complex Synchronization of the Solar System}

The planets move in fairly stable orbits, but their change of positions relative to the Sun makes the Sun move in a complex orbit, also called solar inertial motion (SIM), as demonstrated in Figure 31 for the period 1940-2040.

The SIM-pattern change between a "disordered like" and quasi-regular or "orderly" state with a "tri-foliar-like pattern" that follows the Jupiter-Saturn orbits. Charvátová and Hejda [103] have shown that the orderly pattern lasts about 50 years and is followed by a mildly or strongly disordered period. During disordered states deep solar minima have appeared, and during orderly periods long-term maxima of solar activity are possible. The pattern repeats with a period of $\sim 179$ years: the Jose period [104]. In the last millennium chaotic patterns were present 1270-1350, 1430-1520, 1620-1710, and 1787-1843. In these periods we find deep solar minima and GSBs, as well as maximum ice (BIE minima). The next disorderly phase started in 1985 and lasts until 2040. The lowest sunspot numbers in 200 years were observed in sunspot cycle 24 which ended in December 2019. High level of solar activity was observed in the orderly periods 1192-1241, 1370-1419, 1549-1598, 1727-1777 and 1906-1955.

A theory for the relation between solar activity and its source, the solar dynamo and GM-events has recently been proposed by [105], involving the storing and releasing potential energy in the solar interior. In the SIM pattern shown in Figure 31, the Sun moves in a prograde (counter-clockwise) orbit, except during one of the tri-foliar loops (marked red). Detailed calculations by [106] show that the process of storing and releasing potential energy starts about 40 years before the angular momentum inversion and lasts about 80 years. Simulations show

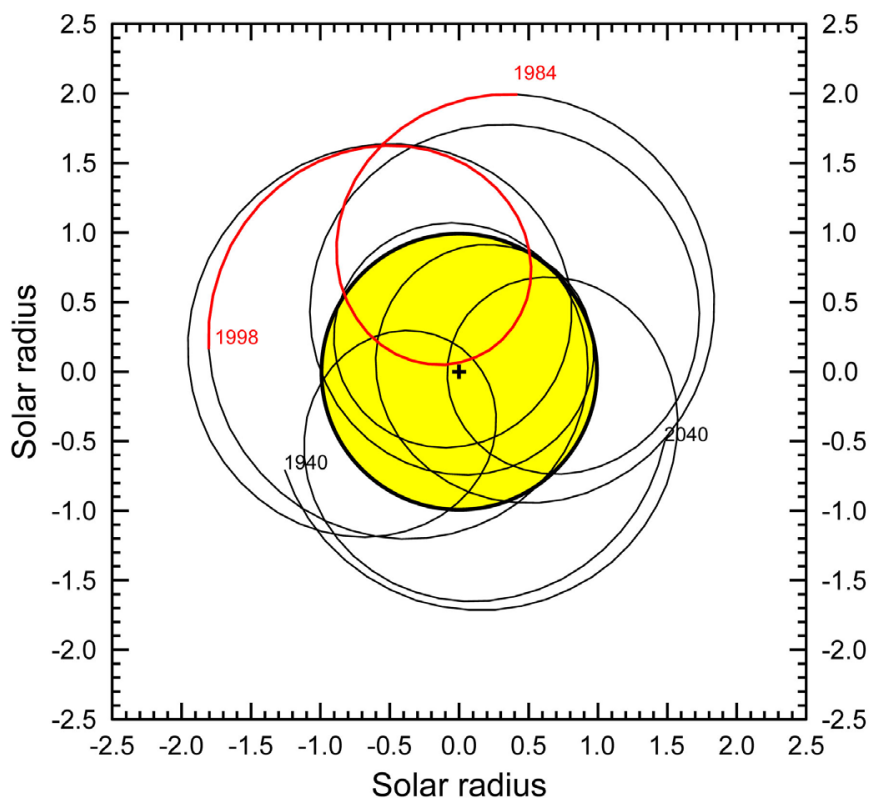

Figure 31. Solar inertial motion (SIM) relative to the solar system barycenter (SSB) for the period 1940-2040. The cross represents the SSB and the yellow filled circle the radius of the Sun. The part with a retrograde orbit is marked red. 
that the angular momentum inversion is a rapid process that takes place in one year. It has during the last millennium only happened at the epochs of Maunder Minimum (1632), Dalton Minimum (1811) and in 1990 before the newly started minimum. The reason for near barycenter passages 40 years before and after the inversion pulse is the Saturn-Uranus synodic period of 45 years when a new quasi-alignment happens. We also notice that the inversion events are 179 years apart, again the Jose cycle of repeated planet positions.

In a study by Fairbridge et al. [107] of the pattern of the solar orbit, the angle between tangents to two successive loops is defined as the Axym-angle. This follows the Saturn-Jupiter synodic period $\left(\mathrm{P}_{\mathrm{JS}}\right)$ of 19.9 years with a shift in angle of 117.4 degrees for each loop, returning to approximately the same part of the sky after 59.7 years. Three full Axym-cycles make a Jose period of 179 years. Duhau and de Jager [78] have calculated the difference in angle between two successive orbits (Daxym) and found that it is modulated with a period of 45 years, which is the Saturn-Uranus synodic period and $1 / 4$ of the Jose period. They also observed that 3 LOD periods of 60 years are close to the Jose period, and that the amplitude in the LOD-oscillations followed the Daxym variations with a 94-year delay in anti-phase of $R$. This is the reason for the repeated LOD pattern with the Jose period shown in Figure 26. Duhau and de Jager [78] concluded that the LOD amplitude modulation follows linearly solar system motions.

In Section 5.5 we have confirmed the anticorrelation with 94-year lag between $R$ and LOD. We have also found the LOD period to be 66 years, or $3 S_{\mathrm{H}}$ periods instead of $3 \mathrm{P}_{\text {SJ }}$ periods, not confirming the period found by [78]. Since the magnetic period is more likely to affect the solar wind's interaction with the magnetospheric ring current, which can magnetize the core of the Earth, we find our interpretation more likely.

Regarding timing of events, we notice that the phase change between 1900 and 1950 inversion happened during a rapid decrease of LOD and increasing solar activity. Thereafter the solar activity is reduced and the cosmic rays count increasing (Figure 28). A phase shift appeared in the BIE sub-centennial period (Figure 10 lower panel) between 1900 and 1950. A rapid move of BIE happened 94 years after the 1632 -inversion and 94 years after the 1811-inversion. It may happen again 94 years after the 1990-inversion, i.e. from about 2085.

The bicentennial period which changes from $\mathrm{P}=145\left(4 P_{J /} / 5\right)$ years to 266 $\left(3 P_{J o} / 2\right)$ years is also a strong indication of planetary synchronization.

\subsection{The Hale Cycle $\left(\mathrm{S}_{\mathrm{H}}\right)$}

The sunspot-cycle length varies between 8 and 15 years with an average of 11.06 years. The amplitude spectrum has 4 peaks at 9.97, 10.66, 11.01, and 11.83 years [14]. The strongest peak at 11.01 years is close to the Venus-Earth-Jupiter recurrent cycle of tidal torque $\left(P_{V E F}\right)$ which produce an increase in the rotation of the outer layers of the Sun for 11.07 years and a decrease in the next 11.07 years, making a full cycle of 22.14 years, which is close to the solar magnetic cycle of $S_{H}$ $=22 \pm 1$ years [108]. The other peaks are interpreted as the Jupiter period $P_{J}=$ 
11.86 years, and the spring (half synodic) tidal oscillation of Jupiter and Saturn $\left(\mathrm{P}_{\mathrm{J}} / 2 \sim 9.93\right.$ years), and a minor peak at 10.57 years, also found in the periodogram of the solar velocity variations [109].

A common objection against planetary tidal gravitational potential energy as the source of solar irradiance variation, is that it is several magnitudes too small. However, if the tidal massage of the Sun results in nuclear fusion variations in the solar core, then one can expect a magnification factor of the order $4 \times 10^{6}$ and solar radiation fluctuations of the same order as observed with the ACRIM satellite [110].

Since the dominant BIE sub-centennial and bicentennial periods show $\mathrm{P}_{\mathrm{Jo}}$-harmonics, we conclude that the planets contribute to the synchronization of BIE position oscillations in addition to the Moon and the Sun.

\subsection{A 60-Year Cycle-Directly from Jupiter?}

In addition to presence in climate records, a 60-year cycle is also found in long records of meteorite falls covering the period 619-1943 CE [111]. Since meteorite falls are related to cosmic dust from comets, and their orbits in many cases are changed by near passages of Jupiter, one may expect a relation between changes in Jupiter orbit and the influx of cosmic dust at the Earth. Since atmospheric dust modify the cloud cover on the Earth, the variation in cosmic dust may also result in climate variations.

The orbital eccentricity of Jupiter shows a strong 60 -year oscillation which is correlated with several climatic records and with the 60 -year cycle of meteorite fall recordings [111]. One of the climate records well correlated is the climatic variability of the North Atlantic based on G. Bulloides abundance variations from 1650 to 1990 [112].

This is an example of possible direct planetary forcing, which don't rely on being transmitted via the Sun or the core of the Earth. The low amplitude stationary 60-year period detected with the Morlet-wavelet (Section 4.6) may be explained by this direct forcing. However, the detection of a 19.9-year weak signal (Section 3.1), which can only be the $\mathrm{P}_{\mathrm{JS}}$ beat signal, indicates this as the source of the 60-year signal, which is also found in the solar wind speed variations.

\subsection{A 60-Year Cycle or a 66-Year Cycle?}

The term "60-year cycle" is given somewhat imprecisely about cycles of the order 60 to 70 years. We can construct two competing 60-year cycles, one being subharmonics of the lunar nodal $\left(L_{N}\right)$ cycle of 18.61 years and its spring cycle 9.3 years or the solar magnetic cycle of $S_{H}=22.1$ years. Both create "65 - 66-year cycles": $7 L_{N} / 2=65.1$ and $3 S_{H}=66.3$ years. The O-C diagram in Figure 10 shows that BIE since 1700 has an 82 -year cycle which may be composed of $3 S_{H}=88$, $4 P_{\text {JS }}=80$, and $9 L_{N} / 2=84$ years cycles.

A high degree of coherence is found between global temperature series (HadCRUT3) for periods of exactly 20 and 60 years and the speed of the Sun 
relative to the center of the mass of the solar system by [113]. They are related to the $\mathrm{P}_{\text {JS }}$ synodic period of 19.95 years. In the BIE record we observe this 60 -year cycle as a low amplitude signal, detected in the Morlet-analysis (Figure 8). This signal is not dominating in our BIE-series, nor in the AMO, NAO and NH temperature series we have analyzed. On the other hand, we observe sub-harmonics of the 60-year cycle as weak 120, 240 and maybe 480-years periods forced by the planets and Earth's morphology into dominant, slightly longer periods as 82 , 145,266 and 490 years.

The fundamental difference from the global analysis is that our BIE-series is a result of the local climate. The Arctic ice cover may influence the global climate, at least if a GSB is initiated. What we observe are local changes to global signals with the Moon and Sun as prime actors.

\section{Discussion}

This is the second in a series of two papers which analyze the BIE position based on a 442-years long dataset covering the period 1579-2020, to understand its time variations. Our first paper was a review of various oceanic and atmospheric factors that may influence the BIE position. We concluded that the GSB with respect to alternations in flow intensity and N-S distribution, plays a central role in combination with external forcing from total solar irradiation (TSI), Earth's shielding strength, Earth's geomagnetic field intensity, Earth's rotation, jet stream changes, etc.; all factors of which are ultimately driven by planetary beat on the Sun, the Earth, and the Earth-Moon system.

Our working hypothesis is that the planetary gravity beat is somehow preserved as a weak signal through a chain of processes schematically shown in [1] Figure 9 and in some cases amplified in local or regional synchronized systems: especially Earth rotation [28] and the polar wobble [102]. In [1] we assumed that the climate of the Northwestern coast of Europe and the position of the ice edge in the North Atlantic Ocean are controlled by the Northern branch of the Atlantic current (Gulf Stream) and by advection modulated by the Northern Jet Stream, which both are controlled by the solar wind. The solar wind also acts on the Earth's speed of rotation, which again forces the ocean currents [1] Figure 7.

In this paper we have analyzed the BIE data set and correlated it with other data sets, and in particular compared periods and phases of oscillations. We have found that oscillations combine non-linearly with variable frequencies, amplitudes, and phases. This makes predictions of future behavior difficult. However, since some of the forcing signals are generated from planetary orbits which have been quasi-stable for millions of years, we expect a high degree of synchronization between planets, Sun, and Earth climate.

We have found that in addition to cycles, the BIE variations have a near linear trend towards a more northerly position from about 1900. This must be the result of an integrated effect or a temporary near linear sum of oscillations. We have investigated different possibilities. In the following we first discuss the data set, then the oscillations, integrated effects, and possible falsifications/verifications. 


\subsection{The Data Set}

A time series of the estimated position for the last two weeks of August ice edge in the sector between $20^{\circ} \mathrm{E}$ and $45^{\circ} \mathrm{E}$, covering the western Barents Sea between Svalbard and Frans Josef Land (see Figure 1) was originally collected and presented by T. Vinje [16]. The data have been collected from ship-logs, polar expeditions, and hunters in addition to airplanes and satellites in recent times. In particular has the European, mainly Dutch whaling that took place around Svalbard in the period 1600-1800 been a valuable source of information. The BIE position has been defined as the occurrence of $15 \%$ ice and has been updated to include the 2020 position. Since 1979 satellite data from microwave sensors have been used. Comparing data from direct sightings with microwave data, we found that the latter moved BIE 1.2 degrees north. We have not corrected the data set for this discrepancy since it is comparable with the uncertainty in the data set.

The data coverage has increased from $34 \%$ in the first century to $100 \%$ after 1979 with satellite observations. The BIE position has varied between $75.5^{\circ} \mathrm{N}$ and $83.4^{\circ} \mathrm{N}$, with a position far south $1625-1670$ and $1784-1830$, i.e. before and during the Maunder and Dalton solar minima. From about 1920, BIE has moved north, except for a southward expansion between 1940 and 1970. The last ten years the position has been variable around $82 \mathrm{~N}$ with no trend. The northernmost position was recorded in 2013 with $83.37^{\circ} \mathrm{N}$. The data varies \pm 1.1 degrees of an average value after 1740, but much more before. Satellite observations in the last 40 years did not reduce the variations.

Sorting the data set in centuries (Figure 4) resulted in a binominal distribution with median values around $76^{\circ} \mathrm{N}$ and $79^{\circ} \mathrm{N}$, except for the $19^{\text {th }}$ century with only one peak around $77.5^{\circ} \mathrm{N}$.

The binominal distribution may be related both to the inflow of warm AW on decadal and centennial scales as well as the prevailing winds that influence the ice drift on a much shorter time scale.

We conclude that BIE extreme southern positions $\left(<77^{\circ} \mathrm{N}\right.$ for 10 years or more) may be precursors of GSB-events, which last as long or longer than the BIE extreme position, with a delay of 10 - 15 years.

\subsection{Correlations with Other Data Sets}

Before we concluded on external forcings we checked possible internal forcings. We have calculated Pearson correlations, assuming linear relations. A correlation does not imply a causal relation-we also must find a physical relation. We have done three types of correlations: Instant, i.e. observed values for the same year or smoothed (i.e. 11-year running mean) or long period mean values. We use the $r^{2}$ as a measure of goodness of fit, i.e. calculated how much of the observed variation can be explained by a linear trend. The best fit found was $r^{2}=$ 0.79 for 30-year average values related to the longest instrumental temperature series from Central England from 1659. The correlation with annual values gives $r^{2}=0.14$. This means that low frequency climate variations correlate well with 


\section{BIE, but not the high frequency variations.}

Another good correlation was with yearly estimates of the Arctic summer ice cover $\left(r^{2}=0.62\right)$ after 1979 estimated from satellites. For data back to 1900 we got $r^{2}=0.22$. This means that BIE estimated by satellites gives a good estimate of Arctic summer ice, but the estimates of ice cover and/or BIE are less precise at earlier times.

BIE tracks NH-SST and land temperatures quite well $\left(r^{2}=0.43\right)$, which is better than for the KolaT $\left(r^{2}=0.29\right)$. This may be due to less noise in the average SST series but may also be a result of the warmer deeper AW under the colder surface water in the Kola section data. Since land and sea surface temperatures react more rapid on solar heating than the deep ocean this indicates a solar source forcing locally.

\subsection{Planetary Orbit Fingerprints}

We have searched for periodicities with the P04 period search program developed for gapped data, Morlet wavelet which gives precise frequencies, and coif3 wavelet for investigation of phase events. We did not find any stationary periods in the bi-decadal range or shorter. Some periods with $\mathrm{P}<50$ years exist for some decades. Only four low-frequency periods are necessary to explain the BIE secular variations. They are harmonically related with $P_{i} \approx 250 / i$ years, with $i=1 / 2,1$, $5 / 3$ and 3 .

We found that the data set showed no trend before 1890, but a steep rise ( $0.035 \mathrm{deg} /$ year) thereafter. Analysis of the detrended data set showed the $\mathrm{P}_{\mathrm{Jo}}=$ 179 years as the dominating period with other periods harmonically related to $P_{J o}$.

We investigated amplitude and phase variations and found that the semi-centennial period $\mathrm{P}=82$ years had a constant period, but with phase shifts before 1700 and between 1900 and 1950. It is amplitude modulated with a nearly zero amplitude between 1900 and 1950 and a maximum between 1600 and 1700, but disappeared completely around 1650. A bicentennial period was on average 252 years but consisted of two periods: $\mathrm{P}=145$ years before 1750 and $\mathrm{P}=266$ years after, although with constant amplitudes. In addition, we found a low amplitude period of 60 years with 120 and 240 years weak sub-harmonics, as expected in [1] Figure 17.

We interpret the detected periods as fingerprints of planetary forcing. The disappearance of the sub-centennial signal at peak amplitude around 1650 may be due to a GSB-event.

\subsection{Search for Mechanisms}

Detrending BIE after 1800 and taking 11-point mean, we compared BIE with KolaT, ArcT, AMO, NAO and LOD (Figure 14). BIE is in phase with ArcT, KolaT, and AMO 1900-1950, but in antiphase with NAO and LOD. Analyzing the sub-centennial periods, we found that LOD, AMO and NAO have periods 65 - 
67 years, in accordance with the Stadium wave periods [46]. They belong to the same Stadium wave temporal group with LOD leading NAO and AMO. ArcT, KolaT and BIE have longer periods (74 and 82 years) and are only temporary (around 1920) in phase with AMO and the Stadium wave. We conclude that BIE does not belong permanently to a Stadium wave temporal group.

In [1] we proposed LOD as the mechanism to transfer external forcings to the ocean surface and atmospheric circulation [1] Figure 7. Mazzarella and Scafetta [55] found that negLOD and integrated NAO-index (INAO) correlated with SST after 1800. As a result, they proposed that also the trend in SST increase could be explained by INAO and LOD and expanded the linear relation back to the Maunder Minimum. Doing the same analysis for BIE, we found that INAO and negLOD correlate with BIE $\left(r^{2}=0.25\right.$ and $\left.r^{2}=0.40\right)$ from 1800. Before 1800 we found no meaningful relation. This indicates that the Earth's rotation can be an agent for forcing BIE, at least after 1800.

\subsection{External Forcings}

Orbital forcing [114], in particular the change in obliquity and precession, is responsible for the reduction in summer insolation and shorter winter and spring seasons the last 3000 years. Increased spring insolation is responsible for the increased LIG $\left(30^{\circ} \mathrm{N}-78^{\circ} \mathrm{N}\right)$ at the start of the melting season of BIE during the last 2000 years. This has contributed to BIE moving north. The heat from solar insolation during the summer season is of the same order as the heat carried with the $\mathrm{AW}$ entering the $\mathrm{BSO}$, and the BIE position correlates with the Hoyt-Schatten revised TSI [69] at $78^{\circ} \mathrm{N}\left(r^{2}=0.23\right.$ back to 1579$)$ or at $1 \mathrm{AU}\left(r^{2}=\right.$ 0.41 from 1706). The better correlation after 1700 may be explained by more accurate observations after 1750 .

In the original BIE data [70] found a good correlation with low pass filtered SCL, indicating that the low frequency BIE variations may be related to solar activity. The relation with SCL is still present $\left(r^{2}=0.48\right)$ with the revised BIE-data, and this led us to investigate the solar wind as a forcing agent as proposed by [75]. The solar wind may interact directly by increased corpuscular pressure on the earth's atmosphere during geomagnetic storms (CMEs), in the sense that increased corpuscular activity causes a deceleration of zonal atmospheric circulation. This causes a deceleration of the Earth's rotation and decreases global SST [76]. When solar activity decrease, we observe a faster Earth rotation and BIE moving north, as seen in Figure 25 since 1975.

We have also found support for another mechanism: The solar wind interacts directly with the (polar) jet-stream and modifies the magnetic shielding (see [1] Figure 20) which protects the Earth from galactic cosmic rays ([1] Figure 4) and contributes to the magnetospheric ring current which controls the magnetic momentum exchange with the Earth's magnetic core. This introduces a change in the Earth's rotation which is observed as LOD-changes. We have confirmed an anti-correlation between $R$ and LOD with a lag of 94 years found by [77] and 
explained by [78]. The near centennial lag explains this as torsional oscillations in the Earth's mantle needing time to progress to the surface. The LOD changes appear as peaks about 60 years apart, and are amplitude modulated with $\mathrm{P}_{\mathrm{J}}$. Since planet positions repeat with $\mathrm{P}_{\mathrm{J}}$, [78] propose that synchronization of LOD pulses takes place with this period. We support this interpretation but find LOD-pulses $\approx 66$ years $\left(3 S_{H}\right)$ apart.

In addition to these two mechanisms, we have found increasing support for an even more direct forcing on the Arctic Climate by the solar wind, in particular CME-events which deposit large amounts of energy in the circumpolar atmospheres [97]. This is in particular evident during periods of low solar activity [93]. We suggest that the reduced magnetic shielding of the Earth during solar minima, leads to increased warming by coronal mass events. This can explain local Arctic warming even in cold periods as during the LIA and the present solar minimum.

By comparing the BIE-series with the LOD-variations we find that BIE respond to LOD-pulses in the following way: BIE starts moving north or stops moving south when an accelerating pulse appears. On the other hand, BIE always moves south when solar activity enters a deep minimum. The relation between BIE, LOD, 94 years lag and anti-correlation with SN has led us to propose that the trend in the BIE position series is controlled by the solar wind speed. Added support for the solar wind-forcing is found in 60 and 100-years periods common for BIE, SWS and SN-variations.

\subsection{Lunar and Solar Periods}

A 60-year period with low amplitude at the noise level, is present during the whole series. It may be a subharmonic of the $P_{J S}=19.9$-year Jupiter-Saturn synodic period. A weak 120-years and a possible 240-years subharmonic period are also detected. The 60 -year period is recently confirmed as a solar activity period together with periods 5.5, 22 and 120 years [115]. This has produced forecasts of a deep solar minimum which will last until about 2050 or longer.

The lunar nodal period of $\mathrm{P}_{\mathrm{N}}=18.61$ years creates a sub-harmonic $4 P_{N}=74.4$ years period, which is the dominant period in sea level variations in the North Sea [100] and in sea temperature variations also in the BS [101] [102]. An alternative interpretation of the BIE-data concluding with lunar forcing is presented by [116]. The main reason for this interpretation is the dominant 74-year period in KolaT We propose instead that the strong sub-centennial period between 80 and 90 years is a combination of $4 P_{N}$ and $P_{J o} / 2$ as shown in the next section.

\subsection{Planetary Synchronization and a Simple Mathematical Model}

One of the goals of this investigation is to identify stationary periods, which can be used for prediction of future changes. We have found that the BIE-curve is quite noisy, and that a simple model with stationary periods based on harmonics of $P_{J_{0}}$ can explain $r^{2} \approx 0.4$ of the variations. 
The model is constructed with three fixed $\mathrm{P}_{\mathrm{Jo}}$-harmonics $(3,3 / 2$ and $4 / 5) \mathrm{P}_{\mathrm{Jo}}$, and an 84-year period as the strongest period in the residuals. In addition we include the 3 strongest periods below the false detection limit: $P_{J S}, P=84 / 6-=14$ and 60 year. The complete set of periods and amplitudes became $(P, A)=[537$, $1.1) ;(268,1.1)$; $(143,0.6)$; $(84,0.7)$; $(60,0.32) ;(19.7,0.41)$; $(14.0,0.37)]$. All periods are related to the planetary system except $P=84$ years, which may be a combination of $P_{J_{0}} / 2$ and $4 P_{N}$. The period between 140 and 150 years may also be a combination of harmonics of $P_{J o}$ and $P_{N}$. The long period of 537 years is close to the 545-year period observed in the solar wind speed [92]. This model with 7 periods gave a sigma $=1.11$ degrees. Figure 32 presents the model and its 4 low frequent (red) and 3 high frequent (black) oscillations. The uncertainty limits of one sigma are also shown (green).

In this model the steep trend 1890-2020 is replaced by a sum of low frequency oscillations which peaks between 2020 and 2040. This means that the steep trend is only a temporary feature.

\subsection{The Near Future}

SC24 which ended in December 2019 was the weakest cycle in 200 years. If cycle 25 also is weak, a new deep solar minimum may evolve in phase with the 210 -year cycle with minimum in 2035 [38]. If solar activity is the only driving agent, the decreasing activity should make the Arctic cool, and BIE move south. However, the LOD and SN11 projections (Figure 26) indicate a deceleration and cooling start about 10 years later.

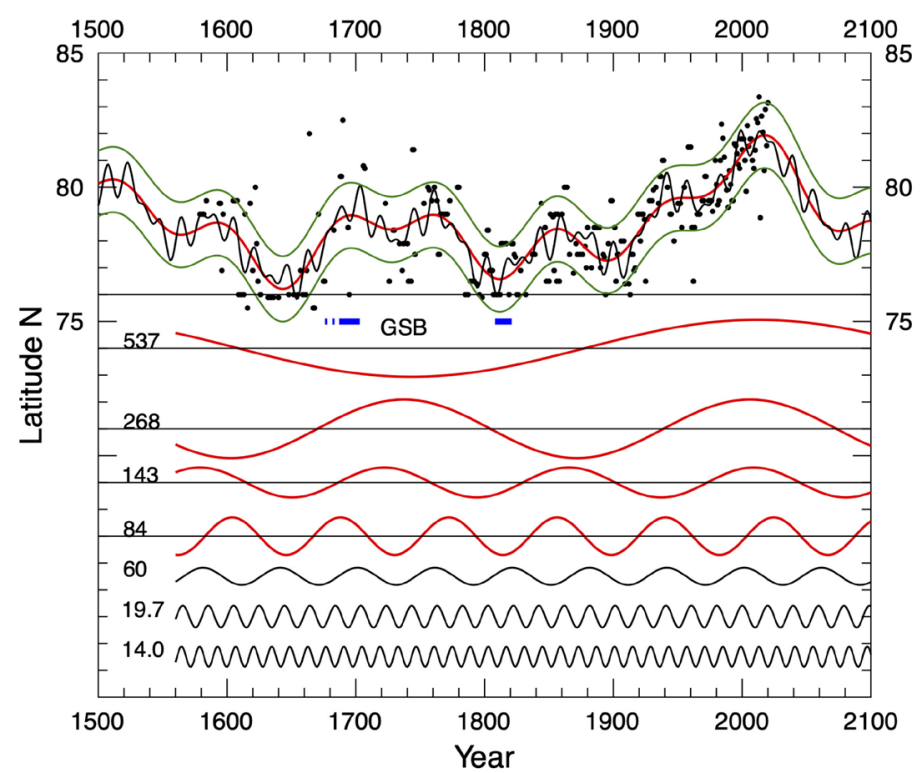

Figure 32. BIE positions with a 4-parameter model based on planetary periods (red) with uncertainty interval (green). The 4 periods $(3,3 / 2,4 / 5) P_{J o}$ and $P=84$ years are shown separately below. In addition, three weaker fast oscillations are included $\left(P_{J} / 9, P=84 / 6=\right.$ 14 and $P=60$ years are shown with thin black lines.) The timing of two GSBs is indicated by thick blue lines. 
The prediction based on the simple 4-period model in Figure 32 is that BIE will peak between 2010 and 2030 and will move south from about 2030 to 2060 . It will remain between 79 and $77 \mathrm{~N}$ from 2060 until 2120. This is a repetition of the BIE location between 1680 and 1780 . There is no sign of a stable low (southern) level at $76^{\circ} \mathrm{N}$ in this or in the next century. We interpret the successive less deep BIE minima because of the precession of the Earth's orbit, creating an early spring effect which leads to earlier ice melting.

\subsection{The Next GSB}

In [1] (see Figure 5), we reported 3 GSBs the previous millennium, all in connection with deep solar minima. The mathematical model in Figure 32 suggests a long cold period lasting at least 100 years, maybe like the period 1850-1900 which may evolve into a new LIA. During the 442 years we have data for BIE we find that a GSB evolves after some decades of $\mathrm{BIE} \approx 76^{\circ} \mathrm{N}$. This may not happen in this century but maybe in the first part of the next.

The gradual and opposite trend in temperature variation in circum-Arctic and circum-Equator ocean temperatures reported in [1] Figure 10, indicates that a change is underway. Since BIE may stay north at least $15-20$ more years, this will probably not evolve into a GSB.

\subsection{Expected Bio-Production and Resource Exploration}

The ice cover in Arctic seas will directly affect the marine light scape, the total and quality of the primary production, the secondary production, and the transfer of energy up through the arctic marine food chain. During periods with little ice the bio-production in the European Arctic will increase due to: 1) increase in the total area of open water available for primary production in the Barents Sea and the Nordic Seas and 2) the late winter and summer upwelling of nutrient rich water along the shelf break between northern Spitsbergen and Frans Josefs Land. In periods with expanding ice cover, there has been a marked and rapid decrease in the bio-production and a large decrease in commercial fish stocks affecting the local communities and the society at large.

\subsection{Falsifications-The Weak Points-What to Look for}

Unlike the projections of general climate models, we already have a possibility for a falsification of our hypothesis if the BIE does not move south after 2040 as our analysis suggests. Avoiding a complete GSB before 2100 is also a consequence of our mathematical model. Exact timing of the reversal of BIE will indicate the relative importance of direct forcing due to CMEs, 10 - 15 years delayed pressure affected LOD-changes, or LOD-changes due to magnetic core rotation delayed 94 years.

The general problem is the noisy curve and the large random changes in wind patterns and currents from year to year. A more systematic analysis of the noise might reveal some pattern or ranges we could use for determination of uncertainties. 
The weakest point is the trend interpretation and its delay of 94 years. And how the ring current transfer angular momentum to the core. We suggest that this may be tested the following way: Since the core is not perfectly spherical this means that changes in LOD may lead to correlated changes in the geoid, and this may be observed as local or regional sea level variations.

Our suggestion is to follow closely the effects of CMEs on the Arctic climate and BIE. We suspect that CMEs in the early melting season will have a strong effect of the BIE position.

\section{Conclusions}

The BIE position has varied between $75.5^{\circ} \mathrm{N}$ and $83.4^{\circ} \mathrm{N}$, with a position far south during the Maunder and Dalton Minima, and through most of the 19th century. From about 1920, BIE has moved north, related to increased solar activity. In addition to a trend which can be interpreted as the result of the combined effect of low frequency oscillations forced by the planetary orbits and the Moon, the position is dominated by large fluctuations from year to year, creating a time series with only low frequency stationary periods.

Our main result is that the BIE position alternates between a southern and northern position followed by Gulf Stream Beats (GSBs) at the occurrence of long deep solar minima. We find that the low frequency variations are related to the planetary repetition Jose period of 179 years. A sum of low frequency periods led to a rapid north movement of the BIE position between 1910 and 2010. Since the variations are forced by planetary periods, stable for millennia, we may project the variations a few centuries forward. This shows a rapid southward movement of BIE between 2040 and 2080 , and a position between $76^{\circ} \mathrm{N}$ and $79^{\circ} \mathrm{N}$ for most of the next century, indicating a long and deep minimum affecting the global climate, but not as deep as required for a full scale GSB.

We have also found evidence for a possible mechanism linking solar activity to variations in earth rotation (LOD) by geomagnetic storms in the solar wind providing a torque on the Earth's rotation and transferring electrical energy to the ring current in the earth's magnetosphere. This magnetizes the earth's solid core and makes it rotate faster. To conserve angular momentum the earth's outer fluid mantle rotates slower with a delay of 94 years observed as changes in LOD. The result is LOD-pulses which appear with a period of about $3 \mathrm{~S}_{\mathrm{H}}=66$ years, amplitude-modulated with $\mathrm{P}_{\mathrm{J}}=179$ years, indicating a planetary forcing. Geomagnetic shock waves created by CMEs may also penetrate to the troposphere and change wind and ocean current pattern, and thereby the position of BIE. We suggest that the recent warmer Arctic is a function of less magnetic shielding and heating by geomagnetic shocks.

The transition of solar activities to a possibly deep and long minimum in the present century and the observation of cooling in the North Atlantic Ocean in the last decade, are signs of an approaching Arctic cooling and the BIE moving south in the middle of the century, with consequences for the ocean bio-production 
and climate in the North Atlantic region. However, due to a gradual early spring effect we don't expect a strong cooling or LIA until late in this century or in the next.

\section{Acknowledgements}

This is a collaboration project which has lasted some years. JES has written most of the text and done most of the analysis and edited the manuscript. SFP has contributed with updated data and knowledge on the marine life and in situ ice conditions. $\mathrm{OH}$ has provided climate information and done the Morlet analysis. NAM has contributed with paleoclimatic information and the information on ocean currents and GSBs.

We thank Olga Pavlova for providing the BIE-data, Malin Daase and Arild E. Johnsen for help with drawings. A special thank to Harald Yndestad for the coif3-analysis, Rodolfo Cionco for the TSI and LIG calculations, Willie Soon for ArcT-data, Nicola Scafetta for updated ACRIM-TSI and Victor Manuel Velaso Hererra for hindcasted and forecasted TSI. We also thank Wim Röst for information on whalers and Göran Henriksson and Egil Pedersen for reading and commenting the manuscript. A special thank to the persons and institutions who have provided data for our analysis. They are mentioned in the text.

\section{Conflicts of Interest}

The authors declare no conflicts of interest regarding the publication of this paper. No financing has been involved.

\section{References}

[1] Mörner, N.A., Solheim, J.-E., Humlum, O. and Falk-Petersen, S. (2020) Changes in Barents Sea Ice Edge Positions in the Last 440 Years: A Review of Possible Driving Forces. International Journal of Astronomy and Astrophysics, 10, 97-164. https://doi.org/10.4236/ijaa.2020.102008

[2] Ikeda, M. (1990) Decadal Oscillations of the Air-Ice-Ocean System in the Northern Hemisphere. Atmosphere-Ocean, 28, 106-139. https://doi.org/10.1080/07055900.1990.9649369

[3] Loeng, H.V. (1991) Features of the Physical Oceanographic Conditions of the Barents Sea. Polar Research, 10, 5-18. https://doi.org/10.3402/polar.v10i1.6723

[4] Falk-Petersen, S., Pavlov, V., Timofeev, S. and Sargent, J. (2007) Climate Variability and Possible Effects on Arctic Food Chains: The Role of Calanus. In: Ørbæk, J.B., Tombre, T., Kallenborn, R., Hegseth, E., Falk-Petersen, S. and Hoel, A.H., Eds., Arctic Alpine Ecosystems and People in a Changing Environment, Springer, Berlin, 147-166. https://doi.org/10.1007/978-3-540-48514-8 9

[5] Muilwijk, M., Smedsrud, L.H., Ilicak, M. and Drange, H. (2018) Atlantic Water Heat Transport Variability in the 20th Century Arctic Ocean from a Global Ocean Model and Observations. Journal of Geophysical Research: Oceans, 123, 8159-8179. https://doi.org/10.1029/2018JC014327

[6] Spielhagen, R.F., Werner, K., Aagaard Sørensen, S., Zamelczyk, K., Kandiano, E., et al. (2011) Enhanced Modern Heat Transfer to the Arctic by Warm Atlantic Water. Science, 331, 450-453. https://doi.org/10.1126/science.1197397 
[7] Smedsrud, L.H., Esau, I., Ingvaldsen, R.B., Eldervik, T., Haugan, O.M., et al. (2013) The Role of the Barents Sea in the Arctic Climate System. Reviews of Geophysics, 51, 1-35. https://doi.org/10.1002/rog.20017

[8] Lique, C. and Steele, M. (2012) Where Can We Find a Sesonal Cycle of the Atlantic Water Temperature Within the Arctic Basin? Journal of Geophysical Research: Oceans, 117, C03026. https://doi.org/10.1029/2011JC007612

[9] Falk-Petersen, S, Pavlov, V., Berge, J., Cottier, F., Kovacs, K.M. and Lydersen, C. (2015) At the Rainbow's End: High Productivity Fueled by Winter Upwelling along an Arctic Shelf. Polar Biology, 38, 5-11. https://doi.org/10.1007/s00300-014-1482-1

[10] Nansen, F. (1924) Blant Selog Bjørn (in Norwegian). Jacob Dybwad forlag, Kristiania.

[11] Oziel, L., Neukermans, G., Ardyna, M., Lancelot, C., Tison, J.-L., Wassmann, P., et al. (2017) Role for Atlantic Inflows and Sea Ice Loss on Shifting Phytoplankton Blooms in the Barents Sea. Journal of Geophysical Research: Oceans, 122, 5121-5139. https://doi.org/10.1002/2016JC012582

[12] Usoskin, I.G., Solanki, S.K. and Kovaltsov, G.A. (2007) Grand Minima and Maxima of Solar Activity: New Observational Constraints. Astronomy and Astrophysics, 471, 301-309. https://doi.org/10.1051/0004-6361:20077704

[13] Ljungquist, F.C. (2010) A New Reconstruction of Temperature Variability in the Extra-Tropical Northern Hemisphere during the Last Two Millennia. Geografiska Annaler, 92, 339-351. https://doi.org/10.1111/j.1468-0459.2010.00399.x

[14] Mörner, N.-A. (2010) Solar Minima, Earth's Rotation and Little Ice Ages in the Past and in the Future the North Atlantic-European Case. Global and Planetary Change, 72, 282-293. https://doi.org/10.1016/i.gloplacha.2010.01.004

[15] Solheim, J.-E. (2013) The Sunspot Cycle Length-Modulated by Planets? Pattern Recognition in Physics, 1, 154-164. https://doi.org/10.5194/prp-1-159-2013

[16] Vinje, T. (1999) Barents Sea Ice Edge Variation over the Past 400 Years. Proceedings of the Workshop on Sea-Ice Charts of the Arctic, Seattle, 5-7 August 1998, WMO/TD No. 949, 4-6.

[17] Vinje, T. (2001) Anomalies and Trends of Sea-Ice Extent and Atmospheric Circulation in the Nordic Seas during the Period 1864-1998. Journal of Climate, 14, 255-267. https://doi.org/10.1175/1520-0442(2001)014<0255:AATOSI $>2.0 . C O ; 2$

[18] Løyning, T.B., Dick, C., Goodwin, H., Pavlova, O., Vinje, T., Kjærnli, G. and Villinger, T. (2003) World Climate Research Programme, Arctic Climate System Study, ACSYS Historical Ice Chart Archive (1553-2002). IACPO Informal Report, 8.

[19] Cavalieri, D.J., Parkinson, C.L., Gloersen, P., Comiso, J.C. and Zwally, H.J. (1999) Deriving Long-Term Time Series of Sea Ice Cover from Satellite Passive-Microwave Multisensor Data Sets. Journal of Geophysical Research, 104, 15,803-15,814. https://doi.org/10.1029/1999JC900081

[20] Fetterer F., Knowles, K., Meier, W.N., Savoie, M. and Windnagel, A.K. (2017) Sea Ice Index, Version 3. National Snow \& Ice Data Center.

[21] Ivanova, N., Pedersen, L.T., Tonboe, R.T., Kern, S., Heygster, G., Lavergne, T., et al. (2015) Inter-Comparison and Evaluation of Sea Ice Algorithms: Towards Further Identification of Challenges and Optimal Approach Using Passive Microwave Observations. The Cryosphere, 9, 1797-1817. https://doi.org/10.5194/tc-9-1797-2015

[22] Connolly, R., Connolly, M. and Soon, W. (2017) Re-Calibration of Arctic Sea Ice Extent Datasets Using Arctic Surface Air Temperature Records. Hydrological Sciences Journal, 62, 1317-1340. https://doi.org/10.1080/02626667.2017.1324974 
[23] Humlum, O. (2021) Climate+History. http://www.climate4you.com

[24] Röst, W. (2021) Private Communication. https://nl.wikipedia.org/wiki/Rede van Vlieland

[25] Nansen, F. (1902) Oceanography of the North Polar basin. The Norwegian North Polar Expedition 1893-1896 Scientific Results. Greenwood Press, New York.

[26] Falk-Petersen, S., Hop, H., Budgell, W.P., Hegseth, E.N., Korsnes, R., Løyning, T.B., et al. (2000) Physical and Ecological Processes in the Marginal Ice Zone of the Northern Barents Sea during the Summer Melt Periods. Journal of Marine Systems, 27, 131-159. https://doi.org/10.1016/S0924-7963(00)00064-6

[27] Saloranta, T.M. and Svendsen, H. (2001) Across the Arctic Front West of Spitsbergen: High-Resoolution CTD Sections from 1998-2000. Polar Research, 20, 177-184. https://doi.org/10.3402/polar.v20i2.6515

[28] Mörner, N.-A. (1996) Global Change and Interaction of Earth Rotation Ocean Circulation and Paleoclimate. Annals of the Brazilian Academy of Sciences, 68, 77-94.

[29] Smedsrud, L.H., Ingvaldsen, R., Nilsen, E.Ø. and Skagseth, Ø. (2010) Heat in the Barents Sea: Transport, Storage and Surface Fluxes. Ocean Science, 6, 219-234. https://doi.org/10.5194/os-6-219-2010

[30] Lind, S. and Ingvaldsen, R. (2012) Variability and Impacts of Atlantic Water Entering the Barents Sea from the North. Deep Sea Research, Part I, 62, 70-88. https://doi.org/10.1016/j.dsr.2011.12.007

[31] Lenz, P. and Breger, M. (2005) Period04 User Guide. Communications in Asteroseismology, 146, 53-136. https://doi.org/10.1553/cia146s53

[32] Scafetta, N. (2014) The Complex Planetary Synchronization Structure of the Solar System. Pattern Recognition in Physics, 2, 1-19.

https://doi.org/10.5194/prp-2-1-2014

[33] Morlet (1983) Sampling Theory and Wave Propagation. In: Chen, C.H., Ed., Issues in Acoustic Signal-Image Processing and Recognition, NATO ASI Series F: Computer and System Sciences, Vol. 1, Springer, Berlin, 233-261.

https://doi.org/10.1007/978-3-642-82002-1 12

[34] SeaSolve (2003) AutoSignal Pioneering Automated Signal Analysis and Advanced Filtering. User's Manual. SeaSolve Software Inc., Framingham.

[35] Torrence, C. and Compo, G.P. (1998) A Practical Guide to Wavelet Analysis. Bulletin of the American Meteorological Society, 7, 69-78. https://doi.org/10.1175/1520-0477(1998)079<0061:APGTWA>2.0.CO;2

[36] Shannon, C.E. (1949) Communications in the Presence of Noise. Proceedings of the Institute of Radio Engineers, 37, 10-21. https://doi.org/10.1109/JRPROC.1949.232969

[37] Abreu, J.A., Beer, J., Ferriz-Mas, A., McCracken, K.G. and Steinhilber, F. (2012) Is There a Planetary Influence on Solar Activity? Astronomy and Astrophysics, 548, A88. https://doi.org/10.1051/0004-6361/201219997

[38] Yndestad, H. and Solheim, J.-E. (2017) The Influence of Solar System Oscillation on the Variability of the Total Solar Irradianc. New Astronomy, 51, 135-152. https://doi.org/10.1016/j.newast.2016.08.020

[39] Daubechies, L. (1992) Ten Lectures of Wavelet. SIAM Journal on Mathematical Analysis, 24, 499-519. https://doi.org/10.1137/0524031

[40] Manley, G. (1974) Central England Temperature: Monthly Means 1659 to 1973. Quarterly Journal of the Royal Meteorological Society, 100, 389-405. https://doi.org/10.1002/qj.49710042511 
[41] Hadley Centre for Climate Change. https://hadleyserver.metoffice.gov.uk/hadcet/cetml1659on.dat

[42] Nordli, Ø., Przybylak, R., Ogilvie, A.E.J. and Isaksen, K. (2014) Long-Term Temperature Trends and Variability on Spitsbergen: The Extended Svalbard Airport Temperature Series 1898-2012. Polar Research, 33, 21349. https://doi.org/10.3402/polar.v33.21349

[43] Boitsov, V.D., Karsakov, A.L. and Trofimov, A.G. (2012) Atlantic WaterTemperature and Climate in the Barents Sea, 2000-2009. ICES Journal of Marine Science, 69, 833-840. https://doi.org/10.1093/icesjms/fss075

[44] Karsakov, A.L. (2009) Oceanographic Investigations Along the "Kola Meridian" Section in the Barents Sea in 1900-2008. PINRO Press, Murmansk, 139 p. https://www.pinro.ru

[45] Soon, W., Connolly, R. and Connolly, M. (2015) Re-Evaluating the Role of Solar Variability on Northern Hemisphere Temperature Trends Since the 19th Century. Earth-Science Review, 150, 409-452. https://doi.org/10.1016/j.earscirev.2015.08.010

[46] Wyatt, M.G. and Curry, J.A. (2014) Role for Eurasian Arctic Shelf Sea Ice on a Secularly Varying Hemispheric Climate Signal during the 20th Century. Climate Dynamics, 43, 2763-2782. https://doi.org/10.1007/s00382-013-1950-2

[47] Enfield, D.B., Mestas-Nunez, A.M. and Trimble, P.J. (2001) The Atlantic Multidecadal Oscillation and Its Relation to Rainfall and River Flows in the Continental U.S. Geophysical Research Letters, 28, 2077-2080.

http://www.esrl.noaa.gov/psd/data/timeseries/AMO https://doi.org/10.1029/2000GL012745

[48] Luterbacher, J., Xoplaki, E., Dietrich, D., Jones, P.D., Davies, T.D., Portis, D., et al. (2004) Extending North Atllantic Oscillation Reconstruction Back to 1500. Atmospheric Science Letters, 2, 114-124. https://doi.org/10.1006/asle.2001.0044

[49] Jones, P.D., Jónsson, T. and Wheeler, D. (1997) Extension to the North Atlantic Oscillation Using Early Instrumental Pressure Observations from Gibraltar and South-West Iceland. International Journal of Climatology, 17, 1422-1450. https://crudata.uea.ac.uk/cru/data/nao https://doi.org/10.1002/(SICI)1097-0088(19971115)17:13<1433::AID-JOC203>3.0.C $\underline{\mathrm{O} ; 2-\mathrm{P}}$

[50] Stephenson, F.R., Morrison, L.V. and Hohenkerk, C.Y. (2016) Measurement of the Earth's Rotation: $720 \mathrm{BC}$ to AD 2015. Proceedings of the Royal Society A, 472. https://doi.org/10.1098/rspa.2016.0404

[51] Divine, D.V. and Dick, C. (2006) Historical Variability of Sea Ice Edge Position in the Nordic Seas. Journal of Geophysical Research, 111, C01001. https://doi.org/10.1029/2004JC002851

[52] Dawson, A., Elliott, L., Noone, S., Hickey, K., Holt, T., Wadhams, P. and Foster, I. (2004) Historical Storminess and Climate "See-Saws" in the North Atlantic Region. Marine Geology, 210, 247-259. https://doi.org/10.1016/j.margeo.2004.05.011

[53] Polyakova, E.I., Journel, A.G., Polyakov, I.V. and Bhatt, U.S. (2006) Changing Relationship between the North Atlantic Oscillation and Key North Atlantic Climate Parameters. Geophysical Research Letters, 33, L04711. https://doi.org/10.1029/2005GL024573

[54] Steele, D. (2013) Perihelion Precession, Polar Ice and Global Warming. Journal of Cosmology, 22, 10106-10129.

[55] Mazzarella, A. and Scafetta, N. (2018) The Little Ice Age Was 1.0-1.5 ${ }^{\circ} \mathrm{C}$ Cooler than Current Warm Period. Climate Dynamics, 51, 3957-3968. 
https://doi.org/10.1007/s00382-018-4122-6

[56] Muilwijk, M., Smedsrud, L.H., Ilicak, M. and Drange, H. (2018) Atlantic Water Heat Transport Variability in the 20th Century Arctic Ocean from a Global Ocean Model and Observations. Journal of Geophysical Research: Oceans, 123, 8159-8179. https://doi.org/10.1029/2018/C014327

[57] Cionco, R.G., Soon, W.-H. and Quaranta, N.E. (2020) On the Calculation of Latitudinal Insolation Gradients throughout the Holocene. Advances in Space Research, 56, 720-742. https://doi.org/10.1016/j.asr.2020.04.030

[58] Andersen, C., Koç, N., Jennings, A. and Andrews, J.T. (2004) Nonuniform Response of the Major Surface Currents in the Nordic Seas to Insolation Forcing: Implications for the Holocene Climate Variability. Paleoceanography and Paleoclimatology, 19 PA2003. https://doi.org/10.1029/2002PA000873

[59] Geirsdóttir, Á., Harning, D.J., Miller, G.H., Andrews, J.T., Zhong, Y. and Caseldine, C. (2020) Holocene History of Landscape Instability in Iceland: Can We Deconvolve the Impacts of Climate, Volcanism and Human Activity? Quaternary Science Reviews, 249, Article ID: 106633. https://doi.org/10.1016/j.quascirev.2020.106633

[60] Lindzen, R.S. (1990) Dynamics in Atmospheric Physics. Cambridge Univ. Press, New York, 310 p. https://doi.org/10.1017/CBO9780511608285

[61] Lindzen, R.S. (1994) Climate Dynamics and Global Change. Annual Review of Fluid Mechanics, 26, 353-378. https://doi.org/10.1146/annurev.fl.26.010194.002033

[62] Cionco, R.G., Soon, W.-H., Elias, A.G. and Quaranta, N.E. (2020) Latitudinal Insolation Gradients throughout the Holocene II High Frequency Variations, Advances in Space Research, 66, 1992-2000. https://doi.org/10.1016/j.asr.2020.07.008

[63] Connolly, R., Soon, W., Connolly, S., Baliunas, S., Berglund, J., Butler, C.J., et al. (2021) How Much Has the Sun Influenced Northern Hemisphere Temperature Trends? An Ongoing Debate. Research in Astronomy and Astrophysics. https://arxiv.org/abs/2105.12126

[64] Velasco Herrera, V.M., Mendoza, B. and Velasco Herrera, G. (2015) Reconstruction and Prediction of the Total Solar Irradiance from the Medieval Warm Period to the 21st Century. New Astronomy, 34, 221-233. https://doi.org/10.1016/j.newast.2014.07.009

[65] Scafetta, N. and Willson, R.C. (2014) ACRIM Total Solar Irradiance Satellite Composite Validation versus TSI Proxy Models. Astrophysics and Space Science, 350, 421-442. https://doi.org/10.1007/s10509-013-1775-9

[66] Cionco, R.G., Valentini, J.E., Quaranta, N.E. and Soon, W.-H. (2017) Lunar Fingerprints in the Modulated Incoming Solar Radiation: In Situ Insolation and Latitudinal Insolation Gradients as Two Important Interpretative Metrics for Paleoclimatic Data Records and Theoretical Climate Modeling. New Astronomy, 58, 96-106. https://doi.org/10.1016/j.newast.2017.08.003

[67] Gray, L.J., Beer, J., Geller, M., Haigh, J.D., Lockwood, M., Matthes, M., et al. (2010) Solar Influences on Climate. Reviews of Geophysics, 48, RG 4001. https://doi.org/10.1029/2009RG000282

[68] Kwok, R., Kacimi, S., Webster, M.A., Kurtz, N.T. and Petty, A.A. (2020) Arctic Snow Depth and Sea Ice Thickness from ICESat-2 and CryoSat-2 Freeboards: A First Examination. Journal of Geophysical Research: Oceans, 125, e2019JC016008. https://doi.org/10.1029/2019JC016008

[69] Scafetta, N., Willson, R.C., Lee, J.N. and Wu, D.L. (2019) Modeling Quiet Solar Luminosity Variability from TSI Satellite Measurements and Proxy Models during 
1980-2018. Remote Sensing, 11, 2569. https://doi.org/10.3390/rs11212569

[70] Vinje, T. and Goosse, H. (2003) ICE Extent Variations during Last Centuries. Final ACCSYS Science Conference, Arctic and Antarctic Research Institute, St. Petersburg 11-14 November 2003. (Unpublished)

[71] Solheim, J.-E., Stordahl, K. and Humlum, O. (2012) The Long Sunspot Cycle 23 Predicts a Significant Temperature Decrease in Cycle 24. Journal of Atmospheric and Solar-Terrestrial Physics, 80, 267-284. https://doi.org/10.1016/j.jastp.2012.02.008

[72] Lansner, F. and Pepke Pedersen, J.O. (2018) Temperature Trends with Reduced Impact of Ocean Air Temperature. Energy \& Environment, 29, 613-632. https://doi.org/10.1177/0958305X18756670

[73] Svalgaard, L. and Schatten, K.H. (2016) Reconstrunction of the Sunsspot Group Number: The Backbone Method. Solar Physics, 291, 2653-2684. https://doi.org/10.1007/s11207-015-0815-8

[74] Source: WDC-SILSO, Royal Observatory of Belgium, Brussels. http://sidc.oma.be/silso

[75] Mörner, N.-A. (2012) Solar Wind, Earth's Rotation and Changes in Terrestrial Climate. In: Borrega, C.D.E. and Cruz, A.F.B., Eds., Solar Wind Emission, Technologies and Impacts, Nova Sci. Publ. Inc., New York, 47-66.

[76] Mazzarella, A. (2008) Solar Forcing of Changes in Atmospheric Circulation, Earth's Rotation and Climate. The Open Atmospheric Science Journal, 2, 181-184.

https://doi.org/10.2174/1874282300802010181

[77] Duhau, S. and Martinez, E.A. (1995) On the Origin of the Length of the Day and the Geomagnetic Field on the Decadal Time Scale. Geophysical Research Letters, 22, 3283-3288. https://doi.org/10.1029/95GL03285

[78] Duhau, S. and de Jager, C. (2012), On the Origin of the Bi-Decadal and the Semi-Secular Oscillations in the Length of the Day. In: Kenyon, S., et al., Eds., Geodesy for Planet Earth, International Association of Geodesy Symposia 136, Springer-Verlag, Berlin, 507-551. https://doi.org/10.1007/978-3-642-20338-1 61

[79] Piecuch, C.G., Ponte, R.M., Little, R.M., Buckley, M.W. and Fukumori, I. (2017) Mechanisms Underlying Recent Decadal Changes in Subpolar North Atlantic Ocean Heat Content. Journal of Geophysical Research: Oceans, 122, 7181-7197. https://doi.org/10.1002/2017JC012845

[80] Bryden, H., Johns, W.E., King, B.A., McCarthy, G., McDonagh, E.L., Moat, B.I. and Smeed, D.A. (2020) Reduction in Ocean Heat Transport at $26^{\circ} \mathrm{N}$ since 2008 Cools the Eastern Subpolar Gyre of the North Atlantic Ocean. Journal of Climate, 33, 1677-1689. https://doi.org/10.1175/JCLI-D-19-0323.1

[81] Henriksson, G. (2021) Private Communication. (Unpublished)

[82] Le Mouël, J.L., Lopes, F. and Courtillot, V. (2017) Identification of Gleissberg Cycles and a Rising Trend in a 315-Year-Long Series of Sunspot Numbers. Solar Physics, 292, 43. https://doi.org/10.1007/s11207-017-1067-6

[83] Berggren, A.M., Beer, J., Possnert, G., Aldahan, A., Kubik, P., et al. (2009) A 600-Year Annual ${ }^{10} \mathrm{Be}$ Record from the NGRIP Ice Core, Greenland. Geophysical Research Letters, 36, L11801. https://doi.org/10.1029/2009GL038004

[84] McCracken, K.G., Beer, J., Steinhilber, F. and Abreu, J. (2013) A Phenomenological Study of the Cosmic Ray Variations over the Past 9400 Years, and Their Implications Regarding Solar Activity and the Solar Dynamo. Solar Physics, 386, 609-627. https://doi.org/10.1007/s11207-013-0265-0 
[85] Beer, J., Tobias, S.M. and Weiss, N.O. (2017) On Long-Term Modulation of the Sun's Magnetic Cycle. Monthly Notices Royal Astronomical Society, 473, 1596-1602. https://doi.org/10.1093/mnras/stx2337

[86] Dergachev, V.A. and Vasiliev, S.S. (2019) Long-Term Changes in the Concentration of Radiocarbon and the Nature of the Hallstatt Cycle. Journal of Atmospheric and Solar-Terrestrial Physics, 182, 10-24. https://doi.org/10.1016/j.jastp.2018.10.005

[87] Korte, M., Constable, C., Donadini, F. and Holme, R. (2011) Reconstructing the Holocene Geomagnetic Field. Earth and Planetary Science Letters, 312, 497-505. https://doi.org/10.1016/j.epsl.2011.10.031

[88] Parker, E.N. (1958) Suprathermal Particle Generation in the Solar Corona. Astrophysical Journal, 128, 677-685. https://doi.org/10.1086/146580

[89] Mursula, K., Manoharan, P., Nandy, D., Tanskanen, E. and Verronen, P. (2013) Long-Term Solar Activity and Its Implications to the Heliosphere, Geomagnetic Activity, and the Earth's Climate. Journal of Space Weather and Space Climate, 3, A21. https://doi.org/10.1051/swsc/2013043

[90] Sonett, C.P. (1984) Very Long Solar Periods and the Radiocarbon Record. Reviews of Geophysics and Space Physics, 22, 239-254.

https://doi.org/10.1029/RG022i003p00239

[91] Stuiver, M., Braziunas, T.F., Becker, B. and Kromer, B. (1991) Climatic, Solar, Oceanic, and Geomagnetic Influences on Late-Glacial and Holocene Atmospheric 14C/12C Change. Quarternary Research, 35, 1-24.

https://doi.org/10.1016/0033-5894(91)90091-I

[92] Shopov, Y. and Stoykova, D. (2011) Cycles of the Solar Wind Flux at the Front of the Earth's Magnetosphere. AIP Conference Proceedings, 1356, 192. https://doi.org/10.1063/1.3598105

[93] Maliniemi, V., Asikainen, T. and Mursula, K. (2014) Spatial Distribution of Northern Hemisphere Winter Temperatures during Different Phases of the Solar Cycle. Journal of Geophysical Research: Atmospheres, 119, 9752-9764. https://doi.org/10.1002/2013JD021343

[94] Roy, I. (2018) Solar Cyclic Variability Can Modulate Winter Arctic Climate. Nature Scientific Reports, 8, 4864. https://doi.org/10.1038/s41598-018-22854-0

[95] D’Andrea, W.D., Vaillencourt, Balascio, N.L., Werner, A., Roof, S.R., et al. (2012) Mild Little Ice Age and Unprecedented Recent Warmth in an 1800 Year Lake Sediment Record from Svalbard. Geology, 40, 1007-1010. https://doi.org/10.1130/G33365.1

[96] Zhou, L., Tinsley, B., Chu, H. and Xiao, Z. (2016) Correlations of Global Sea Surface Temperatures with the Solar Wind Speed. Journal of Atmospheric and Solar-Terrestrial Physics, 149, 232-239. https://doi.org/10.1016/j.jastp.2016.02.010

[97] Makarova, L.N. and Shirochkov, A.V. (2012) Experimental and Modeling Evidence of the Solar Wind Energy Influence on the Earth Atmosphere. In: Borrega, C.D.E. and Cruz, A.F.B., Eds., Solar Wind Emission, Technologies and Impacts, Nova Sci. Publ. Inc., New York, 108-133.

[98] Zubov, V., Rozanov, E, Shirochkov, A., Makarova, L., Egorova, T., Kiselev, A., et al. (2005) Modeling of the Joule Heating Influence on the Circulation and Ozone Concentration in the Middle Atmosphere. Journal of Atmospheric and Solar-Terrestrial Physics, 67, 155-162. https://doi.org/10.1016/j.jastp.2004.07.024

[99] Treolar, N. (2002) Luni-Solar Tidal Influences on Climate Variability. International Journal of Climatology, 22, 1527-1542. https://doi.org/10.1002/joc.783 
[100] Hansen, J.M., Aagaard, T. and Kuijpers, A. (2015) Sea-Level Forcing by Synchronization of 56- and 74-Year Oscillations with the Moon's Nodal Tide on the Northwest European Shelf (Eastern North Sea to Central Baltic Sea). Journal of Coastal Research, 31, 1041-1056. https://doi.org/10.2112/JCOASTRES-D-14-00204.1

[101] Yndestad, H., Turrell, W. and Ozhigin, V. (2008) Lunar Nodal Tide Effects on Variability of Sea Level, Temperature, and Salinity in the Faroe-Shetland Channel and the Barents Sea. Deep Sea Research Part I Oceanographic Research Papers, 55, 1201-1217. https://doi.org/10.1016/j.dsr.2008.06.003

[102] Yndestad, H. (2006) The Influence of the Lunar Nodal Cycle on Arctic Climate. ICES Journal of Marine Science, 63, 401-420. https://doi.org/10.1016/j.icesjms.2005.07.015

[103] Charvátová, I. and Hejda, P. (2014) Responses of the Basic Cycles of 178.7 and 2402 yr in Solar-Terrestrial Phenomena during the Holocene. Pattern Recognition in Physics, 2, 21-26. https://doi.org/10.5194/prp-2-21-2014

[104] Jose, P.D. (1965) Sun's Motion and Sunspots. The Astronomical Journal, 70, 193-200. https://doi.org/10.1086/109714

[105] Wolff, C.L. and Patrone, P.N. (2010) A New Way That Planets Can Affect the Sun. Solar Physics, 266, 227-246. https://doi.org/10.1007/s11207-010-9628-y

[106] Cionco, R.G. and Compagnucci, R.H. (2012) Dynamical Characterization of the Last Prolonged Solar Minima. Advances in Space Research, 50, 1434-1444. https://doi.org/10.1016/j.asr.2012.07.013

[107] Fairbrigde, R.W. and Shirley, J.H. (1987) Prolonged Minima and the 179-yr Cycle of the Solar Inertial Motion. Solar Physics, 110, 191-220.

https://doi.org/10.1007/BF00148211

[108] Wilson, I.R.G. (2013) The Venus-Earth-Jupiter Spin-Orbit Coupling Model. Pattern Recognition in Physics, 1, 147-158. https://doi.org/10.5194/prp-1-147-2013

[109] Scafetta, N. (2016) High Resolution Coherence Analysis between Planetary and Climate Oscillations. Advances in Space Research, 57, 2121-2135. https://doi.org/10.1016/j.asr.2016.02.029

[110] Scafetta, N. (2011) Does the Sun Work as a Nuclear Fusion Amplifier of Planetary Tidal Forcing? A Proposal for a Physical Mechanism Based on the Mass-Luminosity Relation. The Journal of Atmospheric and Solar-Terrestrial Physics, 81-82, 27-40. https://doi.org/10.1016/j.jastp.2012.04.002

[111] Scafetta, N., Milani, F. and Bianchini, A. (2020) A 60-Year Cycle in the Meteorite Fall Frequency Suggests a Possible Interplanetary Dust Forcing of the Earth's Climate Driven by Planetary Oscillations. Geophysical Research Letters, 47, e2020GL089954. https://doi.org/10.1029/2020GL089954

[112] Black, D.E., Peterson, L.C., Overpeck, J.T., Kaplan, A., Evans, M.N. and Kashgarian, M. (1999) Eight Centuries of North Atlantic Ocean Atmosphere Variability. Science, 286, 1709-1713. https://doi.org/10.1126/science.286.5445.1709

[113] Scafetta, N. (2016) High Resolution Coherence Analysis between Planetary and Climate Oscillations. Advances in Space Research, 57, 2121-2135.

https://doi.org/10.1016/j.asr.2016.02.029

[114] Milanković, M.V. (1941) Kanon der Erdbestrahlung und Seine Anwendung auf das Eiszeit-enproblem (Canon of Insolation and the Ice-Age Problem). Acad. Roy. Serbian, Editions Spec (1969 Translation by the Israel Program for Scientific Translation, Edited by B. Benny and I. Meroz), 133, 1-484.

[115] Velasco Herrera, V.M., Soon, W. and Legates, D.R. (2021) Does Machine Learning 
Reconstruct Missing Sunspots and Forecast a New Solar Minimum? Advances in Space Research. https://doi.org/10.1016/j.asr.2021.03.023

[116] Yndestad, H. (2021) Barents Sea Ice Edge Position Variability 1579-2020. Technical Report TN 210214.

\section{Appendix}

Barents sea ice edge estimated positions last two weeks of August 1579-2020².

\begin{tabular}{|c|c|c|c|c|c|}
\hline 157979 & 168880.4 & 179476.4 & 186079 & 192379 & 198381 \\
\hline 158179 & 168980.4 & 179676 & 186280 & 192478.8 & 198482.35 \\
\hline 158279 & 169082.5 & 179875.9 & 186480 & 192576.5 & 198581.83 \\
\hline 158479.5 & 169478.5 & 180077.5 & 186677.5 & 192678.8 & 198681.125 \\
\hline 159479.4 & 169576 & 180177.5 & 186976.8 & 192879.5 & 198780.35 \\
\hline 159579.4 & 170680.8 & 180278.4 & 187177.9 & 193079.5 & 198879.9 \\
\hline 159676.9 & 170780.7 & 180378.4 & 187277.5 & 193179.9 & 198979.25 \\
\hline 159779 & 172379.4 & 180476.9 & 187477.5 & 193380 & 199080.62 \\
\hline 160579.5 & 172676.5 & 180576.9 & 187677.5 & 193579.4 & 199180.1 \\
\hline 160679.5 & 172978.4 & 180676.9 & 187877.8 & 193680.4 & 199279.5 \\
\hline 160879.5 & 173078.4 & 180776 & 187977 & 193780.4 & 199379.5 \\
\hline 160976 & 173477.9 & 180976 & 188078.5 & 193881 & 199481.62 \\
\hline 161176 & 173676.9 & 181076 & 188377 & 193981 & 199581.55 \\
\hline 161376 & 173777.9 & 181276 & 188578.5 & 194280 & 199681.25 \\
\hline 161479 & 174077.9 & 181377.9 & 188778.5 & 194479 & 199780.85 \\
\hline 161675.5 & 174176.5 & 181477.9 & 188978.5 & 194579 & 199880.7 \\
\hline 161879.4 & 174376.5 & 181677.9 & 189077 & 194778 & 199981.8 \\
\hline 162076.9 & 174481.4 & 181777.9 & 189277.5 & 195079.4 & 200081.4 \\
\hline 162280 & 174581.4 & 181976 & 189377.4 & 195279.4 & 200181.8 \\
\hline 162377.9 & 174677.5 & 182177.9 & 189476 & 195378.5 & 200281 \\
\hline 162476.5 & 175379.4 & 182277.9 & 189677.9 & 195580 & 200379.85 \\
\hline 162676 & 175680 & 182377.5 & 189879.5 & 195881.5 & 200482.3 \\
\hline 163275.9 & 175779.9 & 182477.4 & 189979.5 & 196081.5 & 200581.53 \\
\hline 163475.9 & 175979.5 & 182576 & 190178.5 & 196178.5 & 200681.8 \\
\hline 163675.9 & 176180 & 182676 & 190276.5 & 196276.5 & 200781.8 \\
\hline 164075.9 & 176379.5 & 182876.9 & 190377.5 & 196378.5 & 200881 \\
\hline 164876 & 176477.5 & 183276 & 190477.5 & 196579 & 200980.7 \\
\hline 165276 & 176577.5 & 183777.5 & 190678 & 196779 & 201081.38 \\
\hline 165576 & 176679 & 183977.5 & 190878 & 196979.5 & 201182.55 \\
\hline 165776.9 & 176779 & 184479.4 & 190976.4 & 197079.5 & 201282.4 \\
\hline 165976 & 176979 & 184778.5 & 191276.4 & 197180.4 & 201383.37 \\
\hline 166176 & 177179 & 184876.5 & 191376 & 197280.4 & 201478.87 \\
\hline 166276.9 & 177379.5 & 185076.5 & 191477.5 & 197479.5 & 201582.65 \\
\hline 166482 & 177980 & 185179 & 191577.5 & 197579.5 & 201682.05 \\
\hline 166775.5 & 178080 & 185378.9 & 191676.9 & 197679.5 & 201780.625 \\
\hline 166875.5 & 178576 & 185476.9 & 191777 & 197779.1 & 201882.9 \\
\hline 167179 & 178776 & 185579 & 191979 & 197981 & 201981.55 \\
\hline 167576.5 & 178976.5 & 185676.5 & 192079 & 198080.1 & 202083.15 \\
\hline 167676.5 & 179176.5 & 185779 & 192178 & 198179.35 & \\
\hline 168378.4 & 179276.5 & 185876.5 & 192279 & 198279.5 & \\
\hline
\end{tabular}

${ }^{2}$ Each column show year and position in degrees $\mathrm{N}$. 